Florida International University FIU Digital Commons

$11-28-2001$

\title{
Self-regulated learning : the role of a journal in the learning process for students and teachers
}

Lilia C. DiBello

Florida International University

DOI: $10.25148 /$ etd.FI14062279

Follow this and additional works at: https://digitalcommons.fiu.edu/etd

Part of the Curriculum and Instruction Commons

\section{Recommended Citation}

DiBello, Lilia C., "Self-regulated learning : the role of a journal in the learning process for students and teachers" (2001). FIU Electronic Theses and Dissertations. 2807.

https://digitalcommons.fiu.edu/etd/2807

This work is brought to you for free and open access by the University Graduate School at FIU Digital Commons. It has been accepted for inclusion in FIU Electronic Theses and Dissertations by an authorized administrator of FIU Digital Commons. For more information, please contact dcc@fiu.edu. 


\title{
FLORIDA INTERNATIONAL UNIVERSITY
}

Miami, Florida

\section{SELF-REGULATED LEARNING: THE ROLE OF A JOURNAL IN THE LEARNING PROCESS FOR STUDENTS AND TEACHERS}

\author{
A dissertation submitted in partial fulfillment of the \\ requirements for the degree of \\ DOCTOR OF EDUCATION \\ in \\ CURRICULUM AND INSTRUCTION
} by

Lilia C. DiBello 2001 
To: Dean Linda P. Blanton

College of Education

This dissertation, written by Lilia C. DiBello, and entitled, Self-Regulated Learning: The Role of a Journal in the Learning Process for Students and Teachers, having been approved in respect to style and intellectual content, is referred to you for judgment.

We have read this dissertation and recommend that it be approved.

Rebecca P. Harlin

Judith J. Slater

Paul A. Rendulic, Co-Major Professor

Stephen M. Fain, Co-Major Professor

Date of Defense: November 28, 2000

The dissertation of Lilia C. DiBello is approved.

Dean Linda P. Blanton College of Education

Interim Dean Samuel S. Shapiro Division of Graduate Studies

Florida International University, 2001 
(C) Copyright 2001 by Lilia C. DiBello

All rights reserved. 


\section{DEDICATION}

This dissertation is dedicated to my family. Through every step of the process they provided their unconditional support which made this possible. 


\section{ACKNOWLEDGMENTS}

I'd like to thank all four members of my committee for each contributing in a very important way to the completion of this journey. To Dr. Fain, my thanks go back to that initial phone call during which we discussed the Doctoral Program at FIU and the need to have a clear vision of where I wanted to be upon completion of my graduate work. It was his encouragement and questioning that guided my many actions along the way. To Dr. Slater, my thanks for your rigor and the many opportunities you always afforded me to grow in professional ways. To Dr. Harlin, my thanks for the understanding you have of early childhood education and for the unique opportunities we have had to collaborate on projects and presentations. And lastly, to Dr. Rendulic, my thanks for so generously sharing your study and continuously responding to my calls or e-mails throughout the process with support and encouragement. You always put your students first, and I will always be grateful for that. All four of you provided me a very unique experience at FIU and I consider myself extremely lucky.

I would like to thank the three teachers from Sunshine Elementary School that so willingly gave of their time to participate in follow-up interviews (Mrs. O, Mrs. M and Mrs. Q). Furthermore, I met many people throughout my graduate studies: professors in courses I've taken, students in courses I've taught and colleagues...to whom I am indebted for creating a wonderful community of learning. However, I would like to especially thank Veronica and David for their friendship and encouragement. I look forward to many more years of laughter and learning! 
My family has always been an important part of who I am, and those of you who know me understand that I share in the accomplishment of completing this dissertation with them. To Darin, my incredible gratitude for your patience and support (in completing the "three cruise dissertation process"). I love you and I look forward to life without the 'dissertation' hanging over us! To "little Darin" (who suddenly is not so little anymore), I have been a student since the day you were born, but "yes" there will come a day when mom does not have to go to school anymore... but the learning never ends! To Dylan, although you came in at the tail end of this journey, you certainly have made the experience more enjoyable and you continuously remind me of where my priorities should always be. Lastly, to my parents, sister, cousins and grandparents-your words of encouragement and your babysitting services helped more than you'll ever know. I am blessed to be able to share in this accomplishment with all of you. 
ABSTRACT OF THE DISSERTATION

\section{SELF-REGULATED LEARNING: THE ROLE OF A JOURNAL IN THE LEARNING PROCESS FOR STUDENTS AND TEACHERS}

by

\section{Lilia C. DiBello}

Florida International University, 2001

Miami, Florida

Professor Stephen M. Fain, Co-Major Professor

Professor Paul A. Rendulic, Co-Major Professor

A fundamental goal of education is to equip students with self-regulatory capabilities that enable them to educate themselves. Self directedness not only contributes to success in formal instruction but also promotes lifelong learning (Bandura, 1997). The area of research on self-regulated learning is well grounded within the framework of psychological literature attributed to motivation, metacognition, strategy use and learning. This study explored past research and established the purpose of teaching students to selfregulate their learning and highlighted the fact that teachers are expected to assume a major role in the learning process. A student reflective writing journal activity was sustained for a period of two semesters in two fourth-grade mathematics classrooms. The reflective writing journal was analyzed in search of identifying strategies reported by 
students. Research questions were analyzed using descriptive statistics, frequency counts, cross-tabs and chi-square analyses.

Results based on student-use of the journals and teacher interviews indicated that the use of a reflective writing journal does promote self-regulated learning strategies to the extent which the student is engaged in the journaling process. Those students identified as highly self-regulated learners on the basis of their strategy use, were shown to consistently claim to learn math "as well or better than planned" on a weekly basis. Furthermore, good self-regulators were able to recognize specific strategies that helped them do well and change their strategies across time based on the planned learning objectives. The perspectives of the participating teachers were examined in order to establish the context in which the students were working. The effect of "planned change" and/or the resistance to change as established in previous research, from the teachers point of view, was also explored. The analysis of the journal data did establish a significant difference between students who utilized homework as a strategy.

Based on the journals and interviews, this study finds that the systematic use of metacognitive, motivational and/or learning strategies can have a positive effect on student's responsiveness to their learning environment. Furthermore, it reflects that teaching students "how to learn" can be a vital part of the effectiveness of any curriculum. 


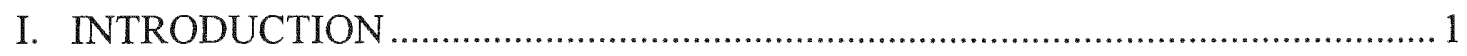

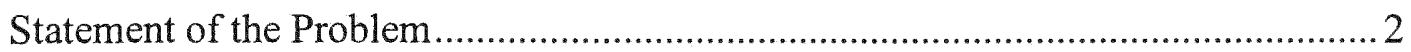

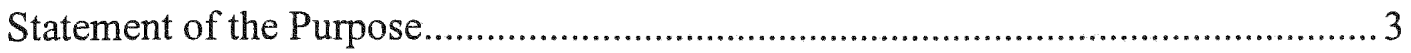

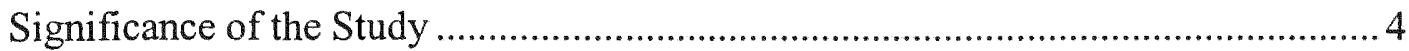

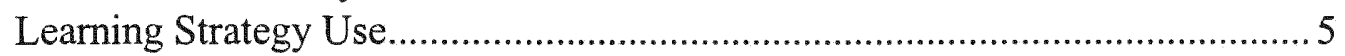

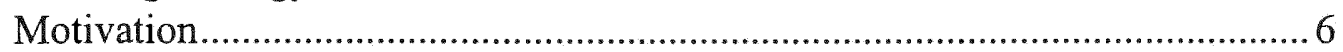

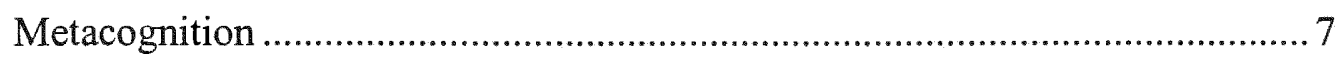

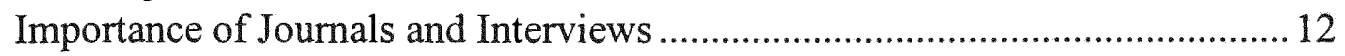

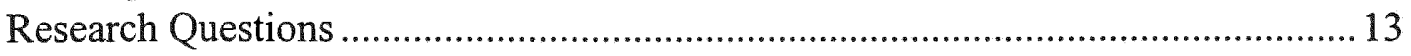

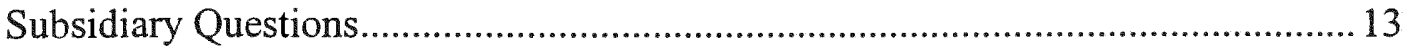

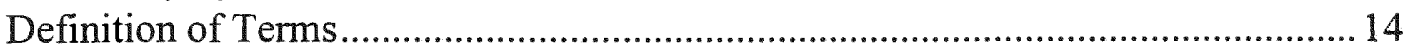

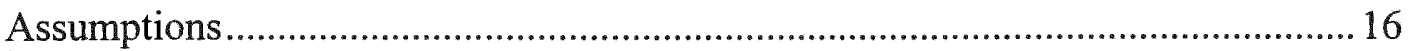

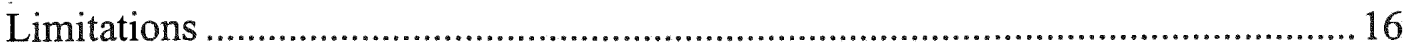

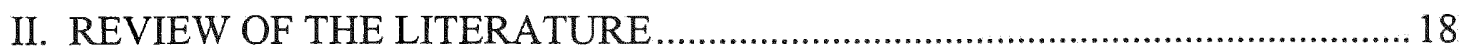

Self-Regulated Learning ..................................................................................... 19

Historical Background on Self-Regulated Learning .......................................20

Operant View of Self-Regulated Learning ............................................23

Phenomenological Views of Self-Regulated Learning ..........................24

Social Cognitive Views of Self-Regulated Learning .............................224

Volitional Views of Self-Regulated Learning .....................................2

Vygotskian Views of Self-Regulated Learning ................................... 25

Cognitive Constructivist Views of Self-Regulated Learning ............... 26

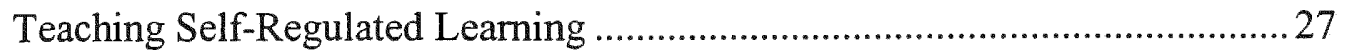

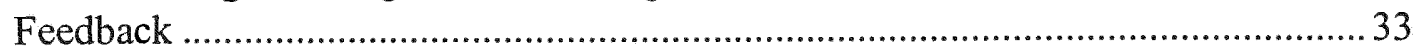

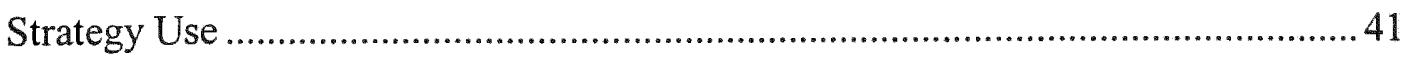

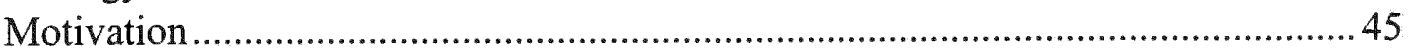

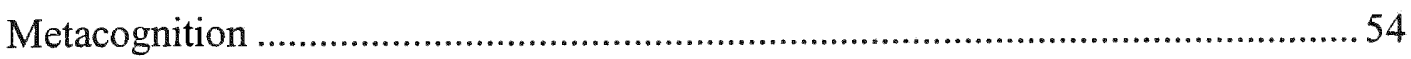

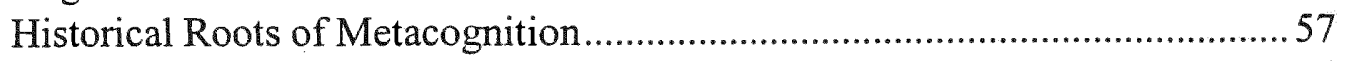

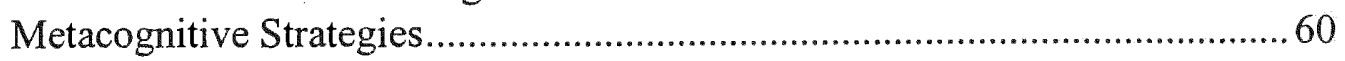

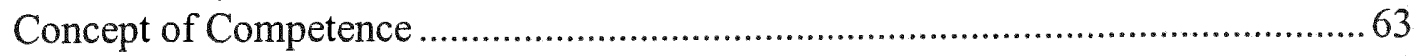

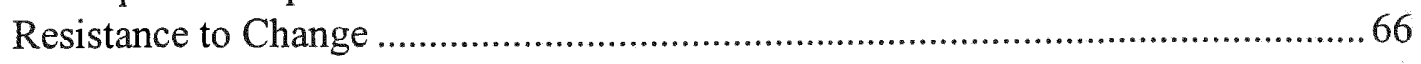

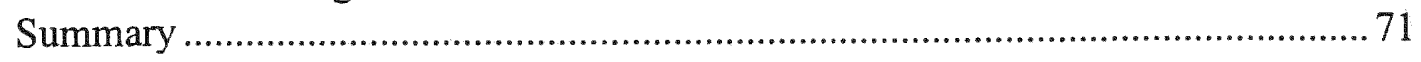

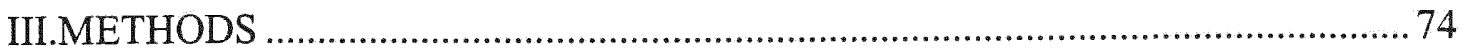

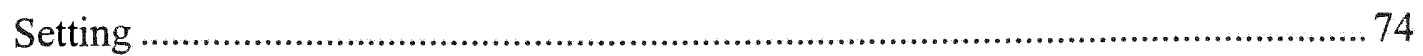

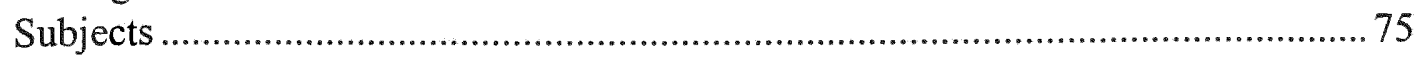

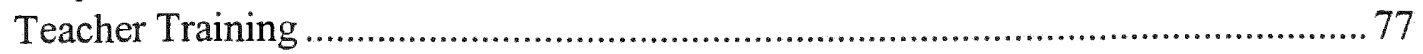




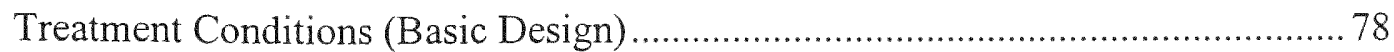

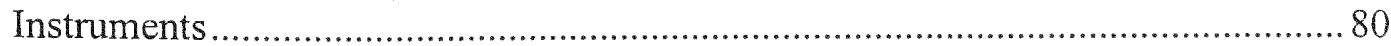

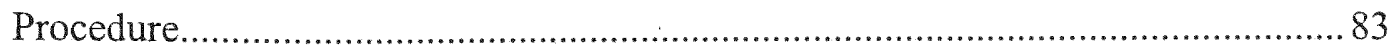

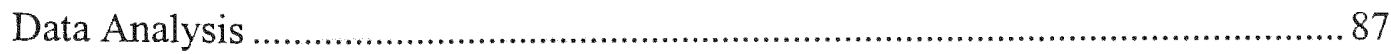

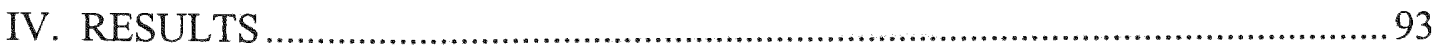

Descriptive Analysis--Preliminary Journal Findings ..............................................99

Reflective Writing Journal Question 1 .......................................................94

Reflective Writing Journal Question 2 ......................................................96

Reflective Writing Journal Question 3 ........................................................ 97

Reflective Writing Journal Question 4 ....................................................... 98

Reflective Writing Journal Question 5 .................................................. 100

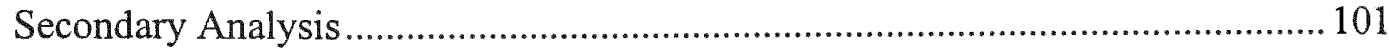

Subsequent Data Analysis Based on Descriptive Statistics ........................... 102

Highly Self-Regulated Learners vs. Minimally Self-Regulated Learners ...... 109

Ancillary Findings from Larger Study ................................................................116

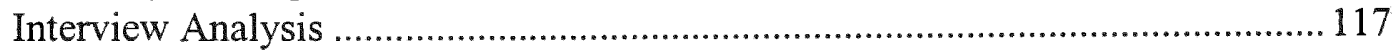

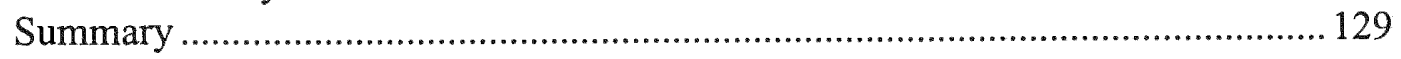

V. SUMMARY, DISCUSSION, AND CONCLUSIONS ......................................... 132

Summary of the Study......................................................................................... 133

Discussion of Research Findings Based on Research Questions ........................... 136

Discussion of Research Findings Based on Subsidiary Questions ........................ 151

Limitations of the Study ................................................................................. 158

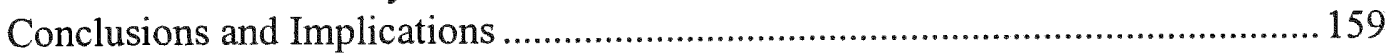

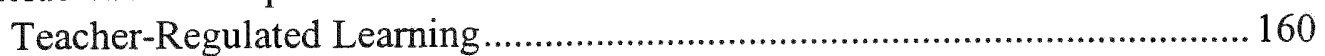

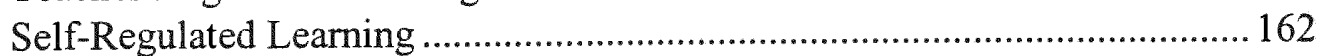

Recommendations for Further Research ....................................................... 165

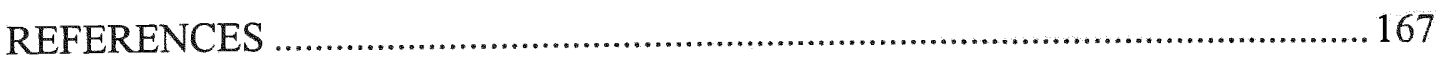

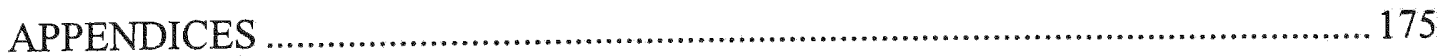

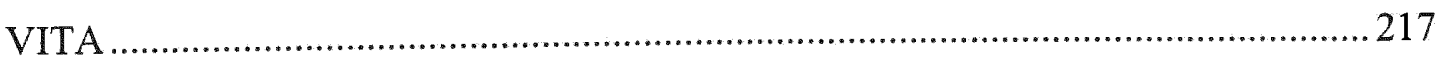




\section{LIST OF TABLES}

TABLE

PAGE

1 Self-Regulated Learning Strategies

2 Frequency Distributions of Student Opinions Regarding Math

Performance for Both Semesters

3 Qualitative Responses Reported to "What did help student learn?"

Across Both Semesters.

4 Distribution of Reported Journal Responses to "What did not help student learn?" Across both Semesters 98

5 Description of Reported Responses to "What are the goals/objectives this week?" Across Both Semesters.

6 Distribution of Responses in Journal to New Plan Across Both Semesters .... 101

$7 \quad$ Use of "Studying" Strategy Across Both Semesters................................... 102

$8 \quad$ Analysis of Reported Use of "Homework" as a Strategy ............................. 103

$9 \quad$ Analysis of Reported use of "Nothing" or No Strategy .............................. 104

10 "TV" or "Playing" as a Reported Response to what Prevented Learning ...... 105

11 Reported Weekly Objectives of "Review" or "Multiplication" ................... 108

12 Rate of Strategy Use on Reflective Writing Journal Instrument.................. 110

13 Percentile of Highly Self-Regulated Learners Answering they

Learned Math "as well" or "better" than Planned

14 Summary of Regression Analysis for Total Math SAT Score Predicting Level of Self-Regulation

15 Summary of Regression Analysis for Each Sub-Section of the Total Math SAT Score Variable Predicting Level of Self-Regulation 


\section{CHAPTER I}

\section{INTRODUCTION}

With schools being under increased pressure to raise standardized test scores, teachers are grappling with the issues of how best to prepare their students. The focus of the learning environment often shifts, yet it has become clear that students who selfregulate are capable of success regardless of the academic goals facing them. In other words, they are potentially able to use these skills and transfer to all areas of their life.

A fundamental goal of education is to equip students with self-regulatory capabilities that enable them to educate themselves. Self-directedness not only contributes to success in formal instruction but also promotes lifelong learning. (Bandura, 1997, p. 174)

Schunk and Zimmerman (1994) cite that although there has been a surge of research on student self-regulation, there continues to be considerable confusion as to what selfregulation is and how it differs from previous research that focused on the learning process (p.ix). This abundance of research in the area of self-regulation has many implications for present and future educators. Perhaps teachers would be wise to pay close attention to the need for teaching students how to learn, how to motivate themselves and how to focus on the important aspects of their educational experience.

The research strongly supports the theoretical point that self-evaluation is a critical component of self-regulation. As students monitor their task performance, effective selfregulation depends on their evaluating their goal progress. Judgments of acceptable progress result in continuation of their task approach; self-evaluations of unacceptable progress may lead them to alter their strategy to one that they believe has a better likelihood of resulting in goal attainment. These self-evaluative activities also strengthen 
students' self-efficacy for learning and motivation for goal attainment. (Schunk \& Zimmerman, 1994, p. 307)

Essentially, educators need to become aware of this research and find ways to use it successfully in our classrooms. A connection exists between self-regulated learners and successful school experiences, what's missing is the bridge to attaining this skill and implementing it into the curriculum or the classroom experience of the learner. Bandura (1997) reminds us that self-regulation encompasses skills for planning, organizing, and managing instructional activities; enlisting resources; regulating one's own motivation; and applying metacognitive skills to evaluate the adequacy of one's knowledge and strategies. The interrelationship between these components of strategy use, motivation and metacognition, are quite relevant to this study.

\section{Statement of the Problem}

The research problem centers on the findings and implications of past research which conclude that students who are capable of self-regulating their learning are more effective learners (Butler \& Winne, 1995; Paris \& Newman, 1990; Zimmerman, 1989a; Zimmerman, Bandura \& Martinez-Pons, 1992). The literature has established that selfregulators are more effective learners (Bandura, 1997; Schunk \& Zimmerman, 1994). The question raised centered on what characteristics made a good self-regulator and how could a reflective writing journal enhance a student's learning effectiveness. Furthermore, the literature proposed that students who struggle in school may not succeed because of their inability to regulate their learning process. "In general, students can be described as self-regulated to the degree that they are metacognitively, motivationally, and behaviorally active participants in their own learning process" (Zimmerman, 1989a, p. 89). Although 
the research points to the advantages of teaching students to self regulate, the problem lies in the fact that many students continue to struggle in school and the activities provided are not aimed at enhancing self-regulatory skills. In fact, teachers are typically assigned the curriculum and the experiences that they are to implement in the classroom. In many cases these guides speak to accepted instructional practices as well as addressing issues of what is to be taught. However, with increasing outside pressures pointing to the importance of standardized test scores it is logical to recognize that very few teachers are given the opportunity to enhance self-regulation skills, or even to provide opportunity for fostering these skills, when the ultimate goal of most elementary and secondary environments has become increasing the standardized test score (Haladyna, Haas, \& Allison, 1998).

\section{Statement of the Purpose}

The primary purpose of this research study was to implement the use of a reflective writing journal to promote or facilitate the use of self-regulated learning strategies. The journal served as a source of self-generated feedback with the goal of reinforcing actions taken by the student that ultimately enhanced their learning. "Selfdirectedness not only contributes to success in formal instruction but also promotes lifelong learning" (Bandura, 1997, p. 174). With this goal in mind, this study was established to determine if fourth grade students who participated in the study with the reflective writing journal and with the supplement of a concrete graphing assignment showed an increase in learning strategy use as a result of the weekly journal entries. A secondary purpose was to determine what role the teachers played in advancing the use of 
the reflective writing journals and how the use of the journal may or may not have effected change upon their personal teaching styles or educational practice.

\section{Significance of the Study}

The study is significant for many reasons and for many audiences. First, the issue of teaching students how to learn and self-regulate has historically been an important concept for researchers in many areas. Zimmerman (1989a) helps us understand that the concept of self-regulated learning has emerged and strengthened with the wave of emphasis on cognitive psychology. A historical review prepared by Zimmerman reveals that self-regulated learning emerges from six prominent theoretical perspectives: operant, phenomenological, social cognitive, volitional, Vygotskian and cognitive constructivist. The review highlights the importance of self-regulated learning research and emphasizes the fact that research on self-regulated learning is of interest to these diverse perspectives. Second, this study is relevant to the literature on instruction and therefore, it is pertinent to those who study curriculum issues and the scope of teaching. Third, this study has many implications for classroom teachers, in that they often search for optimal ways of enhancing the learning process.

Lastly, this study is significant to the learners. If learners recognize that selfregulating their learning strengthens the learning process, they more than likely will employ these strategies in all areas when learning. Consequently, the significance of this study is widespread in that it has implications for those focusing on theory, research, teachers (practice) and most importantly, the learners themselves. The rationale for this study on self-regulated learning is based on the literature encompassing learning strategy 
use, motivation, metacognition and the literature citing the importance of qualitative data such as journals and interviews. A historical look at how researchers have viewed learning reveals a complex system within the field of psychology that is clearly effected by the perspective from which the researcher views the learning process. This particular study will analyze from a cognitive perspective how and what learners think about their learning strategy use and the journal analysis will formally attempt to capture patterns of the ways in which highly self-regulated learners versus minimally self-regulated learners (act and think) respond. The idea that self-regulation is a cyclical process in which a learner must constantly be an active participant (Zimmerman, 1989b) is a major aspect which is considered as a result of this study. With the weekly journal activity, the learner had the opportunity to engage in self-regulation, almost with the idea of guided practice and reinforcement, not unlike the scaffolding techniques proposed by Vygotsky. Furthermore, from a social learning perspective (Bandura, 1997) it was a supplementary goal to employ interview techniques in order to determine what role the teachers felt they may have played in the learning process and how the study may have effected them in their professional practice as well.

\section{Learning Strategy Use}

The use of strategies is a major component of self-regulated learning that on its own has been the focus of much study and research. Pressley and McCormick (1995) ascertain that strategies achieve cognitive purposes and are potentially conscious and controllable activities. They view the use of strategies as playing three major roles: selection, organization and integration of information. Unquestionably, these three roles 
are all related to our memory system and the way in which we store information. We cannot discuss the use of strategies as a learning technique without placing it within the larger context of the psychology of learning. It is through the exploration of cognitive processing that we can begin to grasp how students learn. This informs teachers concerning what can be done to strengthen the learning process.

Brown (1987) established that there are techniques for the teaching of strategies. Among these techniques are metacognitive training, scaffolding and the more formal cognitive apprenticeship. She explains that in order to apply a strategy there must be present the concept of "I" in the learning process, a self-awareness of the process taking place. This is very important. It establishes the distinction between strategies, metacognition and motivation. Just as there has been an evolution in psychology as to the learning process and its underlying theories, there are unique and important differences which are continuously emerging in the study of self-regulated learning.

\section{Motivation}

The present study addresses issues of educational research on motivation. The weekly student journal entries required them to evaluate their situation and find ways to improve their learning or continue what enabled them to have a successful week.

Furthermore, participation required a degree of motivation for the students as well as the teachers to participate in the project. Week after week the participants were encouraged to muster up a level of motivation to fully engage in an activity that could ultimately improve their learning and classroom performance. Driscoll (1994) suggests to us that although the theories that have emerged from research on motivation cannot strictly be 
called learning theories, the study of motivation for educators is certainly confounded with the study of learning (p. 292).

Aside from teaching the actual objective that is to be mastered by a student, a teacher often finds him or herself struggling with issues of how to motivate their students. It no longer is a question of presenting information, but rather presenting it in such a way that the student is prepared to learn it. Teachers want their students to ultimately motivate themselves to learn for their own sake rather than through external forces. Nevertheless, it remains clear that some students would not learn were it not for the outside obligation placed on them by others. This dichotomy between extrinsic and intrinsic motivation was explored in depth by Csikszentmihalyi $(1988$, p. $205-216)$ who determined that almost any activity can be made intrinsically interesting by selecting challenges that match one's perceived capabilities and getting feedback of progress. The most important variable is the feedback which is necessary to maintain a learner's level of interest. The current study addresses the need to provide weekly feedback by incorporating the reflective writing journal and thus motivating students to track their progress.

\section{Metacognition}

The study of self-regulated learning requires a look at motivation as well as cognitive and metacognitive strategies (Bandura, 1997, p. 228). Metacognition, as defined by Flavell (1979), encompasses anything psychological, any kind of monitoring, and perhaps even processes that are not on a conscious level. His metamemory studies that took place in the early 1970 's led to the emergence of the term metacognition and by 1975 to Flavell being known as the founding father of the term (Brown, 1987). Many 
psychologists (Brown, 1987; Paris, Cross, \& Lipson, 1984) found an interest in studying thinking and the thought processes which surround this act. Furthermore, it became quite popular for students and teachers alike to discuss "thinking about thinking" in their classrooms. With time, Flavell's definition has broadened and has come to encompass "knowledge and cognition about cognitive objects, that is, about anything cognitive" (Flavell, 1979, p. 908). The present study takes an interest in metacognitive studies and literature because it is a primary objective of the student's journal activity to think about their thinking and acknowledge actions which may have contributed to their classroom success or failure.

With the confounding of definitions through the years, it becomes difficult to distinguish which definition of metacognition accurately reflects the concept. Nevertheless, it clarifies the fact that metacognition is a construct that is related to the field of self-regulated learning. "Metacognitive control or self-regulatory strategies then include the actual strategies that students might use to monitor, control, and regulate their cognition and learning" (Hofer, Yu \& Pintrich, 1998, p. 67). In spite of the vague understanding of metacognition, it effects studies related to self regulation. The work of Garcia and Pintrich (1994) and Pintrich and DeGroot (1990) are examples of how metacognition relate to planning, monitoring, and ultimately regulating. These are the studies that form the backdrop upon which the concept of the reflective writing journal was developed. This is because planning activities include setting goals, generating questions, and doing task analysis. "These activities seem to help learners plan their use of cognitive strategies and also seem to activate or prime relevant aspects of prior 
knowledge, making the organization and comprehension of the material much easier.

Learners that report using these types of planning activities seem to perform better on a variety of academic tasks in comparison to students who do not use these strategies" (Hofer, Yu \& Pintrich, 1998, p. 68). The reflective writing journal prepared for the current study allows young learners to do things such as plan, monitor and hopefully to ultimately self-regulate.

A series of studies conducted in the 1980's set out to determine at what developmental stage children could begin using metacognitive skills. The study, involving younger groups of children than the present study affirmed the fact that children in early grade-school are not yet able to think about their strategy use and connect that use with successful learning (Ghatala, Levin, Pressley \& Goodwin, 1986). The study that focused mainly on the older elementary school children (Pressley, Ross, Levin \& Ghatala, 1984) had positive results. If the students were prompted about strategy selection (by the teacher), they tended to use the more effective strategy 89 percent of the time. "If children in the middle-elementary grades are to make use of their knowledge of strategy utility in making strategy selections, this study suggested it might be necessary to prompt them to make use of the utility knowledge they possess" (Pressley \& McCormick, 1995, p. 31). Although this can be interpreted as solely reporting progress based on the weekly prompts, there is an element of thinking about their thinking process involved, and it appears it is most successful when they are prompted to do so. The current study takes these findings into account. The reflective writing journal prompts the students to think about successful strategy use and the application of the best strategies for future 
assignments. The prompts are open-ended, and hence supportive of original responses reflecting their use of self-regulatory strategies.

For children to come to understand that the more effective strategy is more effective and that its effects on performance should be taken into account in making future strategy selections, primary-grade children must be given explicit instruction to attend to their performance differences, interpret these differences as indicators of relative strategy effectiveness, and use this information in future decision making. (Pressley \& McCormick, 1995, p.32)

The work of Gray (1991) also provided relevant findings to the current study with respect to metacognitive skills. It was found that instructors can observe students and determine what types of skills they need to practice in order to begin self-evaluating. Metacognitive growth can result if teachers offer suggestions for classroom activities to teach the skills of metacognition: planning, monitoring and evaluative thinking. This particular study involved mathematical problem solving skills. However, unlike the current study that focused exclusively on grades received, the Gray study aimed more at teaching metacognitive skills for math problem solving. Nevertheless, the findings do serve to support that it is possible to teach metacognitive skills to children at the elementary school level.

As emphasized in a study by Sink (1991), metacognition should not be an instructional goal. Rather, "metacognition is a means to empowering learners to control their own cognitive and affective functioning, thereby facilitating academic achievement" (Sink, 1991, pg. 4). Furthermore, it is asserted that planning and self-assessment are the key aspects of metacognition, and that if teachers guide students towards using skills that emphasize these aspects, metacognition will be achieved as a result. Although, Gray 
(1991) asserts that teaching metacognitive skills is a possibility, the goal is similar to that advanced by Sink (1991). Both researchers wish for teachers and learners to focus on the process, which, in turn, will result in more use of metacognitive skills.

Although we've come to recognize that the area of research in metacognition is at times vague and all encompassing, there is an abundance of literature (Berliner \& Rosenshine, 1987; Brown, 1987; Gray, 1991; Sink, 1991; Zimmerman \& Schunk, 1989c) which supports the fact that metacognition is a concept that overlaps with the study of self-regulated learning. It is the process of knowing that teachers should continue to focus on. Effective learners are those who recognize what they did, how they did it, and then employ aspects of self-regulatory characteristics by acting upon the information they have gathered. The current study seeks to develop metacognitive skills. The students are asked continually to reflect upon what went well, reflect upon what did not go well, and ultimately prompts them to develop a strategy or plan for future mathematics lessons. If the opportunity to think about their past actions was not made available to the students, chance alone does not ensure they would take it upon themselves to regulate their own learning. Winne (1997) suggested incorporating a reflective writing journal in order to enhance self-regulation, while Cole (1994) found that students who used journals were helped in constructing meaning and attending to details. The journals also prompted them to ask questions with respect to their own learning, because although they could be focused on answering questions that they were prompted with, they still needed to attend to the thinking process in order to respond to the prompt. For this study the link lies in 
the hypothesis that after much practice, this can be something that students attend to without the prompts.

\section{Importance of Journals \& Interviews}

It is the goal of the present study to establish the relationship between selfregulated learning and successful school experiences. A journal experience was provided to each student for the purpose of measuring self-regulated learning skills. Specifically, the journal was intended to engage students in a reflective activity that would help them focus on their learning process. Framed within the psychological research and literature on motivation (Brophy, 1987; Garcia \& Pintrich, 1994; Weiner, 1990), metacognition (Brown, 1987; Weinert \& Kluwe, 1987) and learning (Driscoll, 1994; Schunk \& Zimmerman, 1994), this study hoped to establish the importance of fostering selfregulated learning skills for the purpose of engaging students in their own learning process. In addition to focusing on the students, an examination of the reflections from the teachers that orchestrated the learning process was thought to be relevant, given that with any action research project the perspectives of all involved helps to shed light on the study as a whole. Zimmerman $(1990$, p. 4) asserts that "a self-regulated learning perspective on students' learning and achievement is not only distinctive, but it has profound implications for the way teachers should interact with students and the manner in which schools should be organized." For that reason, an inquiry into the literature pertaining to teacher influence and resistance to change is examined. The role of the teacher is pivotal to the success or failure of any learning, therefore, an interview with each participating teacher is included in an attempt to triangulate the results of the study 
and establish a complete picture of what took place. The results obtained from analyzing the student reflective writing journals establish a pattern of strategy use, and by reflecting upon the teacher interviews one can shed light upon these findings. At this critical time in our history, with much focus being placed on the successful outcomes of standardized tests, it is imperative that educators pay close attention to how they can enhance the ability of their students to self-regulate their learning. In the end, it will ultimately provide students with a skill that can be applied to future attempted academic and non-academic encounters.

\section{Research Questions}

- To what extent does a reflective writing journal promote or facilitate the use of SelfRegulated Learning Strategies?

- Is a graphing assignment necessary to incorporate with the writing journal due to the developmental level of the students and the need for concrete reinforcement? (Paris \& Newman, 1990)

- Are Motivation scores, Metacognition scores, Standardized test scores (report card grades and SAT's) predictive of what type of learner a student is: high self-regulated learning strategy user or low self-regulated learning strategy user?

- Based on Interviews with participating teachers: Are teachers who participated in the Sunshine/FIU project more likely to employ learned strategies in the future?

$$
\text { Subsidiary Questions }
$$

- Do students who are identified as good self-regulators expect to do "as well or better" than they planned? 
- Do students who are identified as good self-regulators recognize specific strategies that helped them do well?

- For good self-regulators, do their strategies change over time with respect to awareness of why they did better?

- For different educational objectives do students recognize the need to use different strategies?

- For good self-regulators, when they recognize that they "did not do as well as planned", what did they identify as the reasons why?

- Did the participating teachers find that the study influenced their future teaching activities, reflections, procedures, plans or expectations?

\section{Definition of Terms}

Given that this study covers many areas of research in psychology and education, it is important to clearly define certain concepts so as to ensure the reader comprehends the perspective from which the researcher has developed the study. The following concepts are defined for the purpose of establishing a common definition from which to approach this study.

Self-regulation. It refers to students' self-generated thoughts, feelings, and actions, which are systematically oriented toward attainment of their goals (Schunk \& Zimmerman, 1994, p. ix). Zimmerman (1994, p. 1) has provided a conceptual framework for understanding and classifying the diverse research in the burgeoning area of self-regulation studies. In education, he conceives of self-regulation being studied in four areas:

- motives for learning or performing 
- methods used

- performance outcomes or target behaviors

- environmental resources used.

In this study reference will be made to these four areas in journal assignments provided to the students. In the journal entry the students have an opportunity to describe and reflect upon these four areas of self-regulation with the ultimate goal being the improvement of their self-regulatory skills.

Self-efficacy. As defined by Bandura (1997, p. 3) refers to beliefs in one's capabilities to organize and execute the courses of action required to produce given attainments. The word efficacy is defined as having the power to produce a desired effect (Webster's, 1985). Therefore, the concept of efficacy and self-efficacy as established in the literature, takes into account the fact that there is a definite relationship between self-efficacy and self-regulation. Bandura (1997, p. 233) explains that within the sociocognitive framework of bidirectional causality, acquisition of cognitive subskills strengthens beliefs in one's academic efficacy. Both academic and self-regulatory efficacy, in turn, have reciprocal effects on cognitive and metacognitive learning strategies. Compared to students low in perceived self-efficacy, those who have a high sense of academic efficacy make greater use of cognitive strategies, manage their time and learning environments better, and then monitor and regulate their learning more closely. A high sense of academic efficacy, similarly, is accompanied by extensive use of self-directed learning strategies.

Consequently, for purposes of this study, one must keep in mind the relationship that exists between self-regulation and self-efficacy. A student that is highly efficacious 
would employ high levels of self-regulatory skills in that he or she would constantly be using skills or strategies to achieve the ultimate desired result.

Motivation. Although there are many aspects to the study of motivation, the definition offered by Schunk (1990) accurately reflects the meaning applied in this study: "Motivation refers to the process whereby goal-directed behavior is instigated and sustained" (p. 3).

\section{Assumptions}

The basic assumptions guiding this study are as follows:

1. It is assumed that the teachers and students that participated in this study are representative of the general population which they represent.

2. It is assumed that the reflective writing journal was incorporated into the weekly math schedule of each of the participating classrooms.

3. It is assumed that the scores attained by the researcher for each student on the SAT, Metacognition, and Motivation instruments are accurate (reliable and valid) for the purpose of engaging in further statistical analyses.

\section{Limitations}

The limitations that effect this study are as follows:

1. The sample size is limited to fourth graders (intact groups) at one elementary school in Broward County, FL. Furthermore, the special education students (Gifted and LD) attended separate math classes and therefore were not included in the analyses.

2. This investigation took place ex post facto and therefore it lessened the degree of control in the study, as the researcher was unable to manipulate the independent variable. 
3. The student journals for the journal only (Mrs. M's class) group were unavailable to the researcher and therefore a comparison between the graphing/journal and journal only groups could not be made. 


\section{CHAPTER II}

\section{REVIEW OF THE LITERATURE}

The current study is grounded in the psychological literature and research dealing with self-regulated learning. Those working on research in this area (Zimmerman, 1998; see also Bandura, 1997; Schunk, 1997; Zimmerman \& Martinez-Pons, 1988) are in agreement that the research is closely linked with studies and literature pertaining to motivation, metacognition and learning strategy use. Furthermore, the relationship which researchers typically have described as "cognitive competency" (Corno, 1987) will also be explored in order to ascertain whether or not teaching self-regulated learning skills is an option for educators at all grade levels. Of particular importance to the current study is the aspect of feedback. The students are given the opportunity to receive feedback about their work and then are expected to be able to contemplate the significance of this feedback within their writing journals.

Even though we can expect students to be concerned about meeting requirements and earning acceptable grades, it is also reasonable to expect students to be aware and appreciative of the educational objectives of classroom activities and the potential of these activities for enhancing personal growth and quality of life, if teachers consistently draw attention to these objectives and potentials.

Unfortunately, classroom research suggests that few teachers do this systematically. (Brophy, 1987, p. 203)

Therefore, this review will focus on areas of research that explore self-regulated learning and the other related areas of feedback, learning strategy use, motivation, metacognition, as well as some of the literature on change theory which is pertinent to the 
analysis and discussion of the teacher interviews and the possible presence of teacher effect as a consequence of resistance to change.

\section{Self-Regulated Learning}

Educational research has often focused on attempting to determine what works. An educator's ultimate goal is the desire for his/her students to learn successfully. Not surprisingly, it is a complicated task because of the fact that each student is a unique individual who learns differently. Ideally then, the task at hand is to help students become aware of what makes it easier for them to learn. This focus on the process of a student self-regulating his or her own learning involves many different concepts. "In general, students can be described as self-regulated to the degree that they are metacognitively, motivationally, and behaviorally active participants in their own learning process" (Zimmerman, 1989a, p. 89). Hence, it is important to establish how past research has focused on self-regulated learning and how the literature on metacognition, motivation, behavioral learning strategies, feedback and academic achievement provide the framework for this construct.

Much has been written about students who are self-regulated learners tending to be more successful in the classroom (Bandura, 1986; Butler \& Winne, 1995; Winne, 1997). Furthermore, Zimmerman (1998) reminds us that the benefit is not only in the classroom but in life, for "there are many biographies of inspiring figures, such as Benjamin Franklin, Abraham Lincoln, and George Washington Carver, who despite humble origins and limited access to high-quality instruction, educated themselves through reading, studying, and self-disciplined practice" (p. 1). The concept of self-regulated 
learning can be applied way beyond the classroom doors. Although psychologists had yet to view things exclusively from a cognitive perspective, it was clear that educators, philosophers and psychologists alike did acknowledge the fact that a good educational experience certainly must involve the learner. Even in 1897 Dewey in My Pedagogic Creed was advocating the notion that education should not be a preparation for life, but rather that the educational process is life (Cremin, 1959, p. 22). In other words, every aspect of the educational process is a learning experience and that is how it should be viewed.

Active engagement in the learning process provides the student with the advantage that makes learning work. Students who sit idly by with no formal framework or rationale for learning tend to struggle because they lack the goal-directed behavior that keeps their learning focused and connected. Conversely, self-regulated learners somehow engage in self-initiated processes that enable them to become "controllers rather than victims of their learning experiences" (Zimmerman, 1998, p. 1). For that reason, this review discusses the literature that establishes a historical framework upon which the concept of self-regulated learning is based. It is believed that upon this foundation, educators can empower the learners they work with to make the most of their learning experience.

\section{Historical Background on Self-Regulated Learning}

Although most researchers would agree that the concept of self-regulated learning has emerged and strengthened with the increased emphasis on cognitive psychology, few would argue with the influence that the area of Social Learning Theory (Bandura, 1997) has had on the literature pertaining to self-regulation. The strands of research from this 
perspective focus on the need for a model to guide learners through the learning process.

This is quite significant to this study in that the researchers have provided the students with a journal page that provides structure to their writing process. Furthermore, the researchers have walked the students through the journaling process in order to verbally step through the necessary entries in the journal and to aid the students in brainstorming possible responses for their entries. Although this can be thought of as a way to reinforce cognitive skills necessary for completing the assignment, it can also be analyzed from the perspective of the social learning theorists who emphasize the importance of scaffolding.

Through scaffolding,

adults both model good thinking and provide subtle hints and prompts to children when their offspring (or students) cannot manage on their own. Thus, adults direct children's attention to important dimensions of problems they are attempting to solve when the children do not attend to those dimensions in the absence of direction. Sometimes the adult suggests a strategy to the child. The theory is that eventually children adopt as their own the thinking processes and patterns adults have modeled and assisted children in using. (Pressley \& McCormick, 1995, p. 8)

This concept is relevant to the current study (as outlined in chapter three) in that the researchers spent the first nine weeks of the study in each of the classrooms modeling the use of the reflective writing journal for both the students and the teachers.

Many models have emerged to respond to the theories of self-regulated learning, and, not surprisingly, a good number of them are direct responses to the educational crises that spark reform movements within the United States. Zimmerman (1989a) carefully traced the current models of self-regulated learning to changing views of the causes of student learning and achievement. These models fall within starkly contrasting models of learning within the field of psychology, yet they are all clear responses to the societal call 
for change. Zimmerman (1989a) introduces and compares six prominent theoretical perspectives on self-regulated learning: operant, phenomenological, social cognitive, volitional, Vygotskian, and cognitive constructivist approaches (to be explained in detail in the section that follows), by linking them to the historical movements upon which they emerged. His work has very uniquely guided scholars to the understanding that the issue of self-regulated learning has been historically significant in that it has emerged in contrasting areas of psychological research to be a focus.

American educational reform movements have traditionally been led by groups who hold certain important assumptions about how students learn. Zimmerman (1989a, p. 2) tells us that the post World War II period was a time in which "instruction in American schools was heavily influenced by mental ability conceptions of student functioning." There was an emphasis on measurement, ability and aptitude. This shifted in the 1960's because "social environmental formulations of student learning and achievement rose to prominence" (p. 2). With Johnson's War on Poverty program in effect, it was clear that a new social perspective had taken hold of the country and many changes were taking place, such as the establishment of federally funded programs like Head Start. There was widespread concern, however, by the mid 1970's that there were declining measures of national achievement. Zimmerman points to how this spawned a "Back to Basics" movement that reached a national audience and a cry for change. Scholars would likely point to reports such as A Nation at Risk: The Imperative for Educational Reform (1983) or America 2000: An Education Strategy (1991) as corroborating evidence.

Each of these educational reform movements rested on important assumptions about how students learn. The mental ability movement 
assumed that student mental functioning was broad in its impact on academic achievement and relatively stable despite changes in grade and age. It was the task of educators to tailor their instructional methods to this important characteristic of students. In contrast, the social environmental view assumed that students' background was relatively unchangeable. Minority children could not and should not be asked to shed their ethnic and cultural identities in order to learn in school. Instead, it was the task of teachers and school officials to make the children's instructional experiences adaptive to their unique needs. The instructional standards approach put the weight of responsibility on teachers and school officials for maintaining standards of quality. These educational reformers assumed that high standards in schools would ensure optimal teaching and student academic achievement. Each of these reform movements was based on instructional theories that viewed students as playing primarily a reactive rather than a proactive role... In contrast, self-regulated learning theories assume that students (1) can personally improve their ability to learn through selective use of metacognitive and motivational strategies; (2) can proactively select, structure, and even create advantageous learning environments; and (3) can play a significant role in choosing the form and amount of instruction they need. (Zimmerman, 1989, pp. 3 -4)

A historical review would not be complete without presenting a brief description of each of these orientations as described by Zimmerman (1989) on self-regulated learning (for a more comprehensive understanding, the cited text has a chapter devoted to each specific theory with the introductory chapter providing the background necessary to understand the common ground upon which they may overlap).

Operant views of self-regulated learning. Clearly, this view was established with behavioral principles in mind. "Operant researchers have produced one of the largest and most influential bodies of research on self-regulation" (Zimmerman, 1989, p. 6). The studies focus mainly on self-reinforcement and self-recording which was certainly an important area of research at that time. The focus was on self-regulating activities such as weight control, smoking and school academic performance. From this perspective, the self-regulating point of view focused on which proper stimulus and reinforcement could 
shape student behavior to achieve an intended outcome. The findings provided by Carver and Scheier (1981), focus exclusively on the behavioral nature of the learning process, and provide a strong example of this realm of research.

Phenomenological views of self-regulative learning. When the discussion shifts to include the perspective of "self", one must look to the writings and research of the Phenomenologists.

Phenomenologists were perhaps the first theorists to appreciate the great importance of self-perceptions to human psychological functioning. These perceptions were assumed to be organized into a distinctive identity or selfconcept that influences all aspects of behavioral functioning including academic learning and achievement. (Zimmerman, 1989, p. 9)

McCombs $(1989$, p. 52) clarifies that the phenomenological approach is one which is based on the philosophical assumption that the experience of consciousness and of self are real and can be systematically studied and verified. "In the context of self-regulated learning, a phenomenological perspective is one that accepts the primacy of selfphenomena in directing and regulating learning behaviors; it favors a person-referenced over a performance-referenced account of self-regulated learning processes and activities" (McCombs, 1989, p. 52).

Social cognitive views of self-regulated learning. The work of Bandura has been most influential in guiding the extensive research on social factors in self-regulation. Current research by Bandura (1997) emphasizes self-efficacy and acknowledges the shift towards social-cognitive perspectives of learning as opposed to exclusively narrowing in on social learning theory. This is significant in that past research may have looked towards other persons for motivating individuals to learn, whereas the new perspective 
proposes a triadic account of human functioning, "which focuses on the separate but interdependent contributions of personal, behavioral, and environmental influences" (Zimmerman, 1989, p. 11).

Volitional views of self-regulated learning. "Early theological and philosophical conceptions of volition focused on the importance of human will power" (Zimmerman, 1989, p. 14). This led to Lewin's (1929) questioning of whether intentions could be distinguished from needs. "By equating intentions and needs, Lewin was able to explain volition within a classic motivational theoretical framework without additional assumptions" (Zimmerman, 1989, p. 14). Corno (1987) augments the volitional perspective of self-regulated learning by discussing volition in terms of overt and covert processes of self-control. Corno assumes the volitional perspective to fall within the contemporary perspective of information-processing theory and states that the issue of motivation is a complex one that must be studied on many levels.

Vygotskian views of self-regulated learning. Vygotsky (1978) has done much to transform the way in which we view the learning process.

Researchers interested in the role of speech during self-regulation have been attracted by the work of Vygotsky...Their interest centered on two specific features emphasized in Vygotsky's theory: (1) inner speech as a source of knowledge and self-control and (2) social interactions between adults and children as a vehicle for conveying and internalizing linguistic skill. (Zimmerman, 1989, p. 17)

The Vygotskian view has led to work by researchers such as Palincsar and Brown (1984) and their notions of reciprocal teaching, and the contemporary surge in research focused on the importance of scaffolding. This area of research on self-regulated learning would focus specifically on how students talk their way through accomplishing tasks and how 
teachers can optimize the learning process by providing the appropriate levels of help necessary to bring each student to the optimal learning stage.

Cognitive constructivist views of self-regulated learning. Lastly, Zimmerman (1989) included the Cognitive Constructivist view which is presented as evolving from two diverse perspectives to create one unique view. The work of Bartlett (1932) and Piaget (1969) are the two works noted as the foundations upon which this view has emerged. Bartlett's (1932) work focused on the development of schemas to allow for learners to process greater amounts of information as the human memory restructured information to handle it more efficiently. Furthermore; the work of Piaget (1969) is noted for the astute recognition of young children adapting their schemas through what he identifies as assimilation and accommodation.

Both Bartlett and Piaget advanced the notion of a cognitive schema as the underlying basis for human learning and recall, and both ascribed a major role to logic and conceptual coherence in the formation of these schemas. In their view, human experience was formed into schemas, often in idiosyncratic fashion, and psychological analysis should focus on those constructions and the constructive process. (Zimmerman, 1989, p. 19)

All of these perspectives on self-regulated learning have served as a backdrop for the multitude of studies that have begun to emerge in this area. Zimmerman recognizes the fact that although each orientation may have its unique perspective, there are still some common features that many definitions and theories of self-regulated learning share. First, most researchers would agree that there is a systematic reliance on the part of the learner to employ some type of learning strategy. "Undoubtedly, all learners use regulatory processes to some degree, but self-regulated learners are distinguished by (a) their awareness of strategic relations between regulatory processes or responses and learning 
outcomes and (b) their use of these strategies to achieve their academic goals"

(Zimmerman, 1990, p. 5). Second, most definitions of self-regulated learning account for

some type of a self-oriented feedback loop (as established by Carver \& Scheier in 1981).

This loop entails a cyclic process in which students monitor the effectiveness of their learning methods or strategies and react to this feedback in a variety of ways, ranging from covert changes in selfperception to overt changes in behavior such as altering the use of learning strategies... regardless of theoretical differences in what is monitored and how outcomes are interpreted, virtually all researchers assume that selfregulation depends on continuing feedback of learning effectiveness.

(Zimmerman, 1990, pp. 5-6)

Lastly, the third feature of definitions of self-regulated learning is an indication of how and why students use a particular strategy or response. "An important aspect of theories of self-regulated learning is that student learning and motivation are treated as interdependent processes that cannot be fully understood apart from each other" (Zimmerman, 1990, p.

6). In summary, Zimmerman recognizes three features common to all definitions of selfregulated learning: their use of strategies, their dependence on feedback, and their interdependence on the motivational process. Consequently, with the understanding that many of the researchers are approaching this body of work from different theoretical points, yet with common understandings, it's relevant to undertake a critical review of the literature with a focus on feedback, strategy use and motivation. It is with an acknowledgment of these areas that a comprehension of self-regulation emerges.

\section{Teaching Self-Regulated Learning}

One final aspect that appears within the literature on self-regulated learning is quite significant. Corno (1987) asserts that the body of research on self-regulated learning provides an answer for educators that are looking to enhance the student's learning 
process. The position is advanced that we can promote self-regulated learning through

teaching. Although this position is held to be true and it is recognized that the aspects of motivation and volition are part of the equation, Corno goes further and includes the concept of cognitive competency. There is concession of the fact that students may both intend to learn and be able to control their intention but still fail to accomplish tasks because they do not have effective learning strategies or do not know how to use them when situations demand. Here the problem is one of competence. When knowing how to learn in school is outside a student's repertoire, poor performance is not surprising. (Corno, 1987, p. 251)

This view, however, does not focus on the fact that some students may be cognitively more prepared for the learning process, and therefore, the educational process must depend on this readiness. Instead, the acknowledgment centers on the fact that teachers can teach self-regulating skills that will help these students to ultimately become better learners. “ $\ldots$ when students begin to learn how to learn-including how to adapt tasks in ways that remove perceived blocks-and how to manage and control their concentration in school, they generally find that learning becomes easier" (Corno, 1987, p. 252).

Is it possible to instruct children to be self-regulating? This is in many ways a big task, but it is not an impossible task. The development of self-regulatory skills will take time and effort, but it is possible to improve children's skills through instruction. A number of studies have indicated that children can be taught to self-regulate. For example, Graham \& Harris (1989) found that self-instructional strategy training improved children's composition skills and heightened children's sense of self-efficacy. Meloth (1990) found that over a school year, children's reflective knowledge about themselves as learners predicted their strategy use and comprehension. The key is patience and realization that self-regulation instruction cannot be a one-shot, short-term project. Instead, think about how you can include self-regulatory skill instruction in a number of different lesson units across the school year. (Carr, 1996, p. 5) 
Rosenshine (1987) also supports the view that self-regulated learning can be taught, however the position advanced by this researcher is that it often requires explicit teaching on the part of the teacher. It is noted that this is what many call the art of teaching because a teacher has to make decisions regarding the material, the presentation, the pace, the length which are all based on an analysis of the class being taught. Although it would seem that the role of the teacher is insignificant in the discussion of selfregulation, in actuality the teacher plays a primary role. For it is in the establishment of the classroom environment that all students get their cue as to how they should learn, so the role of the teacher is critical in acknowledging that the students must play an active role in the learning process. Rosenshine recommends that teachers take note of six teaching functions, and he emphasizes that although some teachers use these skills some of the time it is the effective teachers that somehow weave these skills in consistently and systematically. These effective teaching functions are highlighted here because of the interesting correlation that they have with the characteristics of a self-regulated learner. You will note that in each of the six categories listed here as characteristics of good teaching functions, that there are also elements discussed in the learning strategies represented in the SRLIS (Zimmerman \& Martinez-Pons, 1986)--to be discussed in the section on "Strategy Use". This suggests that there is a connection between good teaching practice and the elements of self-regulation, which if explored and brought to our attention may enhance our ability to teach young children become good teachers for they themselves (or rather, good self-regulators). Rosenshine (1987) lists the six teaching functions as: 
1. Review

Review homework

Review relevant previous learning

Review prerequisite skills and knowledge for the lesson

2. Presentation

State lesson goals and/or provide outline

Teach in small steps

Model procedures

Provide concrete positive and negative examples

Use clear language

Check for student understanding

Avoid digressions

3. Guided practice

More time

High frequency of questions or guided practice

All students respond and receive feedback

High success rate

Continue practice until students are fluid

4. Corrections and feedback

Give process feedback when answers are correct but hesitant

Give sustaining feedback, clues, or reteaching when answers are incorrect

Reteach when necessary

5. Independent practice

Students receive help during initial steps, or overview

Practice continues until students are automatic (where relevant)

Teacher provides active supervision (where possible)

Routines are used to give help to slower students

6. Weekly and monthly reviews

Not all researchers agree with the use of Rosenshine's six teaching functions

for explicit teaching because of the dependence on the teacher for the learning process.

Nevertheless, there is a similarity in the notion that the teacher does hold a key position in the learning process and the idea that the teacher can be the catalyst for producing selfregulated learners within the classroom. Schunk (1998) makes clear that "models are important sources of teaching self-regulatory skills and for building learners' self-efficacy to employ these skills" (p. 143). His position parallels that of all social-cognitive psychologists who rely on the social model for the learning process. 
Correspondingly, the literature focused on the area of developmental aspects of self-regulated learning reaches much the same conclusions. Paris and Newman (1990) note that "self-regulated learners understand, value, and engage academic learning in ways that are fundamentally different than their peers who have difficulty in school" (p. 87). Yet, their position centers around the idea that developmental changes within students can evolve their learning styles and learning potential. Paris and Newman (1990) explored student's beliefs about schooling and focused on conceptual changes that emerged in students' theories as they progressed through school. Their analysis centered on three distinct areas: academic self-perceptions, knowledge of academic tasks, and social cognition about school.

The area addressing academic self-perceptions revealed that there are distinct differences between how young learners view themselves and how older students view themselves. Paris and Newman (1990, p. 89) clarify that young children often believe that "trying hard, completing tasks and receiving teacher praise are signs of high academic competence." They are not alone in their beliefs, for there exists a large body of literature in the area of early childhood education that would support their assertions (Bredekamp \& Copple, 1997; Piaget, 1969). Preschool and early elementary age children are typically more concerned with immediate feedback received from the teacher rather than how they themselves analyze and interpret their learning or achievement. However, Paris and Newman (1990) feel that this changes as students develop and enhance their own abilities to self-evaluate. They cite studies that reveal 7 and 8 -year olds to be a little better than preschoolers and 11 to 12 -year olds as being more diverse in their abilities to calculate 
their self-perception of ability and thereby exhibiting greater self-control. This has great significance to the present study, in that the fourth graders involved were often required to reflect on the learning process and attempt to analyze and self-reflect as to why they did better or worse during specific academic challenges.

The Paris and Newman (1990) study supports the fact that students at the fourth grade level should be developmentally capable of engaging in abstract thought about their learning process. Their work also supports the idea that having "knowledge of academic tasks" (p. 90) helps students develop an internal conceptual framework that allow them to establish internal standards. Lastly, they acknowledge the fact that by age 11 or 12 students have a very good "social cognition about school" (p. 92). In other words, they are aware of many social aspects within their classroom environment. This aspect was well documented in the writings of Bandura $(1986,1997)$ whose work will be discussed in the section entitled "Motivation." He established an entire body of psychological research known as Social Learning Theory, from which many researchers credit the evolution of social cognitive psychology and a good percentage of the work known as self-regulated learning.

Yet, before focusing exclusively on motivation, of significance is the work of Pintrich (1991) in this area. This researcher developed a questionnaire for use with college students entitled the "Motivated Strategies for Learning Questionnaire". There are essentially two sections to the MSLQ, a motivation section and a learning strategies section. There are a total of 81 items on the questionnaire and the purpose of the selfreport instrument is to assess college students' motivational orientations and their use of 
different learning strategies in an undergraduate psychology college course on learning. The questionnaire was used to gather information about study habits, learning skills and motivation for each student, with the purpose of providing these students the opportunity to receive feedback about their responses with the hopes that by using this feedback they could do something about changing their study skills and motivation if necessary.

Pintrich (1991) notes that "all of the motivational and study skills mentioned on their feedback sheet are learnable" (p. 70). The expectation is that if students are serious about making the most of their educational experience, they will note the areas in which change can be implemented. This study is of relevance to the present study in that it notes that students at the undergraduate level still have difficulty self-regulating, and it highlights the importance of addressing these issues with younger students so that they are capable of making the necessary adjustments by the time they are in a postsecondary educational setting. This of course is a position echoed by Corno (1987) with the statement "...we can promote self-regulated learning through teaching" (p. 249). The role of the reflective writing journal was introduced primarily to support students who may yet lack the skills to begin reflecting upon what helps them learn best.

\section{Feedback}

Of particular importance to this study is the rich amount of literature pertaining directly to the importance of setting goals and receiving feedback throughout the learning process. "Experimental studies have shown that teaching low-achieving students to set proximal goals for themselves enhances their sense of cognitive efficacy, their academic achievement, and their intrinsic interest in the subject matter" (Zimmerman, Bandura \& 
Martinez-Pons, 1992, p. 664). In 1982, Schunk conducted a study to clarify the role of effort attributional feedback in achievement contexts. He studied second and third graders identified by teachers as struggling with mathematical subtraction skills. Students were asked to perceive how capable they were of solving different types of math problems. This pre-study interview served as an indication of what level of self-efficacy the child held for each corresponding arithmetic skill.

The students were divided into four groups. The Past Attribution Group in which the proctor monitored every eight minutes and feedback was given only by informing the student that they've worked hard by linking how far they've progressed. The Future Attribution Group where the proctor monitored in much the same way as the past attribution group, but adding that they needed to continue working hard. The Monitoring group was where the proctor monitored every eight minutes, as in the past and future attribution groups, but they were given no comments. Lastly, the Training Control Group where children had no monitoring by the proctor and they served as a control for the training procedures. It was hypothesized that the students in the Past Attributional feedback group would benefit most and that those in the Future Attributional feedback group would benefit least. The results found that all groups except Monitoring showed significant pre-post increases in arithmetic skill. The study helps provide evidence that attributional feedback that links past achievement with effort promotes task involvement, skill development, and perceived self-efficacy. A complex aspect of the study lies in the fact that "effort attributional feedback contains an element of social reinforcement.

Children who are told they have been working hard may infer approval, whereas those 
told they need to work hard may infer that they are not doing as well as they should" (Schunk, 1982, p. 554).

This particular study supports the idea that children's perceptions of their capabilities have important effects on their subsequent achievement. Teachers that are sensitive to these perceptions will enhance the learning process for their students. This study serves as support for attempting to engage in a journal reflective writing experience with students because journals teach them to monitor themselves and, if they do not like the feedback that they are getting, they can reflect as to what changes need to be made to get at their desired result.

A later piece written by Schunk (1990) focused exclusively on the self-regulated learning processes of goal setting and perceived self-efficacy. Schunk defines a goal as what an individual is consciously trying to accomplish, and goal setting would involve modifying the established goal as necessary. He sees perceived self-efficacy as referring to beliefs concerning one's capabilities to attain designated levels of performance. The research suggests that

students enter learning activities with goals and self-efficacy for goal attainment. As learners work on tasks, they observe their own performances and evaluate their own goal progress. Self-efficacy and goal setting are affected by self-observation, self-judgment, and self-reaction. When students perceive satisfactory goal progress, they feel capable of improving their skills; goal attainment, coupled with high self-efficacy, lead students to set new challenging goals. (Schunk, 1990, p. 71)

This serves as critical support for the use of reflective writing journals within the classroom setting. In the current study the students were asked to write down their weekly learning goal and then to assess to what extent they felt they met their goal. 
Schunk (1990, p. 76) reinforces this technique by asserting that "goals raised self-efficacy, and children who received goals and comparative information demonstrated the highest self-efficacy and skill. Providing children with a goal and information that is attainable may increase self-efficacy for learning..."

Butler and Winne (1995) wrote a review of educational research in the area of feedback. They found that for all self-regulated activities, feedback was an inherent catalyst. In other words, when there was feedback provided to students (either external or internal) the students were more engaged in the learning process. Furthermore, they found that "research generally confirms that learners are more effective when they attend to externally provided feedback" (Meyer, 1986 in Butler \& Winne, 1995, p. 246). This is because students traditionally receive information provided to them by teachers or, in more contemporary settings, by computers. Traditionally, the students engage in a period of learning and activities, and then there is some type of evaluation provided for which the students await their results in order to find out how well or how poorly they've done. Butler and Winne (1995, p. 248) propose a new model based on the outcome of the research on educational feedback. Their model is based heavily on the notion that the more successful learners are those who provide themselves the opportunity to monitor their work and to establish a path of internal feedback. This would require the students set goals, explore tactics and strategies and then monitor their finished product. Interestingly enough, their model makes room for the possibility of accepting external feedback on their performance, but they place that aspect outside of the realm of the student's cognitive system, emphasizing that although external feedback is a reality in 
most educational settings, the more important path to success at reaching self-regulated learning must include internal feedback.

The current study is focused on one aspect of a larger study having been conducted by Rendulic and Terrell (1999). The Butler and Winne (1995) literature influenced Rendulic and Terrell who improved their model of self-regulated learning to include a journal writing activity. Their past research had focused exclusively on the graphical feedback and whether or not this type of performance feedback stimulated intrinsic motivation and ultimately higher academic achievement (Rendulic \& Terrell, 1997a; Terrell, Greenberg \& Rendulic, 1995; Terrell \& Rendulic, 1996). However, as a result of this new model emphasizing the need to enhance intrinsic motivation without relying exclusively on external motivation, the researchers saw the need to investigate the effectiveness of applying a reflective writing journal to their study. This reflective writing journal would meet the Butler and Winne criteria for self-regulated learning that focused on having students set goals and apply their own tactics and strategies.

A study conducted by Sink (1991) with middle school children also served to establish a relationship between setting goals and academic achievement. The hypotheses were based on the fact that because the students were in the sixth grade their developmental level would enhance the findings because "this age is a transitional period in the development of self-regulated learning" (p. 7). Aside from focusing on planning and self-assessment (which were categorized as an aspect of metacognition), Sink also measured self-concept, locus of control and various cognitive and noncognitive variables in predicting academic achievement across several subject areas. Positive results for 
substantiating the hypotheses were found in that certain metacognitive and affective variables are significantly related to mathematics, reading, and science achievement. Of most relevance, Sink found that "those students with better planning skills had significantly higher achievement test scores, providing further evidence for the role planning exerts in students' academic performance" (Sink, 1991, p. 19).

More recently, Schunk $(1996,1997)$ has continued to provide evidence that feedback is an essential component of the self-regulated learning process. In 1996, a paper was presented in which three on-going research projects were summarized on the effect of feedback to the learning process. The first two studies involved fourth graders and focused mainly on whether or not having performance goals or learning goals was most effective in increasing self-regulatory skills. The third study involved preservice college students who were working on a computer project, but the researcher's focus was also on the same variables: goals and self-evaluation. Schunk (1996) found that for the study with the fourth graders the findings "support theory and research on the benefits of goals and self-regulation processes and achievement" (p. 16). Furthermore, it was found that for the college students "combining goals with self-evaluation of progress in learning is an effective way to raise college students' self-efficacy and perceived competency for using self-regulatory strategies" (Schunk, 1996, p. 20). The findings were summarized by providing three implications for teaching and learning: teachers need to provide students with opportunities for self-evaluation; they should design learning environments to provide information about progress; and, whenever possible, they should use learning goals and provide feedback on goal progress (Schunk, 1997, p. 17). 
van Kraayenoord and Paris (1997) conducted a longitudinal study in Australian schools of third, fourth and fifth graders in which they created and applied a "Worksamples Interview" to analyze students' self-assessment skills. They felt that because self-assessment includes both reflection and evaluation of one's work, it helps to develop ownership and responsibility for learning. Hence, the framework for their study was established within the theoretical work of authentic assessment and metacognition. One of the purposes of their study was to investigate whether self-assessment could be measured in a brief interview because one of their goals was to develop and refine the Worksamples Interview. Secondly, they felt that the work done in the area of metacognition served as support for the premise that self-assessment improves with both age and experience, hence the use of three grade levels and the longitudinal model. They established that:

...a Piagetian interpretation suggests that students might not engage in selfassessments of their cognitive processes and outcomes much before the age of 7 - 8 years and that reflection should become increasingly easier, more abstract, and more systematic during adolescence. From a Vygotskian perspective, self-assessment might be expected to improve as a function of teaching practices, specifically, the amount of social assistance provided for students to examine their work samples and evaluate them against various criteria. From an information-processing perspective, self-assessment is a component of metacognition that would be applied more spontaneously, more deeply, and more automatically as students move through elementary school. (van Kraayenoord \& Paris, 1997, p. 525)

It was found that examining students' insights about their classroom work in a situation similar to a student-teacher conference proved to be quite effective. Students appraised samples of their work on the basis of specific dimensions and provided explanations and reasons for their selection of work samples. The quality of the comments 
made by the students suggests that students are able to assess their own work and provide both cognitive and affective evaluations according to particular features that influence learning. They did find that the older students had an easier time by virtue of the fact that they had more practice and of course that developmentally they were better prepared for the experience. Their most important finding however, emerged with the fact that by engaging the students in evaluation, the process became more meaningful for the students. This study fully supports the use of implementing a reflective writing journal, that would be similar to the interview instrument developed by these researchers.

The use of feedback has also been of interest to researchers such as Bandura (1997) who focuses on the social aspects involved in the learning process. Bandura recognizes the way in which feedback can provide motivation to learners. Interestingly enough, Bandura is very engaged in the type of feedback that a student receives. In order for feedback to create a situation that enhances self-efficacy, Bandura believes that it has to highlight certain things. "Feedback that one's work is of good quality progressively raises perceived efficacy, which in turn, predicts subsequent performance. In contrast, factual feedback of how much work one produced without reference to its quality improves neither perceived efficacy nor level of productivity" (Bandura, 1997, p. 226). The reflective writing journal employed in the present study takes into account the assertions made by Bandura. The students have the opportunity to judge for themselves whether or not they accomplished their goals for the week. The feedback provided from the teacher was just the factual information of the grades received for each classroom assignment, however the journal encompasses the recommendation made by Bandura that 
the student think about the quality of the assignment and brings to light their opinion as to how well they felt they did. This extends the journal writing experience by including a quality evaluation component that would not exist had it just been a graphical feedback assignment as in Rendulic and Terrell (1997a). Although their study focuses more on the area of business, the work of Kluger and DeNisi (1998) further serves to underscore these findings in that that they believe "Feedback Interventions" (FI's) that do not refer back to the ultimate learning goals are not as effective as those interventions that include the learner. They suggest that "one clear answer lies in using FI's only in combination with goal setting intervention" (Kluger \& DeNisi, 1998, p. 71). This is an interesting assertion for researchers grappling with what feedback model to use, and yet it is a supportive finding in light of the present study that does attempt to create a situation in which connections are always made to goals having been previously set.

\section{Strategy Use}

Theoretically speaking, establishing that a student exhibits self-regulating behavior can be quite difficult. Originally, the studies on self-regulated learning focused solely on observations based on the abstract definitions provided by researchers such as Zimmerman (1989a) and Bandura (1986). However, the research has progressed to the point in which measurement of a student's ability to self-regulate is possible.

To qualify specifically as self-regulated... students' learning must involve the use of specified strategies to achieve academic goals on the basis of self-efficacy perceptions... self-regulated learning strategies are actions and processes directed at acquiring information or skill that involve agency, purpose, and instrumentality perceptions by learners. They include such methods as organizing and transforming information, self-consequating, seeking information, and rehearsing or using memory aids. (Zimmerman, 1989b, p. 329) 
In 1986, Zimmerman and Martinez-Pons developed a structured interview for assessing student use of self-regulated learning strategies in naturalistic settings. The instrument (SRLIS) was developed using a free response interview format in order to allow for students to answer for themselves and provide the best opportunity for the researchers to distinguish what made the learners different. Previous research and theory in the area of social learning theory helped Zimmerman and Martinez-Pons identify 14 classes of self-regulated behavior (Table 1). The categories established for each of the strategies recognizing self-regulation were of particular interest to the current study. For although the age levels are different, one can recognize the importance of identifying and fostering this type of strategic behavior in the lives of young students in order to encourage an active role in the learning process very early on. Furthermore, this tool advanced the literature in that it prepared for all researchers a point at which to begin exploring self-regulation at any age level.

The reader is referred to their work for a more comprehensive discussion regarding this instrument, in that for purposes of the current study this work was used specifically as a guide for initial evaluation of the reflective writing journals. It was this work by Zimmerman and Martinez-Pons (1986) that initiated the goal of measuring selfregulation, and established the criteria for establishing strategies that students were reporting in the interview process. Note that the student initiated responses were categorized to create fifteen commonly reported strategies. The current study will focus on student responses as a result of their journal writing. 
Table 1

Self-Regulated Learning Strategies

Categories of Strategies

Representative Student Self-Initiated Statements

1. Self-evaluation

evaluations of the quality or progress of their work,

2. Organizing and Transforming

3. Goal-setting and Planning

4. Seeking Information

e.g., "I check work to make sure I did it right." overt or covert rearrangement of instructional materials to improve learning, e.g., "I make an outline before I write my paper.."

student setting of educational goals or subgoals and planning for sequencing, timing, and completing activities related to those goals, e.g., "First, I start studying weeks before exams, and I pace myself." efforts to secure further task information from nonsocial sources when undertaking an assignment, e.g.,"Before writing, I go to the library to get as much information as possible concerning the topic."

5. Keeping Records and Monitoring efforts to record events or results, e.g., "I took notes of discussion." "I kept list of words I got wrong."

6. Environmental Structuring

7. Self-Consequences

8. Rehearsing and Memorizing

9-11. Seeking Social Assistance

12-14. Reviewing Records

15. Other efforts to select or arrange the physical setting to make learning easier, e.g., "I isolate myself from anything that distracts me." "I turned off the radio so I can concentrate on what I am doing." student arrangement or imagination of rewards or punishment for success or failure, e.g., "If I do well on a test, I treat myself to a movie."

efforts to memorize material by overt or covert practice, e.g. "In preparing for a math test, I keep writing the formula down until I remember it." efforts to solicit help from peers (9), teachers (10), and adults (11), e.g., "If I have problems with math assignments, I ask a friend to help."

efforts to re-read tests (12), notes (13), or textbooks (14) to prepare for class or further testing, e.g., "When preparing for a test, I review my notes." learning behavior that is initiated by other persons such as teachers or parents, and all unclear verbal responses, e.g., "I just do what the teacher says." 
The SRLIS (1986) was developed for use with high school students that had previously been identified as low or high achieving based on their track placement in school. The results indicated that there was a substantial correlation between student group and strategy use, with simple t-tests revealing that for all but one of the strategies (self-evaluation) the students from the higher achievement group used the learning strategy significantly more than the students in the lower achievement group. Zimmerman and Martinez-Pons (1986) found that their interview procedure could provide reliable evidence concerning students' self-regulation reports. Furthermore, they went on to do a study validating the use of the instrument (Zimmerman \& Martinez-Pons, 1988) in order to compare actual achievement (standardized results), teacher observations and the results of the interview.

By combining teachers' observational measures factorially with standardized achievement test outcomes, it is possible to separate student achievement outcomes associated with their use of self-regulated learning strategies from their general ability. This factorially refined criterion would offer a basis for examining the construct validity of SRLIS and the underlying model of self-regulated learning. (Zimmerman \& MartinezPons, 1988, p. 286)

The results of this study indicated that both methods (the interview and the teacher observations) revealed a common underlying construct, that of strategy use, therefore providing the evidence necessary for the researchers to assert that the SRLIS does offer a valid viewpoint of how interviewed students identify their own learning strategy use. The results of these two studies are of interest to the present study. Although there is a significant age difference between the subjects being studied (high school vs. elementary school), many of the self-regulated learning strategies identified by Zimmerman and 
Martinez-Pons can also be identified in the writing journals of the elementary school students. Therefore, building upon this past research, age notwithstanding, we can confidently look to the SRLIS for a valid and reliable framework upon which to begin categorization of the self-regulated learning strategies employed by the students in our study as reported in their journals.

\section{Motivation}

In order to self-regulate, children must motivate themselves to learn (Carr, 1996, p. 4). This motivation can be either intrinsic or extrinsic in nature. The literature on extrinsic motivation is most commonly linked to the area of behavioral psychology. The student receives some kind of stimulus that motivates him or her to respond in the appropriate manner. The reinforcement then motivates the student to continue responding to that condition. The work of Carver and Scheier (1981) focuses exclusively on the selfregulated learning activities of a student based specifically on the behavioral model of learning. In contrast, Pintrich and DeGroot (1990) found that typically good selfregulators were intrinsically motivated, and that children monitor and evaluate their own work without the need for a teacher or adult to prompt this behavior. Zimmerman (1990, p. 6) agrees that students who tend to be good self-regulators are high achievers that will create their own rewards and punishments to motivate their achievement. Therefore, the research in the area of motivation is highly relevant to researchers and educators that are interested in establishing how to help students become good self-regulated learners.

According to Schunk (1990), "Motivation refers to the process whereby goaldirected behavior is instigated and sustained" (p. 3). Typically, this is thought of as being 
an important component of the learning process because one associates the word motivation with the concept of completing a task. Teachers refer to a student as being motivated or unmotivated within the context of learning something that is an educational objective. Similarly, a coach may refer to a player as being motivated to participate in competition or in the training process. Both examples serve to set the concept of motivation within a context that requires an ultimate goal. In the case of the school classroom it is learning, while on the playing field it is winning. Weiner $(1990$, p. 621) associates both as being "work-related" as opposed to "play-related", because they are both focused on completing a task and not on the casual participation of the subject. Furthermore, Weiner (1990, p. 618) establishes that the history of research on motivation in education clearly shows that "motivation is often inferred from learning, and learning usually is an indicator of motivation for the educational psychologist."

The history of studying the concept of motivation is well documented as being associated with behavioral psychology in the 1930's and 1940's and then shifting to a cognitive perspective in the 1960's and 1970's (Driscoll, 1994, p. 293); however, even educators in the time of Mann were intrigued by how to motivate students in the classroom. In his reports to the Massachusetts Board of Education (1837 - 1848) he makes clear that he is aware of the importance of motivation, by noting that "until a desire to learn exists within the child, some foreign force must constantly be supplied to keep him going; but from the moment that a desire is excited, he is self-motive (sic) and goes alone" (Cremin, 1957, p. 9). Therefore, even though formal educational studies were not being 
conducted on the topic of motivation, evidence exists that educators as far back as the early 19 th century were considering it conceptually.

Interestingly enough, the studies focused on the concept of motivation are often linked with other areas of psychological research. Pressley and McCormick (1995) remind us that

knowing one's fate is under personal control has been referred to by motivational theorists as self-efficacy...All theorists who have considered this type of knowledge recognize those who believe they can control their destinies are likely to be more motivated to exact great effort in pursuit of goals than those who believe their achievements are out of their control. (p. 102)

The work of Bandura has done much to progress the area of study in psychology known as Social Learning Theory. It is within this context that Bandura establishes the importance of self-efficacy for the learning process.

Bandura notes that

a strong sense of efficacy fosters a high level of motivation, academic accomplishments, and development of intrinsic interest in academic subject matter. A fundamental goal of education is to equip students with selfregulatory capabilities that enable them to educate themselves. Selfdirectedness not only contributes to success in formal instruction but also promotes lifelong learning. (Bandura, 1997, p. 174)

Bandura sees the school as the perfect environment for cultivating self-efficacy. In the true tradition of the field of Social Learning, the school is the place where children can observe others as they express interest in different areas and they can model behaviors and actions which they find rewarding. "According to social cognitive theory, growth of intrinsic interest is fostered through affective self-reactive and self-efficacy mechanisms" (Bandura, 1997, p. 219). To foster an environment that supports self-efficacy is to create 
an environment that encourages intrinsic motivation. This is no easy task when typical elementary classrooms average over 30 pupils (BCPS, 2000). In essence, teachers are forced to adapt their instruction to meet general classroom needs, which ultimately moves away from supporting self-regulatory skills. Yet, Bandura argues educators should recognize this interaction and adjust the school experience to integrate these mechanisms and ultimately create an environment that is supportive of self-regulated learning. Bandura created a model known as Triadic Reciprocality that discusses the three components of the Person, the Environment and the Behavior. This proposed view of student self-regulated learning assumes reciprocal causation among these three influences. "The essence of Bandura's (1986) triadic formulation is captured in the statement 'behavior is, therefore, a product of both self-generated and external sources of influence"” (Bandura in Zimmerman, 1989, p. 330).

It is commonly acknowledged that self-directed learning requires motivation as well as cognitive and metacognitive strategies. Motivation is a general construct that encompasses a system of self-regulatory mechanisms. Attempts to explain the motivational sources of behavior must specify the determinants and intervening mechanisms that govern the three main features of motivation: selection, activation, and sustained direction of behavior toward certain goals. All too often, interlinked facets of a motivational mechanism are fractionalized into separate constructs drawn from divergent theories. The medley of constructs then gets called integrative theorizing. The motivational facet of self-directed learning encompasses a variety of interlinked self-referent processes including selfmonitoring, self-efficacy appraisal, personal goal setting, outcome expectations, and affective self-reactions. These component activities promote engrossment in academic activities through investment of the selfsystem in them. Moreover, cognitive development and functioning are embedded in social relations. Skill in using social resources and managing the social consequences of one's school experiences, therefore, is another important facet of self-directed learning. (Bandura, 1997, p. 228) 
Pressley and McCormick (1995, p. 107) state that the "self-efficacy" perspective makes clear why it is important to provide students with tasks that are just a bit beyond them. For if the task presented to a learner is way beyond their ability to grasp it, then the experience does not serve to motivate the student or challenge them to try again.

Whereas, tasks that are intriguing and within their grasp provide just the right amount of challenge as to peak the interest of the learner and motivate them to take risks. Vygotsky's theories (1978) focus on both developmental and sociocultural factors and have made an impact on the work of contemporary educational psychologists. Much like Bandura's position that self-efficacy requires tasks to be just a bit beyond them, Vygotsky espouses the notion that in order for learning to take place, the task or objective must be within the child's "zone of proximal development" (Pressley \& McCormick, 1995, p. 181).

With the publication of Mind and Society (Vygotsky, 1978), contemporary American educators began focusing on the responsive social world surrounding a learner. Establishing what a learner was thinking and where a learner was (with respect to cognitive processes) became an important factor.

The responsive social world provides assistance on these tasks that are within the child's 'zone of proximal development' according to Vygotskian theory. In fact, the 'zone' is defined as behaviors beyond a child's level of autonomous functioning but within reach with assistance and, as such, reflect behaviors that are developing. Children learn how to perform tasks within their zone by interacting with more competent and responsive others who provide hints, prompts, and assistance to the child on an as-needed basis. (Pressley \& McCormick, 1995, p. 182)

Eventually the child internalizes the process and help is no longer needed. This process of providing less and less help is identified by Vygotsky as scaffolding. 
The literature on the study of motivation is very well established and provides educators with a complex and comprehensive background with which to work. Similar to Driscoll's historical account of the literature, Pressley and McCormick (1995) note that the current research emphasizes the perspective of the writings of Dweck, Nicholls, Borkowski and Ames (p. 111). Their new look at academic motivation research is clearly cognitive in nature and focuses on the American drive for success and evaluation. Their concluding comments on the subject of motivation in the classroom discuss the work of Weiner (1990) and his reviews of the content of chapters on motivation in the editions of the Encyclopedia of Educational Research published since 1941. Weiner (1990, p. 617) states that

...physiological mechanisms underlying motivation dominated in the 1940's and 1950's, with a little bit of Freud (e.g., defense mechanisms) and behaviorism mixed in. Drives and grand theories (e.g., psychoanalytic) dominated the 1960's, with motivation in relation to the cognitive processes of learning, perception, and memory showing up in 1969. By 1982, about one-third of the chapters were concerned with issues like attribution theory, self-esteem, and reinforcement theory. The 1990 volume featured chapters on cognition, including causal attributions, selfefficacy, and learned helplessness. There were also chapters on environmental determinants of motivation, including cooperative and competitive structures, intrinsic and extrinsic rewards, and praise.

Pressley and McCormick (1995) agree confidently with Weiner (1990) and Driscoll (1994) that contemporary thinking on academic motivation is clearly focused on cognition.

Therefore, with this contemporary focus on a cognitive perspective of learning, researchers are now aiming their research towards the application of these ideas. The task now is to inform teachers how to motivate students, seeing that motivation does play such 
a central role in the learning process. The work of Brophy (1987) has focused on establishing tactics teachers should use to intervene and motivate their students. He begins by establishing basic motivational concepts, such as "student motivation to learn is a student tendency to find academic activities meaningful and worthwhile and to try to derive the intended academic benefits from them" (p. 205). He further differentiates the fact that motivation to learn can be construed as both a general trait and a situationspecific state. "As a general trait, motivation to learn refers to an enduring disposition to strive for knowledge and mastery in learning situations", whereas "in specific situations, a state of motivation to learn exists when the student engagement in an academic activity is guided by the goal or intention of acquiring the knowledge or mastering the skill that the activity is designed to teach" (p. 206). With the work of Brophy there is a stated link to the importance of cognition. The emphasis is that "being motivated to learn implies highquality cognitive engagement in the activity, not mere enjoyment of it" (p. 207). So, there is a need to specifically study the cognitive aspects of student motivation, and not just the affective aspects which often times are the focus of motivational studies.

Brophy (1987) states that most approaches to motivation fit within the general context of social learning theory. Then it is specified that this perspective aligns itself within "expectancy $x$ value theory" $(1987$, p. 207). Brophy credits this theory to Feather (1982) who asserted that the effort people put into a task will be a product of two things: 1) The degree to which they expect to be able to perform the task successfully if they apply themselves (and thus the degree to which they expect to receive the rewards that 
successful performance of the task will bring); and 2) The degree to which they value those rewards.

"Expectancy $\mathrm{x}$ value theories of motivation imply that, in order to motivate their students to learn, teachers need both to help their students appreciate the value of academic activities and to make sure that the students can succeed in these activities if they apply reasonable effort" (Brophy, 1987, p. 207). However, it is not just the student that has to provide the effort, there is an aspect of the equation that involves the teacher. Brophy notes that there are essential preconditions for motivating students and that the strategies cannot work effectively if the assumptions and preconditions are not in effect. First and foremost, a supportive environment is necessary. This assumes that a teacher uses classroom organization and management skills to set up an effective learning environment and that the teacher is patient and encouraging to the learner. Second, Brophy recommends that an appropriate level of challenge or difficulty is necessary to entice a student to learn. Third, Brophy says that it is necessary to have meaningful learning objectives because if the activity or objective is pointless then the students assume it is not worth learning. Last, Brophy advocates using motivational strategies in moderation to obtain optimal use. Strategies used too often or too routinely may lose their effectiveness, and any particular use of a strategy can become counterproductive if it goes on too long or is carried to extremes.

With those four preconditions having been met, Brophy lists strategies for stimulating student motivation to learn. To motivate students, teachers should do the following (Brophy, 1987, p. 227): 
- Model interest in learning: Teachers should let students know they like learning (e.g., reading, writing, problem solving) and find academic activities rewarding and generally satisfying.

- Communicate to students that there is plenty of reason to be enthusiastic about what is going on in school.

- Classrooms should be low-anxiety places.

- Send the message that what is occurring in school deserves intense attention.

- Induce curiosity and suspense.

- Make abstract material more personal, concrete, and familiar.

- Let students know the learning objectives and provide them with advance information about upcoming content.

- Provide informative feedback to students (e.g., feedback in the form of praise, as discussed in the last subsection).

- Adapt tasks to student interests as much as possible.

- Offer students choices between alternative tasks or alternative ways of learning content.

- Provide novel input as much as possible.

- Design instructional tasks to allow as much student autonomy as possible.

- Design tasks so there is opportunity for activity.

- Design learning tasks that produce a product (e.g., a class book).

- Include games as part of learning. 
classroom context by emphasizing that contemporary learning theorists have shown that learning is not just a response to a stimulation. Rather, it is a complex process that involves the learner actively processing input and transforming it into a form that integrates it with existing knowledge. Therefore, when discussing motivational strategies within the learning context, Brophy makes clear that the most effective way of presenting these strategies involves teaching these strategies in conjunction with instructional strategies designed to teach students to be aware of their goals during task engagement, to monitor the strategies that they use to pursue these goals, to note the effects of these strategies as they are used, and to monitor their subjective responses to these unfolding events.

Ideally, then, students not only will be motivated to learn and armed with cognitive strategies for doing so, but also will be able to maintain metacognitive awareness of what they are doing as they do it, in order to monitor their progress and adjust their strategies if necessary. (Brophy, 1987, p. 238)

\section{Metacognition}

The psychological literature pertaining to the study of metacognition was first introduced in the early 1970 's by Flavell. This research originally focused on the term metamemory which is defined as:

the knowledge one has about memory in general; knowledge about the peculiarities of one's own memory system; sensitivity to past experience with memorizing, storing, and retrieving different types of information in various situations; and a system of skills for planning, directing, monitoring, and evaluating one's behavior during learning and remembering. (Weinert \& Kluwe, 1987, p. 8) 
This research on metamemory (Flavell, Friedrichs \& Hoyt, 1970) ultimately led to the term metacognition sometime around 1975 (Brown, 1987, p. 66). Metacognition has been widely referred to as "thinking about thinking." With the passage of time, it has conclusively been established as an extension of cognitive psychology. However, researchers have been at odds as to how definitive the term should be in the field of psychology. "The term has been problematic from its inception, denounced as fuzzy and faddish, and even unnecessary...Two primary problems with the term are: it is often difficult to distinguish between what is meta and what is cognitive; and there are many different historical roots from which this area of inquiry developed" (Brown, 1987, p. 66).

The first problem with the term metacognition as established by Brown (1987) deals directly with the difficulty readers and researchers have with distinguishing metacognition from cognition. As psychology evolved, there emerged different areas of focus within the field. Historical accounts make clear the distinction between the popular behavioral focus in psychology to the founding of faculty psychology and ultimately the establishment of cognitive psychology. Yet, as the research has become much more sophisticated and in-depth, the inevitable overlapping of characteristics begins to take place. In science, one notes the blending of fields that had originally been distinct areas of study (biology and chemistry and physics to higher forms of sophisticated engineering) and similarly in education an effort has been made to teach across subject areas and help students establish and integrate a more realistic approach towards learning. For cognitive psychologists there most certainly exists a distinction between metacognition and 
to consider first the interchangeability of cognitive and metacognitive functions.

An area where this problem is particularly acute is the currently popular domain of metacognition and reading, writing, and studying. The following quote by Flavell (1976): "Asking yourself questions about the chapter might function either to improve your knowledge (a cognitive function) or to monitor it (a metacognitive function), " demonstrates the interchangeability of cognitive and metacognitive functions. A particular activity can be seen as the strategy itself (looking for main points), its monitoring function (a metacognitive activity), and a reflection of the knowledge (also metacognitive) that is an appropriate strategy to employ in a given situation. (Brown, 1987, p. 66)

It's not unreasonable to consider the fact that one could easily interchange the two processes and that at times they go hand in hand. This leads directly to Brown's second source of confusion with the term metacognition. With the widespread use of the term, it has been used to refer to two distinct areas of research. The first area of research addresses knowledge about cognition and the second area addresses specifically the regulation of cognition. The two forms of metacognition are indeed closely related. As a researcher it is difficult to separate them because it may lead to an oversimplification of the term. However, they are readily distinguishable, and they do have different historical roots:

Knowledge about cognition refers to the stable, statable, often fallible, and often late developing information that human thinkers have about their own cognitive processes; traditionally, this has been referred to as knowing that. Knowledge about cognition is relatively stable. One would expect that knowledge of pertinent facts about a domain that it is fallible, severely limited for short-term verbatim retention, etc., for example, memory, would be a permanent part of one's naive theory on this topic... This type of knowledge is usually assumed to be late developing; it requires that learners step back and consider their own cognitive processes as objects of thought and reflection. For Piaget, reflected abstraction requires hypothesis testing and evaluation, and the ability to imagine possible worlds 
and their outcomes; therefore, it demands formal operational thought. For others, earlier signs of emergence are possible; however, reflection is rarely attributed to the very young child or novice, regardless of how precocious they might be. (Brown, 1987, p. 67)

The second cluster of activities that is dubbed metacognitive in the developmental literature, consists of the activities used to regulate and oversee learning. These include: planning activities, monitoring activities and checking outcomes (Brown, 1987, p.68).

The fact that Brown (1987) recognized the importance of the developmental element to all research and writing concerned with metacognition is of great significance to the current study. It supports the notion that children are not always developmentally ready to engage in metacognitive skills. This implies that they are also not ready to engage in self-regulation. This was an area of interest, as was discussed earlier, in the work of Paris and Newman (1990), as they explored the implications of when the optimal time would be to engage in teaching learning strategies and in the teaching of concepts of metacognition. It was their contention that younger children were not developmentally ready to think about their learning strategy use; moreover they could not engage in high quality metacognitive actions.

\section{Historical Roots of Metacognition}

Brown (1987) further discussed the diverse historical roots of the family of concepts that are often referred to generically as metacognition. The summary prepared by Brown of the existing field very clearly defined four areas from which the roots of metacognition are derived. The first area identified was Verbal Reports as Data (p. 69). In other words, studies or literature focused on what types of abilities people (adults and children) possessed to provide verbal reports of their own cognitive processes. It was 
basically identified as being a two step process in which the person had conscious access to their cognitive process and then was able to report on that process. Studies on the issue of reflective access (Brown, 1982; Brown \& Campione, 1981; Pylyshyn, 1978), conscious access (Gardner, 1978; Rozin, 1976;) or reflected abstraction (Piaget, 1976) are cited as support for this historical perspective. This particular study has roots in this thread of research in that the reflective writing journal component asks students to reflect back upon their use of learning strategies and requires the learner to think about the work conducted throughout the week in order to determine if their actions taken had a direct result on their outcomes or their future work. Although verbalization may not have taken place as a result of the writing journal process, no doubt the opportunity to write would serve as a representation of important communication in a metacognitive sense.

Brown (1987, p. 79) identifies Executive Control as the second root of metacognitive research. This concept is taken from the many models focused on information processing as a model of cognition. These are theories that emerged in the late 1960 's as a result of the emerging field of computers and information technology. The literature identified some form of "central processor, an interpreter, supervisor, or executive system capable of performing an intelligent evaluation of its own operations" (Brown, 1987, p. 79).

The third root of metacognitive research as established by Brown stems from Self Regulation.

It is certainly the case that human thinkers play with thinking, that is, they subject their own thought processes to examination and treat their own thinking as an object of thought. Similarly, learners regulate and refine their own actions; sometimes this is done in response to feedback 
concerning errors, but often it is done in the absence of such feedback.

(Brown, 1987, p. 89)

This root of metacognition as described by Brown, serves to support the notion proposed by Zimmerman (1989a) that metacognition is often intertwined with self-regulation. There were two ideas very relevant to this study pertaining to self-regulation and presented as a root of metacognition--the first being thoughts related to Piaget (1976) and the second being the notion of levels. For early childhood educators the work of Piaget (1969) serves as support for developmentally appropriate practice in our classrooms. His work established and supported the idea that children develop across four stages that become increasingly complex and abstract. Brown demonstrates how Piaget relates that "the developmental progression is from unconscious autonomous regulation to active regulation, in the absence of anything more than a 'fleeting consciousness"' (p. 89). The second point relevant to the current study deals with levels of self-regulation (Brown, 1987, p. 95). Brown clearly uses the work of Piaget to support the rationale that children work through levels of self-regulation. These ideas serve to support the framework of study which purposely attempt to isolate variables such as the concrete graphing assignment with the abstract journal in order to determine whether or not this is an optimal age for beginning a study based on self-regulation.

Lastly, Brown proposes that the fourth root of metacognition lies in literature which documented other forms of regulation (Brown, 1987, p. 100). It is this root of metacognition that addresses issues of learning stemming from social influences.

A great deal of the work conducted on other-regulation has taken place within the framework of Vygotsky's theory of internalization. Vygotsky (1978) argues that all psychological processes are initially social, shared 
between people, particularly between child and adult; and that the basic interpersonal nature of thought is transformed through experience to an intrapersonal process. (Brown, 1987, p. 100)

It is for this root of metacognition that Brown explores issues such as family influences, mediated learning activities, and tutoring. Clearly, the social aspect of feedback is one which Brown asserted had significant effects on a learner and should be addressed. It is the study of these "Mysterious Mechanisms" (Brown, 1987, p. 65) that guided much of the research conducted by Brown throughout much of her career, and her writings although often centering on the topic of metacognition clearly show that there is a fine line between the research and writings related to feedback, motivation, metacognition and ultimately self-regulated learning, therefore a thorough research would require an investigation into each.

\section{Metacognitive Strategies}

The use of metacognitive strategies enables a learner to focus and enhance the learning process. Research has shown that metacognitive strategies can be taught with some measure of success (Derry \& Murphy, 1986; Duell, 1986; Kurtz \& Borkowski, 1984). Although it is easier to teach older children how to think about their learning, there is evidence that young children are capable of thinking about learning strategies as well. Kurtz and Borkowski (1984) taught first and third graders specific strategies for learning and found that if the students attributed their success to effort, that they tended to use these strategies more regularly.

The study involved three treatment groups: (a) metacognitive training and strategy training, (b) metacognitive training and no strategy training and (c) strategy training with 
no metacognitive training. There were specific instructions given that were appropriate for three memory problems and these were followed by an attributional assessment of the children's perceptions of the causes for specific success and failure outcomes. Kurtz \& Borkowski (1984) found that children receiving the strategy training were more successful if they attributed their success to effort, rather than uncontrollable factors such as ability or task characteristics. The students were aware of the fact that their application to the process was significant.

The research in the area of metacognitive strategy use generally indicates that metacognitive ability depends on "person variables, task variables, strategy variables, and the interaction among all three" (Duell, 1986). With regards to person variables, "the research generally reveals that older learners seem to have a better understanding of their memory abilities and limitations than younger learners" (Driscoll, 1994, p. 103). As would be expected, older learners are more purposeful in their use of strategies and they are capable of planning throughout the learning process. Conversely, younger students would require reminders and some feedback as to when and how to use memory strategies.

With respect to task variables Duell (1986) reveals that the instructional content to be learned has an effect on the learning itself. The metacognitive strategies that learners choose to apply are typically selected as a result of the task or material that they are presented with. If the information is new, the learner applies general learning strategies. However, if the material relates to a subject that they know quite well, then they typically employ more domain-specific strategies (Gagné \& Driscoll, 1988). This is important for 
teachers to keep in mind when preparing lessons or activities with students, this way they can suggest particular strategies which may help students engage more successfully in the learning process.

Lastly, Duell (1986) discussed strategy variables as being important when considering metacognition, because they have to do with the metacognitive strategies themselves--the various ways in which learners may go about encoding, storing and retrieving information. Some of the metacognitive strategies may be simple strategies, such as encoding, storing or retrieving information. Yet, other strategies may require more extensive practice. Educators must be cognizant of the training that may be necessary to teach a metacognitive skill and the age of the students for which the strategy is aimed. Most definitely, Duell (1986) was focused on the learner when reminding educators that person variables, task variables and strategy variables are significant to the success of the student.

Programs that are aimed at enhancing metacognitive strategy use have revealed at least two criteria in common:

First, students must have a base of prior knowledge that may be related to the strategies they are learning. Domain-specific strategies, in particular, are virtually useless when students know little about the subject to which they pertain. Second, students must know when and why various selfregulatory strategies may be effectively employed. Knowing how to be planful is not enough to guarantee that one will be planful. Having such conditional knowledge does not guarantee that one will always use it. But realizing when and why such behavior will be useful in furthering learning goals helps to motivate students to engage in metacognitive, self-regulatory ways. (Driscoll, 1994, p. 104) 


\section{Concept of Competence}

In 1990, Sternberg and Kolligian edited a text entitled Competence Considered. The premise of the text was to explore the many dimensions of competence, particularly focusing on self-perceptions and self-evaluations. The authors for this collection of essays considered competence in the broader context of the developing, evolving person. The developmental aspect of competence is of particular interest to this study, in that the subjects are fourth graders, who have yet to reach their full potential and by nature are growing and changing with respect to this topic. With the book's primary focus being "competence as it is viewed by the self as opposed to others" (p. x), the relevance of this position is of great consequence to this study whose focus is on how a personal reflective writing journal can enhance the competence of students in the area of mathematics.

Norem and Cantor (1990) wrote that a focus on process can help to illuminate an important aspect of the self-regulatory picture: particularly, the relationships among beliefs about competence, beliefs about tasks, motivation for performance, and actual performance. Their research used the concept of cognitive strategies to describe the coherent patterns of appraisal, planning, retrospection, and effort that translate an individual's goals and beliefs into action. They studied college students over a period of three years in order to determine how students with three different levels of competence (defensive pessimists, aschematics, confident optimists) in strategy use responded to particular challenges with respect to academic achievement. They revealed certain dynamics which exist in light of perceived competence and incompetence. The defensive pessimists began the study knowing that they personally needed to struggle for control, 
whereas the aschematics took their time to determine that they needed to gain a better grasp of their academic tasks. In the end, each of these groups demonstrated students that were aware of the fact that it was their responsibility to take control. The last group, the confident optimists, were never in a position in which they felt out of control, but the researchers assume that if or when they are ever in a situation where they encounter obstacles that they would respond to the challenge. The students in this study experienced "curve balls as they valiantly tried to attain and maintain a sense of competence and to ward off feelings of incompetence at their college life tasks" (Norem \& Cantor, 1990, p. 204). This study sheds some light on the issue of competence for the current study, in that the researchers must be cognizant of the fact that each student enters the study at a different level of competence and the journal writing activities need to address these unique perspectives.

Markus, Cross and Wurf (1990) state that

Perceptions of one's own competence--a sense that "I am effective" or "I can do it"--are critical to individual functioning throughout life. Children develop in lockstep with their faith that they can accomplish various imagined undertakings. Later, well-being and successful functioning as an elderly adult are still bound up with one's feelings of competence. (p. 205)

Their central premise is that competence is mutually and reciprocally related to the selfsystem and that "felt" competence is an essential aspect of "actual" competence. Students may believe that they are good spellers, however they occasionally need some actual feedback in order to confirm their beliefs about their spelling ability.

It is also possible to represent one's self as having particular attributes that one does not in fact have. When individuals do not have behavioral evidence to support their felt competence, it will either be disconfirmed and abandoned as a consequence of one's actions or will serve to organize the 
individual's actions so that the desired ability is eventually attained.

(Markus, Cross \& Wurf, 1990, p. 206)

This concept of competence serves to reinforce the notion that a reflective writing journal is an invaluable tool for young students. The behavioral evidence in the case of the present study is the journal and the graph. On a weekly basis students are provided the opportunity to write about how well they feel they did in math, and more importantly the journal affords them the opportunity to creatively address repair strategies that may help them in future weeks.

The exercise of one's competencies in the service of maintaining an identity is in most cases not an effortful or even conscious activity, and it is inherently pleasurable because it validates one's identities. When so engaged, individuals are most likely to experience what is commonly labeled "intrinsic motivation." (Markus, Cross \& Wurf, 1990, p. 212)

They continue by advising that although there is a need for nurturing a feeling of competence, one must be careful not to translate the illusion of competence to reality.

What may appear to an observer as an unfounded optimistic belief that one is competent can actually create competence by selectively directing attention, efforts, and energies toward the desired action, and away from inconsistent or contradictory thoughts, feelings, and actions... Individuals will thus experience not illusions of competence but actual competence. Felt competence, then, is not a cognitive product that can be separated from actual competence. Instead, it is an integral aspect of competence.

Therefore, if you have students engaging in a reflective journal activity and consistently writing that they are performing in mathematics "better than expected", it is the contention of these researchers that the students will begin to engage in "real" activities that will make this a reality. The students will develop a sense of competence that the selfstructure will need to address in order to leave the illusion and make it a sense of reality. 
Lastly, it is relevant to note the writings of Krueger (1990) on this topic. He notes that childhood play is a precursor to work, and that children learn from a very young age about the developmental building blocks of success. There is a distinct difference between the feeling of success one has when he or she accomplishes something on their own, as opposed to being the passive recipient of the efforts of another. "The experience of positive mastery and triumph is a gratifying exchange with one's environment, and leads to further eagerness and motivation to respond to the environment as well as to the optimistic expectation of future mastery" (p. 247). Reflecting in a journal on a weekly basis, affords young students the opportunity to make changes that will lead to success. In essence, the journal can be viewed as a developmental stepping stone from the childhood stage of play to adulthood where work becomes the central focus. At both stages there are most certainly inhibitors to success, nevertheless the challenge becomes how to refocus on the issues of competence, so as to make changes in order to attain success.

\section{Resistance to Change}

Teachers ultimately hold the power to direct the learning experiences within their classrooms. They have the unique opportunity to present material to their students in any manner which they choose will be effective to the learning process. Of course, some teachers will follow the plan that may have been established by their particular school district or state; however, for the most part teachers are free to implement their curriculum and make decisions regarding instruction. This can be a very serious responsibility, in that the learning outcome of all students can be effected by a particular teacher. In recent 
years, there has been a resurgence of inquiry in this area (Driscoll, 1994). Historically speaking, we may categorize this as what Mann (1840) described as "Aptness to Teach" in his Fourth Annual Report.

He who is apt to teach is acquainted, not only with common methods for common minds, but with peculiar methods for pupils of peculiar dispositions and temperaments; and he is acquainted with the principles of all methods, whereby he can vary his plan, according to any difference of circumstances. (Cremin, 1957, p. 48)

In contemporary circles the literature describes it as Teacher Efficacy.

Driscoll (1994, p. 311) asserts that one of the more important variables to be examined for its effect on students is the teacher. A classroom environment, in the traditional sense, involves a teacher and his or her students. There is a social environment and relationship that exists which must be addressed when discussing any classroom setting. "Teaching efficacy is the teacher's judgment about the potential influence of teaching on a child's learning" (Ashton \& Webb, 1986 in Driscoll, p. 311). They further clarify that there is a difference between teaching efficacy and personal teaching efficacy. The addition of "personal" refers specifically to a teacher's judgment of his or her ability to motivate students. The difference being that teachers in general can feel that as teachers they have an ability to effect change in the life of a student and motivate him or her to learn, but the personal aspect refers to his or her notion of how they themselves can effect that change in motivation. "Motivational research among teachers will contribute to our understanding of how efficacy can affect different aspects of teaching (e.g., planning and evaluating), as well as student outcomes" (Schunk, 1990, p. 5). 
The construct of teacher efficacy was first conceptualized by two Rand Corporation evaluations of 100 Title III ESEA projects (McLaughlin \& Berman, 1977). The project results found that teacher's sense of efficacy was positively related to the amount of personal teacher change, as well as project goals achieved, continuation of project methods and materials, and improved student performance. The aspect of change is of great significance to the current study, in that a teacher's role is highly influenced by many issues surrounding this notion. Gibson and Dembo $(1984,1985)$ focused exclusively on the way in which change can effect a teacher's own sense of efficacy (or what Ashton \& Webb, 1986, would call "personal efficacy"). Through a series of factorial analyses they found that a "teacher's sense of teaching efficacy or belief that any teacher's ability to bring about change is limited by factors external to the teacher, such as a home environment, family background, and parental influence" (Gibson \& Dembo, 1985, p. 174). This finding can have serious implications for any researcher considering a study within a classroom setting. If a teacher believes that outside forces will always be a powerful force in his or her classroom, he or she may not wish to give new methods a chance, for they're convinced that change is too difficult to implement and not within their control,

For example, teachers with high performance efficacy may believe that they are effective in their own classrooms but may not believe that working with other teachers in planning curriculum change or improving faculty-principal relationships (organizational efficacy) will lead to any school improvements. As a result they resist participation in organizational interventions and refrain from cooperating with change strategies. (Gibson \& Dembo, 1985, p. 180) 
These observations are extremely significant to the current research. Often studies take place within school organizations that are prepared by researchers and administrators without the input of the participating teachers. Ultimately, issues surface which can affect teacher efficacy and can often times be attributed to the change or perhaps the resistance to change.

Chin and Benne (1985), in preparing The Planning of Change, wrote about general strategies that exist for effecting changes in people within organizations. They discuss how a change agent within an organization has three ways to go about implementing change. The first strategy they identify as "empirical-rational strategies." These are the strategies that one can employ that appeal to people because it is assumed they are rational. The change agent enters the organization and provides evidence of why the change should be implemented, and the organization chooses the rational choice.

The second group of strategies they identified as "normative re-educative." These are strategies that key into the fact that people are motivated by underlying beliefs and values. Therefore, real change must take place at this level. It requires more than just rationally providing evidence which explains why change is necessary. Normative reeducation involves an explanation of why you are doing what you are doing. This second set of strategies stems from the work of Lewin. "Lewin's contribution to normative reeducative strategies of changing stemmed from his vision of required interrelations between research, training and action (and, for him, this meant collaborative relationships, often now lacking, between researchers, educators, and activists) ..." (Chin \& Benne, 1985, p. 31). They make clear that man must participate in any change in order for re- 
education to occur, primarily because there is a cognitive aspect to the change that can only take place through participation. For normative re-educative strategies to be successful, the planned change agent must work collaboratively with the project.

Lastly, they identify "Power Coercive" strategies. Much as the name implies, these strategies implement change by virtue of authority. In other words, administrative policies go into effect and the change is ordered to take place, regardless of the feelings, ideas or positions of those involved. The change can be authorized from many perspectives ranging from moral power, coercive power, economic power or even political power. All studies implemented in existing school systems must ultimately address the issues of how to effect change. As a researcher, you are ultimately studying the change that takes place when a particular treatment is implemented. Ideally then, time should be allotted to discuss the best methods of implementing change so as to involve the teachers and consider teacher efficacy if what is wanted is for the innovation to be long-term and systemic.

Inevitably, there are always those who resist any type of change. The dynamics which exist as a result of resistance to change are very pertinent to any research study. Klein (1966) wrote of the defender role that evolves as a consequence of change.

It is probably inevitable that any major change will be a mixed blessing to those undergoing it in those instances when the status quo or situation of gradual change has been acceptable to many or most people... under such circumstances the major change must be desired by those affected if it is to be accepted. (Klein, 1966, p. 99)

Klein further discusses the fact that a defender always emerges when change is implemented. In some cases the defender chooses to work with the change agent and 
collaboratively they come upon a solution which will ultimately allow the desired change to result. However, in other cases the defender finds him or herself struggling to justify retaining the status quo. In the case of our school systems and the researchers who wish to test theories in an effort to make schools better and help students learn, it is a difficult balance. Often, school administrators find themselves in the role of both defender and change agent.

It is important that they learn how to differentiate between change which may pose real threat and change which is resisted simply because it is new and feels alien. Perhaps most important of all, they have the opportunity of educating the change agents with whom they work, either those inside their systems or those who come from the outside, to the point where change agents perceive, understand, and value the basic functions and purposes of the schools. (Klein, 1966, p. 104)

In preparation for the current research, much time was taken by the researchers to discuss with the teachers and school administrator how the different components would effect change within the instructional school day. Ultimately, the changes that were proposed came from the perspective of both the learner (via the researcher) and the teacher. As a result of an interest in this area, it was clear that teacher interviews would be necessary to explore and understand teacher perspectives and effects on teacher efficacy as a result of the proposed planned change.

\section{Summary}

Self-regulated learning is a complex construct that has emerged from the literature in a variety of areas. A true understanding of this concept can only be established if the literature pertaining to feedback, strategy use, motivation and metacognition are explored. 
For, it is with a merging of the literature from these areas that one begins to develop a working knowledge of why self-regulated learning is so important to research.

Students are described as self-regulated "to the degree that they are metacognitively, motivationally, and behaviorally active participants in their own learning process" (Zimmerman, 1989a, p. 89). It is the historical framework upon which selfregulated learning emerges that we are given the focus as to why this issue is so unique, in that it exists in what usually are considered unique and specific areas of research. More importantly to this study, is established the literature that provides for educators the rationale for incorporating the teaching o self-regulatory skills (Corno, 1987; Paris \& Newman, 1990; Rosenshine, 1987; Schunk, 1998).

The literature pertaining to feedback is of particular interest to the current study in that the journal writing assignment was incorporated specifically to address the issue of students being able to keep track of how well they were doing on an on-going basis, the Schunk (1982) study established that young students can increase their mathematical scores when given the appropriate feedback, furthermore, Butler and Winne (1995) confirmed that learners are more effective with feedback and the research of Rendulic and Terrell (1997a) provided the impetus to conduct the current research specifically with the addition of a reflective writing journal component.

The use of learning strategies to increase self-regulation was also explored. the research conducted by Zimmerman and Martinez-Pons (1986) established the existence of self-regulated learning strategies and created categories upon which to categorize them. The development of this instrument did much to further the research with respect to 
learning strategy-use and self-regulation. Of course, of further consequence is the extensive literature in the areas of motivation and metacognition. Carr (1996, p. 4) clarifies that children cannot self-regulate if they are not motivated to learn. Although the work of Bandura (1997) and Vygotsky (1978) support the social learning aspect which is an inevitable component of motivation, it is the work of Pintrich and DeGroot (1990) which distinguishes that the important difference must be in fostering intrinsic motivation. The literature on metacognition (Brown, 1987; Flavell, Friedrichs \& Hoyt, 1970) and competence (Sternberg \& Kolligian, 1990) were also presented in order to enhance the discussion regarding the need for a journal, in that a structured journal by nature of the questioning involved supports a student's use of thinking and supports their need to evaluate.

Lastly, a discussion of the change literature is introduced (Chin \& Benne, 1985; Driscoll, 1994; Gibson \& Dembo, 1985) in order to support the role of the teacher in the learning process. Teachers are a very important component in any classroom, and this literature establishes the need to engage in inquiry regarding their role, hence the need for interviewing them and providing a qualitative connection to the data collected. 


\section{CHAPTER III}

\section{METHODS}

The review of the literature indicated that psychologists and educators have expressed an interest in understanding the relationship that exists between self-regulation and academic success. Although the literature established that there has been much written with respect to metacognition, motivation and strategy use, the literature also makes clear that the relationship between and among these areas of research are hard to distinguish. The intent of this research study is to focus on the use of a reflective writing journal in an elementary school classroom in order to increase the levels of strategies used and ultimately improve self-regulation and academic achievement. This chapter provides a description of the participants, setting, teacher training, research design, instruments, and methods used to collect and analyze the data.

\section{Setting}

The current research study took place at a public elementary school in Broward County, Florida. The school serves students of a predominantly lower socioeconomic background. County demographic records report that Broward County Public Schools is one of the fastest growing districts in the nation, with a unique urban/suburban mix of students. During the 1999-2000 school year the district served almost 240,000 students in a system that averages 6,000 to 8,000 new students a year and is the nation's largest, fully-accredited school district (BCPS Web site, 2000). Broward County is located in South Florida, and they have large groups of new students joining their schools each year due to rapid growth (new construction) in the area. 


\section{Subjects}

The subjects chosen to participate in the study were 48 fourth grade students (ranging in age from nine years to ten years). The sample included all of the fourth grade regular education classes from this Broward County public elementary school. The special education students (gifted or learning disabled) did not participate in the study, given that the portion of the school day used for mathematics instruction was a time in which these special populations were not included. From a total of 160 possible fourth grade subjects, 107 of the students participated in the main study (Rendulic \& Terrell, 1999). With the current study focusing solely on the effect of the reflective writing journal, only those classes that were randomly assigned to receive that component are being described. The initial intention was to have all of the fourth grade students participate in the study, but to identify the special education students and the gifted students in order to have the option of treating them in the analysis separately. Once the study was underway, it was noted that the special education students were being removed from the classrooms in order to be taught as a group for mathematics (the same was happening with the gifted group). As the researchers began implementing the graphing component, it became evident that it would take several more weeks before the students would be prepared to participate in the project (the addition, division, graphing skills were above their developmental level). The group as a whole struggled with the most basic skills and there were behavioral issues that impeded their participation. At the other extreme were the gifted students who were already quite capable of self-regulation (as established by the literature: Zimmerman, 1990). Since we were aware of the literature confirming that high achieving students 
already self-regulate their learning more effectively than lower achieving children, it was decided that an intervention with this sub-section would not be as beneficial to them as a group. With both the special education and the gifted children removed from the classes, this aided in controlling for extraneous variables, particularly since these were intact groups.

Therefore, of the 107 students participating in the Rendulic and Terrell (1999) study, there were 48 fourth grade students that participated in the reflective writing journal/graphing component, which is the focus of this particular study. The gender of the participating students was almost equal, with $49 \%$ of the students being male and $51 \%$ of the students female. The larger study reported ethnographic data of $35 \%$ White nonHispanics, 44\% African American/Black, 15\% Hispanic and 6\% other. The ethnographic data for this study is highly representative of the county-wide distribution which reports: 42.4\% White, 35.9\% Black, $17.5 \%$ Hispanic, $2.7 \%$ Asian and $1.5 \%$ other (BCPS Web Site, 2000).

The students were randomly assigned to one of three treatment groups in the larger study: graph only, journal only, graph and journal. This particular study focused on the analysis of the two classes that had the reflective writing journal/graph component randomly assigned to them. Two classrooms were assigned the reflective writing journal and graphing component. Each of the two graph and journal groups were comprised of the same number of subjects $(n=24)$, for a total of 48 students participating in the combined treatment groups. Statistically, the students were almost equally distributed across the participating groups, in that the class sizes and the ethnographic data are quite 
similar. The unique opportunity of having two 'combined groups' permitted the researcher to further analyze the influence of teacher effect on the study.

\section{Teacher Training}

The four teachers involved in the main study (Rendulic \& Terrell, 1999) met with the researchers approximately one month prior to implementing the treatment conditions. The researchers explained to the teachers the overall concept of the study and the way in which they wished for the study to be implemented. The actual presentation of the graphing and journal assignments to the students were made by the researchers. They met with the students on a weekly basis at the beginning of the study (for the first nine weeks), in order to ensure that all of the classes had the material presented in the same manner. It was at this stage (with the recommendation of the teachers) that it became evident that including the special populations at the school would not be feasible. Teachers were free to ask questions of the researchers. In fact, prior to implementing the second semester of journal assignments with the students, the teacher recommendations were taken into account in order to adjust the journal writing papers to better meet their class needs. A follow-up interview was conducted with all three of the classroom teachers who implemented the journal component, in order to assess their overall opinions of having participated in the study. The teacher who implemented only the journal was included for the interview component. It was important to get as many perspectives on the journal as possible. Furthermore, it was surmised that an opportunity to speak with the teachers after they had time to reflect on their participation, would yield some interesting insights 
into the study concerning their perspectives on change, motivation, and the effect of the journal implementation on the dynamics of their classes.

\section{Treatment Conditions (Basic Design)}

This research focused on two classes that implemented one treatment condition: students participating in the reflective writing journal and graphing group. The treatments (use of the journal) were implemented once weekly for two separate grading periods (two nine-week grading periods, for a total of 18 weeks). The students were taught by the researchers (Rendulic \& Terrell) to keep track of their grades in mathematics. Then, on a weekly basis the students were to write about their grades and complete a journal entry discussing their math grades (Appendix A).

The study was designed to retrospectively analyze the treatment variable of "journal use" in order to determine if students using reflective writing journals in combination with graphs had changes in their metacognitive skills or their class grades. Both groups of students maintained a reflective writing journal to keep track of their math grades, reflect on their math grades, write about strategies they used that helped them learn, strategies they used that did not help them to learn, plan math objectives for the week to come, and write about their strategies for the upcoming week in mathematics. In addition, they also kept a mathematics graph where they plotted their math test, homework and classwork scores.

In late October, the teachers began meeting with the researchers with regards to implementation of the study and to discuss the logistics and expectations involved. It was decided at the conclusion of these meetings that the students enrolled in special education 
classes would not be involved in the study in order to use the intact class groups that could be matched and representative of fourth grade populations as a whole. A total of four classrooms participated in the study. The first group $(n=26)$ used only a line graph to keep track of their math grade averages; the second group $(n=27)$ used only a reflective writing journal to keep track of their progress in math; the third $(n=24)$ and fourth $(n=24)$ groups used a combination of the reflective writing journal and the line graph. The teachers and intact classrooms were randomly selected to participate in the treatment conditions. The current study focused exclusively on the analysis of those two classrooms (of equal size, $n=24$ ) that were required to keep both a reflective writing journal and a graph.

For each of these classrooms, the researchers prepared the reflective writing journal pages and provided the students with duo-tang folders to store their work stored. The folders were all the same color (blue) and they all had labels attached to the front of the folder with a picture of the school mascot, stating the school name, and stating "This portfolio is the property of..." with the student name added. The label also identified the teacher. These folders were all prepared in advance of the first researcher visit in order to facilitate the explanation of the assignment to the students. Additionally, ensuring that the students all had the same color folders and the same labels attached to the front of the folder eliminated the possibility of bias on the part of the students, teachers or researchers. The students attached a value to their writing journals, and the researcher ensured that the groups were equal with respect to the materials provided. 
The actual treatments (reflective writing journal and graph) were implemented by the researchers for the first nine weeks of the study. This was done to ensure that the correct implementation of the different treatment conditions were taking place and that the teachers had an opportunity to observe and assist in the process. The conditions were implemented only by the teachers for the second nine-week grading period, with the researchers occasionally stopping by to check on the progress of the study.

For the very first treatment of the reflective writing journal, the students were asked only to plan what they intended to learn in math for the upcoming week, and to plan what strategies they wished to implement in order to help them learn math. The first session involved presenting the writing journals and allowing the students time to ask questions about what was required of them. A discussion ensued in each classroom about the importance of thinking about their learning and this discussion was guided by the researcher. The classroom teachers were given the opportunity to discuss upcoming math plans with their students and then the students were asked to write in their own words what they would be learning in math in the upcoming week based on the plans written on the board by their teacher. Secondly, the researcher guided students to brainstorm about different things they could do to prepare themselves to better learn their math objectives. These strategies were then discussed and the students were free to write in their journals about what they individually planned on doing to help themselves in the learning process.

Instruments

Baseline data was gathered. All of the students were administered a pretest to measure their metacognitive skills. These results, as well as individual student grades from 
report cards, student Standard Achievement Test scores, and scores on motivation instrument, were made available to the researcher from prior research results (Rendulic \& Terrell, 1999). Aside from access to this information for analysis purposes, the current study collected the individual reflective writing journals from each participating student (18 weeks worth of journal assignments), and the teacher interviews as further sources of evidence and authority.

The weekly journal assignments (Appendix A) required the students to respond to a series of five questions or statements. The first was a reflection of how well they feel they did in preparing for the math grade they earned the previous week. They were presented with three possible choices:

I think I learned math better than I had planned,

I think I learned math as well as I had planned, or

I did not learn math as well as I had planned

This enabled the students to really think about their math performance and the effort they put into their work. The second and third questions in the journal assignment focused exclusively on the strategies the students felt they employed the previous week. The second question asked them to recall what they did that helped them to learn. The third question asked them to recall all of the things that might have prevented them from learning. The fourth question asked the students to write what they planned on learning in the upcoming week. That question was added to the journal in order to get teachers to think about what their plans were; and, most importantly, to communicate those plans to their students. Ideally, all students in the classroom should have similar statements 
written for question four if the teachers were consistent about expressing the coming week's plan to their students. Last, question five asked the students to think about how they learned best and to reflect upon what they planned to do in the upcoming week in order to learn math. The whole purpose of developing this reflective writing instrument was to get students to recognize how their actions have an effect on the learning process and, if they think about it, how that might ultimately have a positive influence on the way in which they learn and on their success. The data was collected on a weekly basis, with the first nine weeks being monitored by the researchers in order to ensure that the groups were having equal access to the journals and that the teachers were presenting the assignment in a consistent manner. The second nine weeks, the teachers implemented their treatments individually. At the conclusion of the study the researcher collected 75 duo-tang folders, each containing 18 weeks worth of reflective writing journal pages.

The data attained from the teacher interviews were all based on a series of twenty questions (Appendix B) that were prepared by the researcher to guide the interview process and ultimately allow for the teachers to reflect on some select issues which are of importance to the outcome of this study and the development of future studies. The questions were designed to begin with the basic concepts of participation and extended to focus primarily on the aspects involved in implementation of the project. The literature on planned change and resistance to change (Benne, Bennis \& Chin, 1985) makes clear the difficulty that individuals have when implementing new procedures or programs. The interview questions were designed with this body of literature in mind, and allowed the teachers the opportunity to express their opinions with regard to how difficult or easy they 
felt it was to participate in the study. The data collected from the interview component of this study served to enlighten the researcher with respect to difficulties and benefits which may have emerged as a result of participating. It is this in-depth look at the participants of a study that truly help to shed light on what took place during implementation. The interviews were conducted at the convenience of the teachers involved in order to facilitate their participation in the project.

All of the interviews were conducted by phone, so that the format and procedure could remain the same for all three teachers. At the completion of the study, one of the teachers moved to another state; a second teacher moved to a middle school setting within the same school district; the third teacher remained at the same school and grade level. The researcher employed the use of a speaker phone and a dictaphone to facilitate the conversation and eliminate the need to take extensive notes. Each teacher received a copy of the interview questions prior to the interview. In response to a request by the teacher that currently lives in another state, the researcher agreed to provide her with the questions in advance so that she could reflect upon them before our conversation. The same procedure and use of instruments was followed for each of the interview sessions.

\section{Procedure}

The metacognition instrument and motivation instrument were administered to the students as part of a pretest at the start of the larger study conducted by Rendulic and Terrell (1999). These instruments were administered one week prior to the beginning of this research project. The current research project began at the start of the second school semester (second nine-week grading period). It encompassed the second and third 
grading periods of the fourth grade year. This time frame allowed the researchers time to prepare and implement the study and the teachers and students time to get to know one another. Furthermore, at the conclusion of the study it was helpful to the researcher to know that the students and teachers would remain together for the final nine weeks in school. This time period permitted the researcher to prepare for follow-up interviews and to gather all of the remaining data from the school (such as SAT scores and final course grades).

Week two of the study involved the first use of the entire reflective writing journal page that the students would be using for the remainder of the study. The journal pages all began with the same narrative:

Look back at what you wrote last week about learning math. Think about what you actually did last week to help yourself learn math and think about how well you did in math. Do you think you did well or do you think you could have done better? Ask yourself each of the following questions and write out your answers in the space provided. Remember, there are no right or wrong answers. (Appendix A)

The researcher read the narrative along with the students, and then allowed them time to discuss what they felt that the assignment involved. The first question, as explained earlier, asked the students to check only one of the statements regarding their impression of how they did in math the previous week. Was the grade they earned in math last week reflective of what they had planned, not reflective of what they had planned, or better? This statement was read to the students by the researcher and the students had the opportunity to answer by placing a check in their journal.

Secondly, the researcher had students read aloud the second statement: "When I think about how well I did in math last week, these are the things I did that helped me to 
learn:" (Appendix A). The researcher had students brainstorm ideas about learning strategies employed that actually helped them do well in math. The students were then free to write about their personal experiences. Thirdly, the researcher had another student read aloud the third statement to be addressed: "When I think about how well I did in math last week, these are the things I did that did not help me to learn:" (Appendix A). Once again, students commented about situations or strategies that prevented them from learning mathematics in an effective way. After discussion, students individually addressed the third statement in their personal writing journals. The fourth statement involved the participation of the teacher. The researcher guided the teacher in presenting the plan for mathematics in the upcoming week. Objectives were discussed with the students, and the students were made aware of learning expectations. In most cases, teachers were encouraged to write learning objectives on the board for the students to have a clear notion of expectations for the future. Students were then encouraged to take these plans and write them in their journals.

Lastly, the researcher guided students to answer the last statement on the page which stated: "When thinking about how I learn best, I plan to do the following things this week when I am learning math" (Appendix A). This final statement allows for students to reflect on what works individually for them and encourages them to plan on re-using the successful strategy to continue learning mathematics. The process of implementing the journal required more time at the outset of the project, however at the end of the first nine week grading period the researcher was spending an average of about 15 to 20 minutes in each classroom to guide the journal activity. The researcher came at 
an established time each week, and the students were prepared to participate in the activity. Students were told at the outset of the study that they could have access to their journals at any time. If they wished to write about a particular strategy or experience, they were encouraged to do so and were not required to wait until the assigned time.

Additionally, all journals had pages attached with the title "Notes and Whatever", where they were encouraged to write things down that they may later wish to reflect upon. This section of the journal was added for the students to draw or write whatever they wished; it was a free space not guided for them by statements or questions.

The groups which had the reflective writing journal component and the graphing treatment required a bit more time for initial training in that they also had to learn how to complete a Computational Math Grade Worksheet and a Weekly Graph of Math Achievement. This sample of fourth grade students required a review on how to average grades (the process of adding individual scores and determining the total number of scores to divide by). Furthermore, they required a lesson on how to calculate cumulative averages. The teachers and the researchers were both involved in teaching these lessons and then subsequently teaching the students how to graph these results. Consequently, the two combined treatment groups required a bit more attention from the researcher at the outset, and the groups (of each $n=24$ ) required more time for the students to complete both the journal and the graphing tasks. Both combined groups kept their journals and their graphing assignments within the same folder. This served two purposes, it was convenient for the teachers and students, and it made access to the graphing component 
easier for the students who were to then write about the experiences and results in their journals.

At the conclusion of the first nine-week grading period, the researchers no longer participated in the weekly journal or journal and graphing assignments. The teachers took over the role of guiding the students through the process. By the tenth week the students were very familiar with the format and the expectations. The last nine weeks of the study were conducted at the site without the direct supervision of the researcher. Nevertheless, there were occasions in which the researcher did enter the classrooms to evaluate progress and to insure the teachers that if they were in need of follow-up that it could be provided. After eighteen weeks of implementing the reflective writing journal in each of the treatment classrooms, the journals were collected and the researcher completed the component of the study requiring data collection from the students.

\section{Data Analysis}

Upon completion of the data collection, the analysis of the journal entries required qualitative techniques for organization; these included analyses such as listing key words, counting repeated phrases, and establishing a reference list of strategies employed by many students (Bliss, 1983). The researcher was particularly interested in determining which learning strategies the students felt helped them to learn (question 2) and which learning strategies the students felt did not help them to learn (question 3). Having determined from the review of the literature that the Self-Regulated Learning Interview Schedule (SRLIS) established by Zimmerman and Martinez-Pons (1986) was a valid and reliable instrument for describing students' use of strategies in naturalistic settings, the researcher 
had a statistically valid instrument from which to guide analysis of the reflective writing journals. Given that the SRLIS was established for use with much older students, the researcher kept in mind the appropriateness of applying an instrument exclusively developed for analysis of older subjects.

Therefore, the purpose of applying the work of Zimmerman and Martinez-Pons (1986) was to ground the researcher in a theoretical framework from which to draw categories of strategies that may be evident in the work of much younger children. This research did not involve the exclusive application of the SRLIS, but rather built upon the work of Zimmerman and Martinez-Pons (1986) in order to compare and contrast categories of strategies recognized by both their study and the present research. The SRLIS identified 15 categories of learning strategies (as discussed earlier in the section labeled "Strategy Use" of the review of the literature). For purposes of analysis of the current reflective writing journals, a checklist was created using many of the strategies identified by Zimmerman and Martinez-Pons (1986) including many strategies which were identified by the current researcher as themes or trends established by the subjects in this study. The researcher read each individual journal and established from the answers provided to questions one through five the most appropriate way of categorizing the answer given by each student. The analysis of each writing journal was done exclusively by the researcher, therefore eliminating the need to train readers or to engage in any form of inter-rater reliability analysis.

Once the coding for each reflective writing journal was completed, the researcher proceeded to enter the information into SPSS by establishing variables for the most 
commonly used strategies in the content analysis and entering either a ' 1 ' if the strategy was employed or a ' 0 ' if the strategy was not employed by the learner. This coding permitted the researcher to statistically determine from frequency count distributions and chi-square analyses, which strategies were most employed by students participating in the study. The chi-square analysis was determined to be the most appropriate statistical technique to be employed due to the nature of the data. Given that the data collected was in the form of a journal, the researcher worked with the nominal data to confirm the characteristics of the data set, in order to be able to establish with a high degree of confidence that the data characteristics did not arise by chance but rather from having engaged in the particular journal/graphing treatment.

Using the established SPSS data sets, the researcher was able to engage in procedures to describe the qualitative data: such as frequencies, crosstabs and chi-square analyses. The researcher produced all frequency distributions for strategy-use upon determining which strategies showed high levels of distribution. The researcher was then able to use the crosstabs function to generate contingency tables for a clearer and more indepth look at the employment of the strategy and the class (or teacher) and semester in which it was most employed. Furthermore, if the crosstabs analysis revealed a pattern of interest for the researcher then an additional test was performed after taking into consideration the question asked, the level of measurement of the data and the plan or design of the research (Kinnear \& Gray, 1996, p. 73). This in-depth analysis was conducted largely by using the chi-square function, given that this statistic "is used for determining the presence of an association between two qualitative variables. The 
rejection of the null hypothesis by means of chi-square, however, only establishes the existence of a statistical association: it does not measure its strength" (Kinnear \& Gray, p. 162). With this in mind the researcher was able to establish $2 \times 2$ contingency tables and establish association by using the chi-square statistic and the phi coefficient (because of the nature of the data coding establishing only two categories--0 for non-use of strategy and 1 for use of strategy).

Frequency counts were established for all categories in each of the five questions coded for the journals. Most importantly, this content analysis of the reflective writing journals resulted in frequency distributions which enabled the researcher to establish a criteria and classify the students as "low self-regulated learners" or "high self-regulated learners" while also establishing the possibility of relationships. The classification criteria were established using a method similar to the one employed by researchers conducting an item-analysis.

When determining how well students perform, it is important to look at the distribution of scores that result. This distribution points out the low versus the high end of scores that were obtained. Similarly, when analyzing the distribution of self-regulated learning strategies employed by fourth grade students in a reflective writing journal across an eighteen week period there appears to be a similar pattern established. In other words, some students employ the use of many self-regulated learning strategies whereas others write about very few. Given this information and the results of the SRLIS analysis of validity and reliability (Zimmerman \& Martinez-Pons, 1989) to support the choice of strategies being measured, the researcher proceeded to divide the students into three 
separate groups. The top group (high self-regulated learners) employed between 34 and 117 strategies across the 18 weeks with the median being 48 strategies for this group. Conversely, the bottom group (low self-regulated learners) employed between 0 and 15 strategies across the 18 weeks of the study with a median of 8 strategies being used. This method allowed the researcher to determine that for both groups there were 52 opportunities to list strategies in the writing journal and in the top group these students actually had a $92 \%$ response rate, whereas the bottom group responded only $15 \%$ of the time.

The criteria for establishing "low" versus "high" self-regulated strategy users was kept to these specifications only, in that the researcher had to stick to the journal component of the study for establishing categories. On the basis of this classification system, the researcher was then able to run statistical analyses using the low or high selfregulated learner rating and the student's scores on the different standardized instruments made available as a result of the larger study (Rendulic \& Terrell, 1999). Furthermore, the researcher collected data from the separate teacher interviews which then served to help support results and explain ideas and issues which may not be clear from just the data analysis alone. Ideally, the teacher interviews were conducted to reveal aspects of the study that the researcher had no way of knowing. It provided teacher perspectives that otherwise may have gone undocumented, but that taken as a group bring life to aspects of the study that the researcher may have been unaware of. Furthermore, the teacher interviews also provided a background for the researcher to clarify why certain classrooms may have performed better as a whole and the issues of resistance to change are made 
clear and although suspected by the researcher, could only be reaffirmed by the interview. Although conducted by the researcher and fully transcribed for analysis, the main function of the interviews was to bring to life the role of the teacher. The transcribed interviews served as an instrument from which the researcher pulled together underlying themes and consistent responses. 


\section{CHAPTER IV}

\section{RESULTS}

The process of data analysis took place in two phases: the first was an exploration and description of the data; the second was the confirmation of data characteristics. Given that the data collected was of a qualitative nature (writing journals) the researcher was primarily engaged in an analysis of nominal data with the primary purpose of exploring the data set thoroughly enough to find therein characteristics of significance. Each of the five questions within the journal were analyzed from a whole group perspective (both classes) in order to discuss trends emerging from implementation of the journal/graph treatment. Furthermore, an additional analysis took place by separating the two treatment groups in order to compare classroom effects and to uncover effects which emerged across time.

Second, in order to answer many of the research questions and subsidiary questions posed by the researcher, it was necessary to recode the data in order to establish a variable that could measure the relative frequency of strategy use employed in the reflective journal writing activity across two semesters. The results of merging the frequency counts of reported strategy use for questions two, three and five of the journal entries were used to ultimately categorize the top third of students as good self-regulated learners. The literature justifies establishing these categories for purposes of comparison and analysis. Therefore, upon establishing the top third of students (with respect to strategy use), the researcher was able to employ statistical techniques that could address the many questions regarding good self-regulated learners. Lastly, the teacher interviews are presented in order to provide a more complete picture of what took place during this 
study as a result of having implemented a reflective writing journal with their students in their classrooms. As you recall, the interview component was created in order to acknowledge the fact that teachers do have a major role in any classroom and to study self-regulation and the possibility of teaching self-regulatory skills, it would be futile without the perspective of the teachers.

\section{Descriptive Analysis--Preliminary Journal Findings}

Each of the questions which comprised the reflective writing journal were analyzed separately in order to have a greater understanding of what the students themselves were thinking and reporting about their thoughts. It's important to restate that although the students received training as to how they could use the reflective writing journal and what they would be using it for, the journal writing time was typically a time in which the students worked alone to gather their thoughts and prepare responses in order to report their thoughts, ideas and actions with respect to their ability to self-regulate. An interesting trend emerged upon the preliminary analysis of question number 1 which focused on asking the students a question regarding their feelings about the math grade that they earned:

\section{Reflective Writing Journal Question 1}

When I think about the grade I earned in math last week (check only one of the following):

- I think I learned math better than I had planned

- I think I learned math as well as I had planned

- I did not learn math as well as I had planned 
Table 2

Frequency Distributions of Student Opinions Regarding Math Performance for Both

Semesters

\begin{tabular}{lcccc}
\hline Week Reported & $\begin{array}{c}\text { Better than } \\
\text { Planned }\end{array}$ & $\begin{array}{c}\text { As well as } \\
\text { Planned }\end{array}$ & $\begin{array}{c}\text { Not as well as } \\
\text { Planned }\end{array}$ & No Answer \\
\hline WEEK 2 & & Semester 1 & & \\
WEEK 3 & 23 & 19 & 5 & 20 \\
WEEK 4 & 20 & 14 & 7 & 26 \\
WEEK 5 & 21 & 15 & 11 & 20 \\
WEEK 6 & 16 & 13 & 14 & 24 \\
WEEK 7 & 20 & 9 & 4 & 34 \\
WEEK 8 & 18 & 7 & 4 & 38 \\
WEEK 9 & 11 & 7 & 8 & 41 \\
& 3 & 2 & 2 & 60 \\
WEEK 1 & & & & \\
WEEK 2 & 22 & 8 & 5 & 32 \\
WEEK 3 & 14 & 9 & 5 & 27 \\
WEEK 4 & 20 & 16 & 4 & 31 \\
WEEK 5 & 19 & 10 & 7 & 35 \\
WEEK 6 & 15 & 14 & 3 & 35 \\
WEEK 7 & 17 & 8 & 5 & 29 \\
WEEK 8 & 14 & 14 & 4 & 36 \\
WEEK 9 & 13 & 15 & 10 & 3 \\
\hline
\end{tabular}

The researcher recognized a pattern of responses as a result of tallying the answers provided by the students. The most popular answers were grouped together and added to the log. For virtually every week, the pattern of response reflected that the majority of students felt they performed "better than planned" as opposed to "as well as planned" or "not as well as planned". Yet, of even greater significance is the fact that in 16 of the 18 weeks during which the study took place there were even a greater number of students that provided "no answer" to the first question (Table 2). 


\section{Reflective Writing Journal Question 2}

The second question to which the students responded in their journaling experiences asked:

"When I think about how well I did in math last week, these are the things I did that helped me to learn:"

As opposed to the first question, for which the students had three responses from which to choose, the second question used an open-ended format for reflection from the student. This was the first question for which students could respond or report their use of strategies and further comment upon any ideas they may have had with respect to what made learning easier for them. A content analysis of the journals revealed that eight strategies were consistently employed across classes and semesters. The initial content analysis took place by identifying strategies that were noted on the SRLIS and further exploring if these were strategies that were employed quite often by this group of students. Then, further taking this data and determining if students may have another strategy for which the SRLIS did not account.

Table 3 presents the most common categories of responses emerging from the journals when the students were asked to reflect upon what helped them learn. Note that for twelve of the eighteen weeks, the strategy most frequently appearing in their journals was "studying". Furthermore, "homework" was the next strategy most commonly found as a response (Table 3). Also, note that strategies such as "trying hard" and "listening and following directions" were noted, however there were not as many students that felt this was a priority in what was helping them learn. 
Table 3

Qualitative Responses Reported to "What did help student learn?" Across Both Semesters

\begin{tabular}{|c|c|c|c|c|c|c|c|c|c|}
\hline \multirow{2}{*}{\multicolumn{2}{|c|}{ Responses to Question 2}} & Week & Week & Week & Week & Week & Week & Week & Week \\
\hline & & 2 & 3 & 4 & 5 & 6 & 7 & 8 & 9 \\
\hline \multirow{2}{*}{\multicolumn{10}{|c|}{ Semester 1}} \\
\hline & & 11 & 5 & 9 & 5 & 8 & 2 & 0 & 1 \\
\hline \multicolumn{2}{|l|}{ Trying hard helped me learn } & 4 & 5 & 2 & 1 & 0 & 1 & 2 & 1 \\
\hline \multicolumn{2}{|l|}{ Flash cards helped me learn } & 4 & 4 & 7 & 3 & 4 & 3 & 4 & 1 \\
\hline \multicolumn{2}{|l|}{ Studying helped me learn } & 23 & 23 & 16 & 18 & 12 & 9 & 6 & 4 \\
\hline \multicolumn{2}{|l|}{ Homework helped me learn } & 13 & 13 & 11 & 10 & 11 & 11 & 7 & 2 \\
\hline \multicolumn{2}{|l|}{ Classwork helped me learn } & 7 & 3 & 5 & 2 & 3 & 4 & 3 & 1 \\
\hline \multicolumn{2}{|l|}{ Listening/Following directions } & 1 & 1 & 8 & 0 & 2 & 1 & 2 & 0 \\
\hline \multicolumn{2}{|l|}{ Student did not answer } & 4 & 5 & 7 & 10 & 17 & 11 & 11 & 25 \\
\hline \multicolumn{10}{|c|}{ Semester 2} \\
\hline Parent helped me learn & 8 & 4 & 6 & 6 & 3 & 3 & 4 & 5 & 4 \\
\hline Trying hard helped me learn & 3 & 0 & 6 & 4 & 4 & 4 & 4 & 2 & 3 \\
\hline Flash cards helped me learn & 2 & 2 & 3 & 3 & 2 & 2 & 1 & 1 & 2 \\
\hline Studying helped me learn & 13 & 9 & 8 & 13 & 14 & 11 & 7 & 9 & 12 \\
\hline Homework helped me learn & 6 & 7 & 7 & 5 & 5 & 3 & 5 & 5 & 8 \\
\hline Classwork helped me learn & 3 & 2 & 6 & 7 & 4 & 4 & 4 & 5 & 5 \\
\hline $\begin{array}{l}\text { Listening/Following } \\
\text { directions }\end{array}$ & 4 & 5 & 9 & 6 & 4 & 4 & 6 & 4 & 5 \\
\hline Student did not answer & 7 & 5 & 4. & 8 & 8 & 9 & 9 & 10 & 7 \\
\hline
\end{tabular}

Note. Data not collected for week one of semester one.

\section{Reflective Writing Journal Question 3}

Conversely, the third question probed the students to respond to:

"When I think about how well I did in math last week, these are the things I did that did not help me to learn:"

The results of the descriptive analysis revealed that most of the students felt that "nothing prevented their learning." Therefore, it can be safe to deduce that a majority of the students reflected upon this question and felt that nothing was impeding their ability to learn. Interestingly enough, it is important to note however that the analysis did reveal that "playing too much" and "watching television" were the next two answers most commonly found reflected in their writing (Table 4). 
Distribution of Reported Journal Responses to "What did not help student learn?" Across Both Semesters

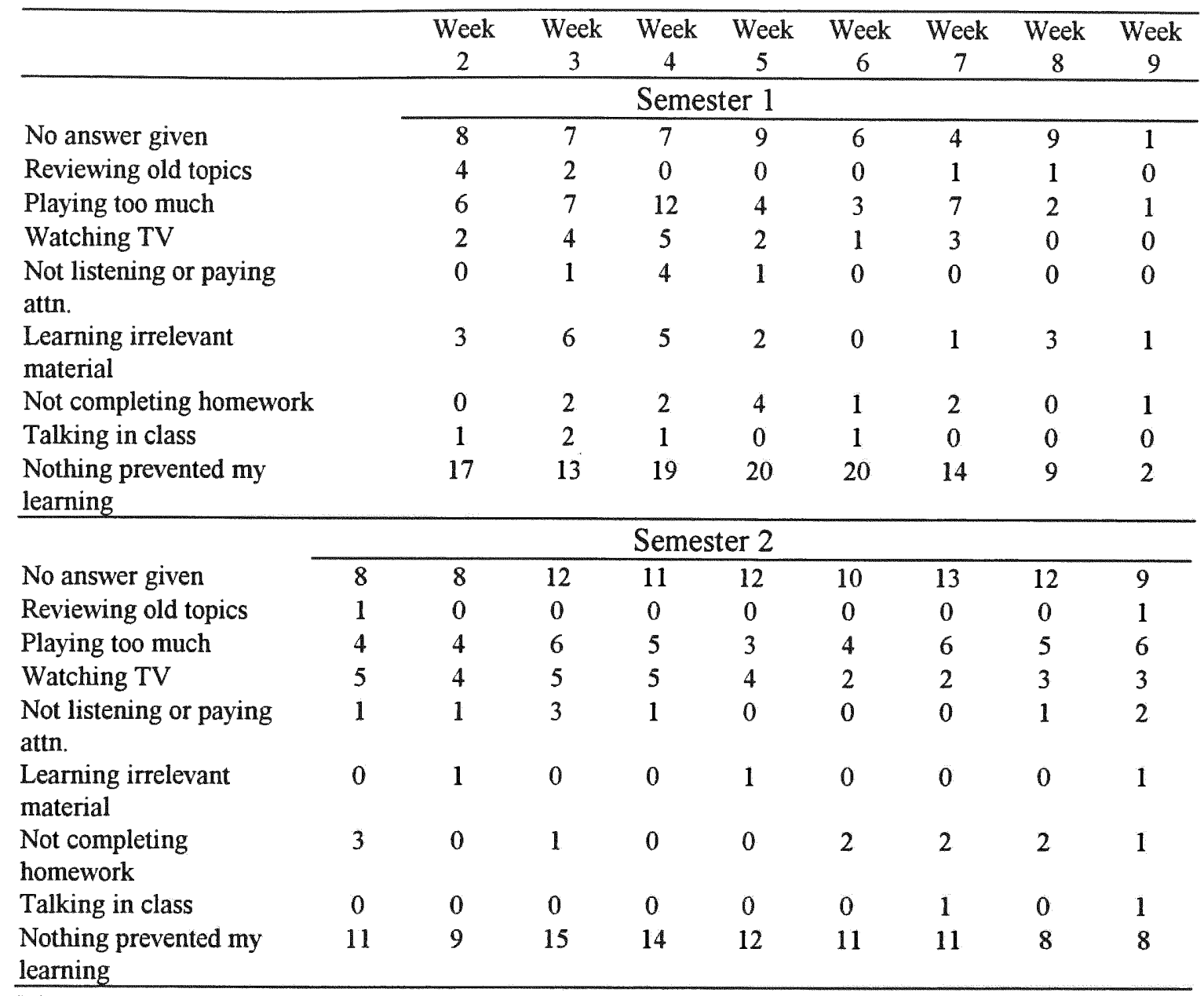

Note. Data not collected for week one of semester one.

Reflective Writing Journal Question 4

As the fourth question to guide their journal writing experiences the students were asked to write about their plans for the upcoming week. This component of the journal activity was guided by the teacher, in that one of the many roles of the teacher is to plan for upcoming educational experiences. It was intended that this question would require adult intervention for completion. The statement read: 
"I plan to learn the following in math this week:"

Table 5

Description of Reported Responses to "What are the goals/objectives this week?" Across

Both Semesters

\begin{tabular}{|c|c|c|c|c|c|c|c|c|c|}
\hline & $\begin{array}{c}\text { Week } \\
1\end{array}$ & $\begin{array}{c}\text { Week } \\
2 \\
\end{array}$ & $\begin{array}{c}\text { Week } \\
3 \\
\end{array}$ & $\begin{array}{c}\text { Week } \\
4 \\
\end{array}$ & $\begin{array}{c}\text { Week } \\
5\end{array}$ & $\begin{array}{c}\text { Week } \\
6 \\
\end{array}$ & $\begin{array}{c}\text { Week } \\
7\end{array}$ & $\begin{array}{c}\text { Week } \\
8\end{array}$ & $\begin{array}{c}\text { Week } \\
9\end{array}$ \\
\hline & \multicolumn{8}{|c|}{ Semester 1} & \\
\hline No answer given & 2 & 7 & 12 & 11 & 15 & 23 & 18 & 15 & 23 \\
\hline Plan includes review & 30 & 29 & 27 & 25 & 15 & 4 & 4 & 5 & 1 \\
\hline $\begin{array}{l}\text { Plan includes } \\
\text { memorizing }\end{array}$ & 0 & 0 & 0 & 0 & 0 & 0 & 0 & 0 & 0 \\
\hline $\begin{array}{l}\text { Plan includes } \\
\text { Multiplication }\end{array}$ & 24 & 34 & 23 & 23 & 26 & 19 & 14 & 8 & 5 \\
\hline Plan includes Division & 14 & 7 & 11 & 15 & 15 & 12 & 13 & 12 & 7 \\
\hline Plan includes Quiz prep & 11 & 0 & 1 & 0 & 0 & 1 & 0 & 0 & 0 \\
\hline \multirow[t]{2}{*}{ Geometry } & 0 & 0 & 0 & 0 & 0 & 0 & 0 & 0 & 0 \\
\hline & \multicolumn{8}{|c|}{ Semester 2} & \\
\hline No answer given & 5 & 6 & 7 & 9 & 12 & 9 & 12 & 7 & 7 \\
\hline Plan includes review & 4 & 2 & 2 & 1 & 2 & 1 & 1 & 2 & 3 \\
\hline $\begin{array}{l}\text { Plan includes } \\
\text { memorizing }\end{array}$ & 0 & 0 & 0 & 0 & 0 & 0 & 0 & 0 & 0 \\
\hline $\begin{array}{l}\text { Plan includes } \\
\text { Multiplication }\end{array}$ & 9 & 8 & 18 & 4 & 6 & 1 & 5 & 2 & 1 \\
\hline Plan includes Division & 6 & 9 & 4 & 11 & 13 & 9 & 8 & 4 & 2 \\
\hline Plan includes Quiz prep & 0 & 0 & 0 & 0 & 0 & 0 & 0 & 0 & 0 \\
\hline Geometry & 20 & 2 & 13 & 3 & 2 & 8 & 4 & 12 & 6 \\
\hline
\end{tabular}

The teachers were asked to provide students with a class plan for the upcoming week in mathematics. The journal format still remained open ended in that students could include personal plans as well, however this answer typically reflected a class objective for mathematics. The results of the descriptive analysis clearly show that a majority of the students responded on a weekly basis with a teacher directed goal. Table 5 reflects findings in which the first four weeks of the first semester are spent largely on plans which include a review of material and multiplication skills. Furthermore, the table reflects 
trends of study in that "geometry" does not appear as a planned objective until the second semester, when both classes clearly appeared to begin their semester with a study of this area. An analysis of the patterns of responses to this question serve to check that most students were prepared to answer in their journals what their plans were, because it was presented in class by the researcher or teacher.

\section{Reflective Writing Journal Question 5}

The fifth and final question to which the students were asked to respond within the reflective writing journal dealt primarily with their repair strategy. The question probed the students to reflect by asking:

"When thinking about how I learn best, I plan to do the following things this week when I am learning math:"

Of the five questions which guided the reflective journal writing activity, this was the question which elicited the most diverse responses. This question allowed for each student to individually reflect upon the previous answers and then decide what their plan for learning would be based on that information. Consequently, an interesting trend in the responses made by the children revealed itself. In the first week of the first semester of the study, the students overwhelmingly wrote that they planned to study and they planned to solicit help from their parents. Asking for help from their parents then drops dramatically, and for the next seventeen weeks very few students wrote this as a potential strategy for learning math. The trend shifted to include a good majority of students reflecting upon the fact that completing homework and classwork and listening in class would benefit their ability to better learn mathematical objectives (Table 6). 
Table 6

Distribution of Responses in Journal to New Plan Across Both Semesters

\begin{tabular}{|c|c|c|c|c|c|c|c|c|c|}
\hline \multirow[b]{2}{*}{ Repair Strategy } & \multicolumn{7}{|c|}{ Week } & \multirow[b]{2}{*}{8} & \multirow[b]{2}{*}{9} \\
\hline & 1 & 2 & 3 & 4 & 5 & 6 & 7 & & \\
\hline \multicolumn{10}{|c|}{ Semester 1} \\
\hline No strategy plan given & 4 & 7 & 13 & 10 & 10 & 13 & 9 & 6 & 2 \\
\hline Will ask for parental help & 23 & 9 & 5 & 5 & 3 & 2 & 3 & 0 & 0 \\
\hline Will quiz him/herself & 18 & 6 & 3 & 0 & 3 & 3 & 1 & 3 & 0 \\
\hline Will review old material & 14 & 12 & 4 & 5 & 1 & 1 & 4 & 5 & 0 \\
\hline Will use flash cards & 8 & 4 & 2 & 0 & 1 & 4 & 1 & 2 & 0 \\
\hline Will complete homework & 5 & 8 & 7 & 12 & 6 & 9 & 7 & 5 & 2 \\
\hline Will listen in class & 6 & 10 & 6 & 5 & 6 & 5 & 5 & 4 & 1 \\
\hline Will complete classwork & 3 & 5 & 4 & 2 & 7 & 6 & 5 & 6 & 2 \\
\hline Will study & 28 & 16 & 8 & 12 & 13 & 6 & 4 & 3 & 1 \\
\hline Will teach my pet strategies & 5 & 2 & 5 & 2 & 1 & 2 & 0 & 0 & 0 \\
\hline Will pay attn. in class & 7 & 4 & 4 & 4 & 1 & 2 & 2 & 1 & 0 \\
\hline Will work in quiet place & 4 & 2 & 0 & 1 & 2 & 1 & 0 & 0 & 0 \\
\hline \multicolumn{10}{|c|}{ Semester 2} \\
\hline No strategy plan given & 11 & 8 & 12 & 9 & 10 & 13 & 10 & 10 & 3 \\
\hline Will ask for parental help & 1 & 2 & 3 & 6 & 4 & 3 & 2 & 2 & 3 \\
\hline Will quiz him/herself & 2 & 0 & 2 & 3 & 1 & 1 & 2 & 3 & 2 \\
\hline Will review old material & 3 & 0 & 0 & 1 & 1 & 0 & 0 & 1 & 1 \\
\hline Will use flash cards & 3 & 1 & 2 & 1 & 0 & 2 & 1 & 2 & 0 \\
\hline Will complete homework & 7 & 3 & 6 & 8 & 4 & 4 & 5 & 5 & 5 \\
\hline Will listen in class & 5 & 6 & 5 & 6 & 8 & 4 & 4 & 5 & 4 \\
\hline Will complete classwork & 3 & 4 & 6 & 5 & 4 & 3 & 5 & 3 & 5 \\
\hline Will study & 6 & 4 & 7 & 8 & 7 & 5 & 6 & 8 & 11 \\
\hline Will teach pet strategies & 1 & 0 & 0 & 1 & 0 & 0 & 0 & 0 & 0 \\
\hline Will pay attn. in class & 2 & 1 & 2 & 1 & 2 & 0 & 1 & 1 & 2 \\
\hline Will work in quiet place & 0 & 0 & 1 & 1 & 1 & 1 & 1 & 0 & 1 \\
\hline
\end{tabular}

Secondary Analysis

Upon summarizing the descriptive nature of the data that was collected, it became

clear that the journal entries were revealing particular patterns for each of the questions and a more in-depth review of the data would be necessary to uncover the trends which were emerging across semesters and between classrooms. The focus would be to determine if there was a difference between the two classroom environments. 
The preliminary analysis of the second question revealed to the researcher that students found "studying" and completing their "homework" to be the two most frequent strategies employed by this sample of students when reflecting upon what helped them to learn mathematics. These findings led the researcher to question if in fact both classes if analyzed separately would reveal the same patterns of strategy use. A cross tabulation helped the researcher confirm that in fact "studying" was a strategy employed frequently by both samples of students and that both groups consistently applied this strategy across time (both semesters). Table 7 summarizes these findings.

Table 7

Use of "Studying" Strategy Across Both Semesters

\section{Week}

\begin{tabular}{ccccccccc} 
Teacher & 2 & 3 & 4 & 5 & 6 & 7 & 8 & 9 \\
\hline 1--Mrs.O & 17 & 17 & 14 & 15 & 13 & 11 & 8 & 8 \\
2--Mrs.Q & 19 & 15 & 10 & 16 & 13 & 9 & 5 & 5 \\
\hline
\end{tabular}

The results indicate that across both semesters there appears to be no difference between students from teacher 1 or teacher 2 with respect to the amount (or frequency) of students answering that "studying" is what helped them to learn.

The findings for the "homework" strategy however are quite different. A crosstabulation of the data discloses that the use of the homework strategy as a tool for helping students to learn is dependent on the teacher variable for this sample. In other words, 
week after week, the students who worked with teacher $\mathrm{O}$ consistently stated that homework was an important part of their plan for learning mathematics. The teachers were trained to engage in dialogue regarding strategy use with the children, however this was not a main thrust of the program. Table 8 summarizes the findings of the cross tabulation and the Chi-Square analysis which assert that there is a significant difference between the two classes with respect to how often they assert that homework is a learning strategy which they employ.

Table 8

Analysis of Reported Use of "Homework" as a Strategy

\begin{tabular}{cccccccccc}
\hline & \multicolumn{1}{c}{ Week } \\
\cline { 2 - 9 } Teacher & 2 & 3 & 4 & 5 & 6 & 7 & 8 & 9 \\
\hline $1--M r s . O$ & 17 & 17 & 15 & 11 & 10 & 10 & 9 & 5 \\
$2--M r s . Q$ & 2 & 3 & 3 & 4 & 6 & 4 & 3 & 2 \\
\hline & & & & & & & & \\
$\chi^{2}(1, \underline{N}=48)$ & $-.36^{* *}$ & $-.33^{* *}$ & $-.30^{* *}$ & $-.20^{*}$ & -.12 & $-.18^{*}$ & $-.18^{*}$ & -.12 \\
${ }^{*} \mathrm{p}<.05,{ }^{* *} \mathrm{p}<.001$ & & & & & & & & \\
\end{tabular}

The cells represent the frequency of students that responded that "Homework" was the strategy used. Across both semesters there appears to be a difference between students from teacher 1 or teacher 2 with respect to frequency of students answering that "Homework" is what helped them to learn.

The third question addressed by the students in the journal focused the students to discuss what may or may not have prevented them from learning. This was the component of the journal page that was established with the intention of focusing young 
learners on the many things which prohibit them from learning. An analysis of the answers to this question revealed that an average of one quarter of the students on a weekly basis recorded that "nothing" prevented them from learning mathematics that week. This high percentage of response led the researcher to do further analysis to determine if an underlying relationship could be determined. For it was noted by the researcher that there could be a significant relationship emerging for this particular question. Once the researcher combined the data across both semesters, a crosstabulation of the results revealed that a pattern of response was present.

Table 9

Analysis of Reported Use of "Nothing" or No Strategy

$$
\text { Week }
$$

Teacher

3

5

6

7

89

1--Mrs.O

7

5

7

7

11

9

7

2

2--Mrs.Q

21

17

27

27

21

16

13

8

\begin{tabular}{llllllllll}
$\chi^{2}(1, \underline{\mathrm{N}}=48)$ & $.20^{*}$ & $.19^{*}$ & $.28^{* *}$ & $.28^{* *}$ & .11 & .08 & .08 & .14 \\
\hline${ }^{*} \mathrm{p}<.05,{ }^{* *} \mathrm{p}<.001$, & & & & & &
\end{tabular}

The cells represent the frequency of students that responded that "Nothing" prevented their learning. Across both semesters there appears to be a difference between students from teacher 1 or teacher 2 with respect to frequency of students answering that "Nothing" is what prevented them from learning. 
Although students in both classes were responding that "nothing" impeded their learning, the crosstabs and chi-square analysis were able to reveal that the students from Mrs. Q's class were more likely to respond "nothing" (Table 9). This difference between the two classrooms was found to be significant across the 18 weeks of implementation, as noted by the Phi measure for the chi-square analysis represented in Table 8 as well.

Interestingly enough, the third question also revealed that it was Mrs. O's students who were more likely to respond that "watching tv" or "playing too much" were hindering their ability to learn mathematics (Table 10). A new question arose at this point, as to how independent the students were when preparing their journals? Table 10

"TV" or "Playing" as a Reported Response to What Prevented Learning

\begin{tabular}{lrrrrrrrr}
\hline & \multicolumn{7}{c}{ Week } \\
\cline { 2 - 9 } Teacher & 2 & 3 & 4 & 5 & 6 & 7 & 8 & 9 \\
\hline 1--Mrs.O & 7 & 7 & 8 & 7 & 4 & 4 & 2 & 2 \\
2--Mrs.Q & 0 & 1 & 2 & 0 & 1 & 1 & 0 & 1 \\
\hline & & & & Play & & & & \\
1--Mrs.O & 9 & 9 & 15 & 7 & 4 & 9 & 8 & 6 \\
2--Mrs.Q & 1 & 2 & 3 & 2 & 2 & 2 & 0 & 0 \\
\hline
\end{tabular}

The cells represent the frequency of students that responded that "TV or Playing" prevented their learning. Across both semesters there appears to be no real difference between students from teacher 1 or teacher 2 with respect to frequency of students answering that "too much TV or playing too much" is what prevented them from learning. The results here however, did not involve as large a percentage of students as the group that answered "nothing". These analyses revealed that at times across the 
implementation of the study around eight percent of the students would answer that the TV or their playing prevented them from learning their best. Of this eight percent it is telling that the majority are from Mrs. O's class, yet this is not surprising given the high percentage of student's from Mrs. Q's class that had answered "nothing". The way in which the journals were coded permitted the researcher to include every item that a student may have listed (e.g. a student could have written that baseball practice and too much t.v. had contributed to their lack of learning), however if the student wrote 'nothing' only one thing would be coded because the students felt that absolutely nothing prevented them from learning. This limited the responses of the students and accounts for the fact that the strategies named by Mrs. O's students may be spread across a variety of alternatives, whereas the students from Mrs. Q's class overwhelmingly answered only "nothing". This led the researcher to assert that perhaps the students in this class were permitted to write whatever they wanted with no guidance, whereas the students in Mrs. O's class were really trained and enthusiastic about the task.

The results of the preliminary analysis of the fourth journal entry led the researcher to further question the use of the journal for recording mathematical objectives that were to be learned. Although the preliminary analysis did reveal patterns of objectives that were being recorded (review, multiplication, division and geometry) it was unclear as to whether or not the students in both classes were consistently recording their objectives and if the two classes were studying the same objectives simultaneously (this was not a requirement of the study or of the school). A crosstabulation which isolated the teacher variable did reveal that both groups of students indicated that "reviewing" was an 
important part of their learning plan, particularly in the first few weeks of the semester. Furthermore, when isolating the semester variable there was further evidence that the students in each class were consistently identifying the same plan of study.

When a consistent pattern emerges that alerts the researcher to similar strategies being used across the board, it is necessary to pay close attention to the dynamics of the situation. Further study is the most prudent plan of action in order to focus in on the interesting trend and establish if there is some type of consistency that can indicate what students are thinking as they emerge from their study to write and reflect their thoughts.

The cells represent the frequency of students that responded that "Review" or "Multiplication" was their objective for the week. Frequency counts show that plans did reflect a common goal on occasion across the weeks. This would support the use of the journal for planning purposes, in that the classroom environment should reveal similar trends in study goals.

As further evidence that this trend was consistent, the researcher ran a crosstabulation with the multiplication objective being isolated and the same patterns emerged (Table 11). Certain weeks this variable appeared to have a higher frequency of response, which supports the assertion that the students were committing to a plan of learning based on objectives provided to them in the classroom by their particular teacher. An analysis of the table reflects that in the first semester both teachers consistently provided review and worked on the multiplication objective. Yet, there was a significant drop in the second semester for both of these objectives. A review of the student journals 
will reveal that the second semester was largely spent on division and geometry objectives, with one particular week being dedicated exclusively to FCAT review.

Table 11

Reported Weekly Objectives of Review or Multiplication

\begin{tabular}{|c|c|c|c|c|c|c|c|c|c|c|}
\hline \multicolumn{11}{|c|}{ Week } \\
\hline Teacher & 1 & 2 & 3 & 4 & 5 & 6 & 7 & 8 & & 9 \\
\hline \multicolumn{11}{|c|}{ Review } \\
\hline 1--Mrs.O & 8 & 14 & 12 & 18 & 15 & 3 & 4 & & & 1 \\
\hline 2--Mrs. Q & 22 & 15 & 15 & 7 & 0 & 1 & 0 & & & 0 \\
\hline \multicolumn{11}{|l|}{ Semester 2} \\
\hline 1--Mrs. O & 4 & 4 & 2 & 0 & 3 & 6 & 0 & & & 3 \\
\hline 2--Mrs.Q & 0 & 2 & 0 & 0 & 8 & 0 & 0 & 0 & 0 & 4 \\
\hline
\end{tabular}

Semester 1

Multiplication

\begin{tabular}{cccccccccc} 
1--Mrs. O & 15 & 5 & 10 & 11 & 5 & 4 & 3 & 3 & 0 \\
2-Mrs. Q & 19 & 18 & 13 & 15 & 14 & 10 & 2 & 2 & 0 \\
\hline Semester 2 & & & & & & & & & \\
1--Mrs. O & 0 & 2 & 6 & 2 & 0 & 3 & 0 & 0 & 0 \\
2-Mrs.Q & 0 & 0 & 3 & 1 & 0 & 5 & 0 & 0 & 0 \\
\hline
\end{tabular}

Journal entry number five completed the journaling task each week for the students. The preliminary analysis did reveal the widest variety of strategies emerging from the entries to this question. Not surprisingly, this serves as evidence of the fact that the students were using the journals as intended and creating their own individualized repair strategies. Upon further analysis, the results do not reveal any significant trends or 
patterns that are worth noting due to the widespread dispersion of answers and variety of repair strategies noted by students.

\section{Highly Self-Regulated vs. Minimally Self-Regulated Learners}

For purposes of evaluation, the researcher recoded the data in order to establish three categories of strategy users. Using techniques adapted from the procedures used in conducting an item analysis, the researcher identified the top third, middle third and lower third of students with respect to use of strategy in the reflective writing journal in response to questions two, three and five. The analysis of strategy use revealed that the top third of students used between thirty-four and one-hundred seventeen strategies throughout the eighteen weeks of journal use. The middle third used between sixteen and thirty-three strategies and the lower third used between zero and fifteen strategies across the implementation. An analysis of the sixty-six journals using descriptive statistics revealed that the mean was twenty-six strategies employed across eighteen weeks, the median was twenty-two strategies, and the mode was zero strategies $(n=13)$ employed.

The researcher determined that the students involved in the study had fifty-two opportunities to answer questions with respect to strategy use across the eighteen weeks of the study [Semester one--question two (eight entries), question three (eight entries), question five (nine entries); Semester two--question two (nine entries), question three (nine entries), question five (nine entries) $=$ a total of a possible fifty-two entries]. Given this number of possible entries, and using the median number of strategies used for each established category of self-regulation, the researcher determined that the "High" selfregulators provided a $92 \%$ average response rate $(48 / 52)$ to the journal task, whereas the 
Rate of Strategy Use on Reflective Writing Journal Instrument

\begin{tabular}{llll}
\hline $\begin{array}{l}\text { Total number of } \\
\text { strategies used } \\
\text { across questions } 2,3\end{array}$ & $\begin{array}{l}\text { Frequency of } \\
\text { students using this } \\
\text { and } 5\end{array}$ & $\begin{array}{l}\text { Cumulative percent } \\
\text { of students in each }\end{array}$ & $\begin{array}{l}\text { Highly/Minimally } \\
\text { Self-Regulated } \\
\text { Learner }\end{array}$ \\
\hline 117 & 1 & & \\
84 & 1 & 1.5 & Highly \\
73 & 1 & 3.0 & Highly \\
65 & 1 & 4.5 & Highly \\
61 & 1 & 6.1 & Highly \\
59 & 1 & 7.6 & Highly \\
54 & 1 & 9.1 & Highly \\
49 & 1 & 10.6 & Highly \\
48 & 2 & 12.1 & Highly \\
47 & 1 & 15.2 & Highly \\
44 & 1 & 16.7 & Highly \\
43 & 1 & 18.2 & Highly \\
41 & 1 & 19.7 & Highly \\
39 & 3 & 21.2 & Highly \\
37 & 3 & 25.8 & Highly \\
35 & 1 & 30.3 & Highly \\
34 & 3 & 31.8 & Highly \\
33 & 1 & 36.4 & Highly \\
32 & 1 & 37.9 & Middle Third \\
31 & 1 & 39.4 & Middle Third \\
27 & 2 & 40.9 & Middle Third \\
25 & 1 & 43.9 & Middle Third \\
24 & 2 & 45.5 & Middle Third \\
22 & 3 & 48.5 & Middle Third \\
20 & 1 & 53.0 & Middle Third \\
19 & 4 & 54.5 & Middle Third \\
18 & 1 & 60.6 & Middle Third \\
17 & 2 & 62.1 & Middle Third \\
16 & 2 & 65.2 & Middle Third \\
15 & 1 & 68.2 & Middle Third \\
12 & 1 & 72.7 & Minimally \\
11 & 1 & 74.2 & Minimally \\
8 & 13 & Minimally \\
7 & 1 & Minimally \\
4 & 1 & Minimally \\
2 & 10.8 & Minimally \\
0 & Minimally \\
\hline
\end{tabular}

Note: Descriptive Statistics Showing Rate of Strategy Use Across Both Semesters for Questions 2, 3 and 5 on the Reflective Writing Journal Instrument and the Corresponding Level of Strategy Use (High, Middle or Low) based on Item Analysis Techniques 
"Low" self-regulators provided a $15 \%$ average response rate $(8 / 52)$. Given the

establishment of the High self-regulated strategy user group, the researcher was prepared to analyze the multitude of subsidiary questions which were written to address this group and the third research question which was aimed at establishing if standardized scores could be predictive of the extent to which journals affected reporting of strategies.

Table 13 reflects the findings of the analysis conducted to answer the first subsidiary question which asked if high self-regulated learners had a tendency to feel they learned math "as well or better" than planned each week. The analysis required the use of the Highly or Minimally self-regulated learner categories established for Table 12 and it also required the researcher to tally the amount of times that each Highly self-regulated learner answered that he or she felt they learned math "as well or better" for the first question posed on their journal page. The table represents counts established for each semester as well as a look at the percentages for each high self-regulated learner of the times they answered "as well or better."

The researcher obtained standardized test scores ( Total Math SAT pre and post) for each student, the scores on a motivation instrument (pre and post) and the scores on a metacognition instrument (pre and post) given to the students for purposes of analysis during the main study (Rendulic \& Terrell, 1999). It was the purpose of one of the main research questions to determine if the scores on these tests could be predictive of the type of learner the journal analysis indicated the student to be. The researcher was prepared to conduct a multiple regression analysis with the post-metacognitive score, the postmotivation score and the post Math-SAT score serving as the independent variables with 
the dependent variable being the total number of strategies used across the eighteen weeks of implementation for questions 2, 3 and 5 of the journal task.

Table 13

Percentile of Highly Self-Regulated Learners Answering they Learned Math "as well" or "better" than Planned

\begin{tabular}{ccccc}
\hline Student ID & $\begin{array}{l}\text { Semester 1 } \\
\text { number of times } \\
\text { answered "as } \\
\text { well or better" }\end{array}$ & $\begin{array}{l}\text { Semester 2 } \\
\text { number of times } \\
\text { answered "as } \\
\text { well or better" }\end{array}$ & $\begin{array}{l}\text { Total number of } \\
\text { times answered } \\
\text { "as well" or } \\
\text { "better" }\end{array}$ & $\begin{array}{l}\text { \% of time } \\
\text { answered "as } \\
\text { well" or "better" }\end{array}$ \\
\hline 302 & 7 & 5 & 12 & $70 \%$ \\
303 & 2 & 8 & 10 & $59 \%$ \\
304 & 6 & 7 & 13 & $76 \%$ \\
306 & 4 & 6 & 10 & $59 \%$ \\
311 & 6 & 9 & 15 & $88 \%$ \\
312 & 6 & 6 & 12 & $70 \%$ \\
316 & 3 & 9 & 12 & $70 \%$ \\
318 & 2 & 6 & 8 & $47 \%$ \\
321 & 5 & 8 & 13 & $76 \%$ \\
322 & 5 & 8 & 13 & $76 \%$ \\
324 & 2 & 5 & 7 & $41 \%$ \\
325 & 5 & 9 & 14 & $82 \%$ \\
326 & 7 & 6 & 13 & $76 \%$ \\
327 & 3 & 7 & 10 & $59 \%$ \\
328 & 6 & 8 & 14 & $82 \%$ \\
330 & 5 & 6 & 11 & $65 \%$ \\
408 & 5 & 4 & 9 & $53 \%$ \\
412 & 3 & 0 & 3 & $18 \%$ \\
506 & 5 & 3 & 8 & $47 \%$ \\
508 & 5 & 5 & 10 & $59 \%$ \\
512 & 6 & 1 & 7 & $41 \%$ \\
520 & 3 & 6 & 9 & $53 \%$ \\
521 & 7 & 4 & $65 \%$ \\
522 & 2 & 4 & & $35 \%$ \\
\hline
\end{tabular}


Prior to conducting the statistical analysis, the researcher needed to establish that it was appropriate to run this test based on the data collected. Stevens (1998) states that at least 15 subjects per predictor are needed for a reliable equation, which is an equation that will cross-validate with little loss in predictive power. Since the regression equation chosen uses three predictors (metacognitive score, motivation score and SAT Math score) there must be a minimum of 45 subjects in order to run this regression-this condition was met given that there were 48 students. Secondly, Stevens (1998) asserts that the ideal situation is to have predictors (metacognitive score, motivation score and SAT Math score) that are each significantly correlated with the dependent variable (total number of strategies used), but to have low correlation between predictors.

In this study it was revealed that the metacognitive score was not highly correlated with the dependent variable $(\underline{r}=.07, \mathrm{p}<.63)$. This may result in metacognition being a non-significant variable when predicting the number of strategies used by the students. On the other hand, the motivation score was highly correlated with the dependent variable $(\underline{r}=.94, \underline{p}<.01)$ and the Total Math SAT score was significantly correlated with the dependent variable $(\mathrm{r}=.47, \mathrm{p}<.001)$. Multicollinearity is the case where the predictor variables are highly correlated with each other. Analysis of the intercorrelations between the set of predictor variables established that there was no highly significant correlation between the metacognitive scores and the Total Math SAT scores $(\underline{r}=-.22, \underline{p}<.13)$ or the metacognitive scores with the motivation scores $(\underline{r}=.34$, $\mathrm{p}<.02)$ or the motivation scores with the Total Math SAT scores $(\underline{r}=.06, \mathrm{p}<.66)$. When there are moderate to high intercorrelations among the predictors it is a real 
problem to use a multiple regression analysis, however checks established that this was not the case in for study.

Table 14 reflects the findings from a simple regression analysis. Given that our pre-analysis revealed that there was no significant correlation between the metacognition scores and the dependent variable or the motivation scores and the dependent variable, the researcher heeded the instructions delineated by Stevens (1998) which established that a multiple regression under these conditions would not yield favorable results in that the predictors do not appear to show any type of relationship to our measure of regulation. This led the researcher to conduct a simple regression using the only measure of prediction that was significantly correlated with our dependent variable.

Table 14

Summary of Regression for Total Math SAT Score Predicting Level of Self-Regulation

\begin{tabular}{cccc}
\hline Variable & $\underline{\mathrm{B}}$ & $\underline{\mathrm{SE}} \underline{\mathrm{B}}$ & $\beta$ \\
\hline (Constant) & 5.497 & 5.946 & $.477^{* *}$ \\
Math SAT Scores & .433 & .103 & \\
\hline Note. & \\
\hline
\end{tabular}

The results of the simple regression analysis indicate that Total Math SAT scores are a good predictor of the type of self-regulated learner that a student appears to be based on the criteria set from analyzing the reflective writing journals. Based on the significance of this analysis the researcher is able to establish a regression equation. The regression equation enables a researcher to take the regression coefficient and the constant given in Table 14 and then to use Total Math SAT scores obtained by the students to predict a 
student's level of self-regulation. In actuality, since the criteria of highly self-regulated or minimally self-regulated were previously established (Table 12), this equation serves to confirm predictions and acknowledge the relationship that exists between Total Math SAT scores and the dependent variable of "total strategies used" across the eighteen weeks of the reflective writing journal.

The Total Math SAT scores served as good predictors, so this led the researcher to question if it was a certain sub-section of the Total Math Scores that were leading to these results. Consequently, the three subsections of the Total Math SAT score (Concepts, Computation and Application) were each used separately in a simple regression equation to determine if one was a stronger predictor than any of the others of the level of strategy established by each student. Table 15 reflects the findings from each of these analyses in that each section of the table reflects the findings from one of the three SAT Subsections that together make the Total Math SAT score used previously. The whole purpose of separating the scores lies in the importance of finding if one subsection is a better predictor than any other, given that they are measuring very different math skills.

The results of these analyses showed that two of the three subsections (Computation and Application) were contributing strongly to the findings of the Total Math SAT results. The Math Concepts sub-section regression was not significant which indicates that the scores obtained by students on this subsection alone are not enough to predict what type of self-regulated learner each student is. However, the scores obtained for the Math Computation sub-section and the Math Application sub-section were shown 
to be significant, which indicates that the scores from these two sub-sections can be used as strong predictors of what type of learner (Highly self-regulated or Minimally selfregulated) each student is.

Table 15

Summary of Regression Analysis for Each Sub-Section of the Total Math SAT Score Variable Predicting Level of Self-Regulation

\begin{tabular}{llll}
\hline Sub-Section of SAT & $\underline{B}$ & SE $\underline{B}$ & $\beta$
\end{tabular}

\begin{tabular}{cccc}
\hline (Constant) & 18.618 & 5.876 & .230 \\
Math Concepts & .195 & .106 & \\
\hline (Constant) & 2.834 & 6.262 & $.494^{* *}$ \\
Math Computation & .447 & .102 & $.444^{* *}$ \\
\hline (Constant) & 8.999 & 5.573 & \\
Math Application & .369 & .097 & \\
\hline${ }^{*} \mathrm{p}<.05,{ }^{* *} \mathrm{p}<.001$. & & &
\end{tabular}

Ancillary Findings from Larger Study

The Rendulic and Terrell (1999) study gathered pre-study data for all of the students with respect to motivation, metacognition and math SAT scores from third grade. Their analyses established that the treatment groups were equal based on the results obtained on two pre-study measures. The ANOVA results showed the students to be statistically equivalent on their math achievement at the beginning of the study $\underline{F}(3,82)=$ $1.21, p>10$. Furthermore, they were also statistically equivalent on their pretest measure of metacognition $\underline{F}(3,97)=2.45, \underline{p}<.07$. In other words, there was no significant 
difference between students who were placed in either Mrs. O or Mrs. Q's class prior to the study on the measure of metacognition or on the basis of their math SAT scores.

The reader is referred to the Rendulic and Terrell (1999) study for information regarding the instruments used for motivation and metacognition data collection.

However, for purposes of advancing the discussion based on the posed research question, one must be advised that the pre and post tests on the measures of metacognition and math SAT scores showed a significant increase from pre to the post tests. The results of a General Factorial Analysis of Variance show that there is a significant difference between treatment groups for the post-measure of metacognition $\underline{F}(3,100)=5.84, \underline{p}<.001$. Furthermore, a Bonferroni post hoc test shows the significant difference to be within the combined treatment group of Mrs. O's class. For the measure of math achievement the Rendulic and Terrell (1999) analyzed the post math SAT scores using a General Factorial Analysis to reveal these differences to be statistically significant, $\underline{F}(3,98)=3.25, \mathrm{p}<$ .025. These results of the larger study will be necessary for the researcher to consider when advancing the discussion of the research questions.

\section{Interview Analysis}

There were three interviews conducted with teachers from Sunshine Elementary School. The three teachers interviewed were those whose classes received the reflective writing journal treatment. The purpose of the interview component was to provide teachers with an opportunity to voice their opinions regarding the Sunshine Elementary School/FIU project. Furthermore, it served to get details and in-depth information from teachers who were an integral part of this study. The fact that teachers were such an 
important part of this study can influence it in both negative and positive ways. The interview allowed for the researcher to ask probing questions of each teacher and to make some assertions as to when to ask for further explanation, etc. This particular element of the study was intended to bring life to the journals and the classrooms in which they were implemented. The interview component was composed of twenty questions devised by the researcher which focused on a variety of issues which the researcher believed to be pertinent to the study (Appendix B). The analysis will focus on the responses provided by the teacher, in an effort to establish a clearer picture of the perspectives held by each of the participating teachers.

The first question asked the teachers to provide some background information about themselves as teachers (demographics). All three teachers have more than ten years experience teaching (ten years, thirteen years and eleven years, respectively). One of the teachers entered the teaching profession as a second career, while the other two teachers graduated with their first careers being in education. Interestingly enough, two of the three teachers entered elementary schools with jobs as science specialists. Also of significance is the fact that all three teachers are currently enrolled in a Master's program in education.

All three teachers recalled having participated in the Sunshine Elementary/FIU project, with two of the three teachers specifically stating the impact that the head researcher from the larger project had on their school sites: "Well, I remember most that Dr. R coming in and working with the kids..." (Mrs. M) and "Okay--I remember Dr. R very well--coming in and, you know, very enthusiastic..." (Mrs. Q). These statements are 
quite significant in that they attest to the fact that the teachers as well as the students recognized the researcher as an important guide for their classes.

The third question posed was aimed at establishing if the teacher's participation in the project was either voluntary or mandatory. Two of the three teachers recalled that their participation was a voluntary activity, whereas the third stated that "I don't believe it was presented either way. We were just told we were going to participate in a project and we said okay." (Mrs. Q) Clearly, all three teachers involved in the journal component of the study were in agreement that it was not a mandatory assignment for them, but rather a unique opportunity and "we did it as a group" (Mrs. O).

The fourth question asked each of the teachers was to tell in their own words what they believed the study to be about. It was clear that each of the teachers had concerns with respect to the time that had elapsed and their ability to remember. Nevertheless, the three teachers were able to describe the purpose of the study. Interestingly enough, the two teachers who participated in the graphing/journal treatment groups had a clearer concept of what the study was attempting to measure: "I think that Dr. R was trying to find out if the students really felt like they were in control of their own grades at such a young level and that they shall learn to be self-tracking and self-responsible for the end result..." (Mrs. O) and "In a nutshell, [it] is making kids accountable for their own performance. To be able to monitor their progress and see what they need to do to possibly improve..." (Mrs. Q) In contrast, the teacher who participated in the journal only treatment group was focused much more on the subject area involved, as expressed 
in the statement "...they were looking at what variables, or what components create or cause the greatest increase in math, I think it was." (Mrs. M)

In an attempt to establish just how much time the journaling activity was taking up in the classroom, the next question asked the teachers to recall how much time they spent on average each week with the reflective writing journals. The "journal only" teacher (Mrs. M) could not recall how much time was spent each week, however the two combined groups cited about thirty minutes (Mrs. O) and twenty minutes (Mrs. Q) respectively, with the required amount of time reducing significantly as each week passed and the children became more and more interested and accustomed to participating in the project.

The follow-up question inquired about how the teachers planned for the journal writing assignment and how they actually used it. Once again, the teachers from the two combined classes were able to establish a clearer picture of how the project was implemented with their students. Mrs. O mentioned that she planned for it to take place every Wednesday because "that's when Dr. R came to the classroom to make observations about them and I felt that for him to become even more in tune to what was happening with his project that it was important for them to do it when he was there". Mrs. Q stated that "I went according to what I had planned for the week. You know, letting them know what was coming and then they would then set their goals or whatever they were doing according to whatever math lesson was coming". Although Mrs. O was focused on the plan in the sense of when she would implement the project, Mrs. Q took the question to mean the actual objective to be taught to the students. Both interpretations still serve to 
reveal that one teacher had built the journal writing component into her routine, whereas the second teacher did not necessarily have a set day or time of the week, but rather implemented the use of the journal as a way of supplementing her plans. The third teacher (representing the journal only group) could not recall how she planned for the journal writing activity, "I know that they did do the journaling at least once a week but I don't know if we did it after... at the beginning...I just truly...". At this point in the interview process, the researcher did offer to read the questions posed on the journaling sheet for Mrs. M. This allowed her to bring back to mind the key questions posed of the children and it was hoped that it would provide for a much more comprehensive interview in that she could refocus on the topic. It is of consequence to note that all of the teachers did receive a copy of the interview questions prior to their interviews. This was due to the fact that a request was made by the teacher living in North Carolina to preview the questions in order to be prepared and expedite the process. The same procedure was followed for all three of the interviews.

The next question asked the teachers to reflect upon how the students actually used the journal. All three teachers were in agreement that the journals were exclusively part of the project. Mrs. O stated that "It was used specifically for the research project." However, she also made it clear that "...it was used cross-curriculum and they did reflect back on their journals when they got their weeks worth of papers... and so it was used as a personal reflection." Mrs. M supported that "It was a part of the math--during the math block. That's when I would allow time for that--for the journaling...It wasn't something that was open at some point during the day." The answer provided by Mrs. Q truly 
summed up the consensus of how the teachers felt the journals were used by students: "I believe [the journals were used] only when required but the intent was for everything. Not just to monitor your math progress but for any type of situation in school. That's what was encouraged but I'm not sure--I guess as they got more familiar with it they were more comfortable using it and I guess maybe some of them were using it for other things."

Questions eight and nine asked the teachers to rate the level of enthusiasm that existed for the reflective writing journal from both the student and teacher perspectives. The scale was from one to five, with five being very enthusiastic and one being not at all enthusiastic. Each teacher was asked to respond from both perspectives, in order to get feedback from the teachers regarding their experience with the journal implemented and to determine if they felt students enjoyed having participated in the experience, since they were there on a daily basis during all implementations (with or without researcher).

The average score for the students was reported to be a 4.3 which indicates that the teachers felt generally that the students were enthusiastic about using the reflective writing journal. Of special note is the fact that Mrs. O indicated that "It was a chore to begin with, because they were unfamiliar with the task." Mrs. Q corroborated her sentiments by expressing that "At first I would say not that enthusiastic because they weren't really clear until it was clear what was needed..." So, it is clear that two of the teachers felt that a student's enthusiasm increased with time and experience.

Similarly, the average rating for teacher's enthusiasm was rated a 4.3 as well. This indicates that generally the teachers were enthusiastic about the project. Of interest, is the fact that Mrs. O noted she thought the project was wonderful, but that... 
...the other teacher who had [only] journal writing had expressed some concern about the length of time that the journal writing did take... and then some of the other teachers' comments were that they were wondering if our students were being so successful, then were their students lacking in some area of not writing in the journal or not doing the graph. And not being able to understand that that's the way the experiment had to be. There had to be some doing nothing, some doing one, some doing the other, and some doing both.

Her observation was corroborated by Mrs. $\mathrm{M}$ in that she also rated a ' 4 ' and stated "that was a strange year. I did not, to be very frank, I did not really have a rapport, even though I... the connection. I didn't have the connection I guess with the other teachers so we didn't really talk about it. I didn't have lunch with them or anything."

Ironically, this led to the next question on the instrument which asked "Did you talk to the other teachers?" As expected, Mrs. M reiterated "No. It was a personality thing I guess, and it just didn't work...we rarely discussed anything...I was the outsider." Mrs. Q supported her sentiments in that she responded,

Honestly,...I don't really recall talking about it that much with Mrs. O or Mrs. M because we weren't really--their classrooms were so far away and we hardly ever met except for team meetings and things like that and I would imagine--I think that I had it probably the best because we were doing both the journal and the graphing and then I heard--just the journals or just the graphing--I don't remember exactly what everybody was doing. Its just that I remember saying, well maybe if we were doing the graphing or maybe if we were doing the journals--you know, so I think together it seemed to make a difference because I thought it was great.

The answers to this question did provide some interesting insight, in that Mrs. O did mention the fact that initially they did speak as a group with $\operatorname{Dr}$. R to set up the implementation of the project, which supports the fact that the researcher did attempt to open the lines of communication among the participating teachers. Yet, their answers clearly reveal that the logistics of where their classrooms were located did not support this 
type of communication among teachers. It was the answers to this question that first gave the researcher an indication that the "change" involved in the implementation of this project was difficult for all involved. Furthermore, the answers provided by all three of the teachers implementing the reflective writing journal are supportive of the fact that there were some indications of resistance to this change (implementation).

The eleventh question on the interview instrument asked the teachers to reflect back upon the students in the class and to recall one student who might have benefited from the reflective journal writing assignments. All three teachers were in agreement that they could think of at least one student who may have benefited. Mrs. Q added that "actually I'm probably still in contact with about six or seven of them that write to me and we talk about different things but I believe that it did benefit the majority of the class". Specifically, Mrs. M recalled a female student who always struggled but was motivated by Dr. R to try a little harder. "She wasn't always able to reach... you know, she'd set her goals I guess a little bit beyond where she was academically, I guess, but she always had such a positive feel and a positive sense of the program and you did see some growth for her but nothing like she would always set her goals for". So, although Mrs. Q recalls a group of students benefiting and Mrs. M recalls a child eager to please the researcher and perhaps aiming a little higher because of that motivation, Mrs. O recalls a male student that truly changed as a result of the writing journal assignment.

I started with a student, and he was classified as socially maladjusted. He was not a happy person or a nice student. He tripped people and he spit on their food and stuff like that. He was really not a very sociable character; but when he began to record his own grades and realize that he was in control and could do good things and see it, its more of almost instant gratification. It's Wednesday to Wednesday, whereas to get your report 
card you wait for nine weeks and you have no idea where you stand for that whole nine weeks until you get your report card and either you're in trouble or you're not...He was very receptive to the positive that he got each week and his grades definitely went up and he became more responsible for his own work in all subjects.

Interestingly enough, although all three teachers answered in the positive that they did recall certain students, two of them specifically recalled that the feedback aspect was what effected students most. One thrived on the feedback from the researcher and the other from the feedback generated by the grades recorded in the journal.

From the specific to the general, the next question focused on the class as a whole and the teacher's opinions as to how the reflective writing journal may/may not have effected the class. Both of the teachers who had students participating in the journal/graphing components affirmed that there was a benefit to having participated. For instance, Mrs. O answered, "I think that it was very, very beneficial for students to do selftracking. To realize that they have control over the grade by studying and so they have to learn what studying means..." However, the teacher that did not engage in the graphing component of the model found it to be much more difficult for her students in general. Mrs. M said,

I don't think they had a true sense of the program because that's all they did was the journaling. I think that had they had the other component then there would have been more of a connection or more of a thing of how it all came together. Because they didn't quite get the connection between the--I don't think they truly got a sense of why they were doing it or what it was supposed to achieve.

This led to the question regarding the benefits to the teachers where the interview asked if having participated in the FIU project made a difference in the way they taught, their teaching methods or styles. All three teachers overwhelming answered that the 
project encouraged them to have students constantly set high goals. Mrs. O told of how she motivates students after a test by saying "These are your numbers and where are you and where do you want to be, and what can you do if you want to be in the place that you're not?" Mrs. M took the time to explain that although she is not currently using the journal sheets and she doesn't have kids write that she "always tries to encourage them to set high goals."

The follow-up question had the teachers reflect upon how the teachers may have changed as a result of participation in the project. Mrs. Q recounted that "as far as setting goals, I mean I always have the children set goals but this brought it to light a little bit clearer." Clearly, the teachers were all in agreement that one of the benefits was the opportunity to reflect and write about the weekly goals, objectives, and outcomes of strategy use. Mrs. M added that "I don't have kids to write (goals), but I always try to encourage them to set high goals." Mrs. O answered with respect to how the project effected change upon her teaching focus, in that she is currently applying some of the techniques used in the project with her current class. After she gives her students an exam she tells them: "These are your numbers and where are you and where do you want to be, and what can you do if you want to be in the place that you're not?" She also described how using this technique helped a group of students to improve significantly in reading scores; in fact, "the end result was that this group of fifth graders scored third highest in improvement points in the entire school on the Reading end of grade test."

Having the opportunity to set goals for the week was a very important part of the reflective writing journal assignment. One of the questions the teachers were asked 
focused on whether they felt that having students write down the goals made an impact.

All three teachers responded "yes" and Mrs. O elaborated by stating:

I think it was, because we all have strengths and weaknesses...for them to know ahead of time what their expectations were helped them decide on what some of their strategies were...I think its important for them to know where they're headed because some of them know that they need to study more for that particular area and some of them might sit back and say Phew, I already know that. My study strategies don't have to be as complicated as the person next to me because I already know how to divide or I already know how to multiply.

The next question focused on asking each teacher how they believed the two other teachers may have benefited from having participated in the project. There was resistance from each of the teachers to answer this particular question. Mrs. O stated "I really can't give an honest answer to that question." Mrs. M stated "I have no idea. Sorry. I had no connection with them at all.” Furthermore, Mrs. Q attempted to answer; however, she redirected her answer so as to focus again on the student: "Well I would imagine any student who realizes that they have the opportunities to somehow make a difference or shed some light on how their grade is changing each week because they've done this or this, I mean I think that that's exactly what we want them to do. Become accountable for their progress."

When asking the teachers if they have considered incorporating the reflective writing journal into their current curriculum, the responses were generally positive. Mrs. O summarized that her current group uses writing journals and a self-tracking score sheet. Mrs. Q told of how the

school provides the student with a planner and at the bottom it has space and I have them set goals for the week. I have them set long term and short term goals. At the beginning of the year we do a long term goal and 
then we do short term goals and then we conference and we have the children set up different goals according to their needs...As far as the averaging the grades and the graphing? That was too time consuming in my opinion. It was very difficult for a lot of the students and he'll probably remember that too because we did spend a lot of time teaching them how to average and it just...I don't know... because we did spend a lot of time teaching them how to average and it just...I don't know...

The answer provided by Mrs. M. indicated that although she does not find herself using any aspects of the study currently, however “...now that I think about it, it's interesting. For them, something like that would be perfect." The researcher did provide her with a copy of the study sheet because she showed interest in implementing the reflective writing journal with her current class of sixth graders. Of importance is the fact that although the two teachers from the graphing/journal component did indicate use of some of the techniques previously employed, none of the teachers were focused on all aspects of the writing journal with reflective questions. Rather their focus was placed more on the graphing component (or ability to track grades and goals), not the use of learning strategies.

The researcher then probed the teachers to reflect upon any limitations they believe inhibited the use of the reflective writing journal in their classes. Mrs. Q could not recall any specific limitations, however Mrs. M cited "time" and Mrs. O brought up the matter of "limited writing skills." The follow-up question allowed for the teachers to discuss what aspects of the study they would change in order to make this project work. Mrs. O recalls that it was not difficult and she just worked it into her plans, however both Mrs. M and Mrs. Q felt that they needed to prepare their students more for participating in the project. Specifically, Mrs. M states that in order to make it work in the future that she 
would "talk it more to the children. I think that was my shortcoming. I did not talk it enough to them."

The last interview question asked the teachers for any comments or suggestions they might give for handling any future projects. Mrs. O wished to get some feedback with regard to the results and she also suggested that perhaps in the future it could be "cross-curriculum" and incorporate more of the subject areas. Mrs. M suggested that perhaps the project could have been more successful with an older group of students, sixth graders. Furthermore, the exchange between the researcher and Mrs. Q highlighted the fact that fourth graders in our state are very busy with FCAT preparations and administrations, therefore "...it is a lot of pressure, it is a lot of time." This particular aspect of pressure stemming from standardized testing should more readily be explored.

\section{Summary}

The results of this study emerge from two very distinct data sources: the student reflective writing journals and the teacher interviews. In isolation, each of these sources of data provide a significant amount of information regarding the implementation of a reflective writing journal into a fourth grade math curriculum and Chapter 4 highlights the findings of interest that emerged as a result of this action research project from each source of data. However, Chapter 5 will take the analyses from these distinct sources to tie together the findings.

The researcher concentrated first on presenting the findings which were evident as a result of separately analyzing each question posed in the student reflective writing 
journals. The analysis of Question 1 brought to light the fact that a significant amount of times the students provided "No answer" for how they felt they did in math each week.

With Questions 2 through 5 being of an open-ended format, the responses were more widespread. A content analysis of the journal responses revealed that "studying and homework" were reported most often as what did help students learn. Of the responses cited for what did not help students learn, they most often cited that "nothing" impeded their learning, however, "playing too much and watching television" were also revealed. The goals and objectives for the week were clearly established by the teacher in that a majority of students responded in much the same manner across the 18 weeks. Lastly, the final question attempted to isolate the repair strategy that students intended to focus on. The first week it appears that seeking parental help was a major goal, however this strategy quickly disappeared and was replaced with "completing homework, classwork and listening more in class."

The secondary analysis of the student writing journals involved isolating crosstabulations to determine if the patterns which were revealed were significant on the basis of chi-square analyses for both classes being investigated. Chi-square results revealed that the students with Mrs. O consistently used homework as a strategy that helped them learn; furthermore, students in Mrs. Q's class were more likely to note that "nothing' prevented their learning.

Upon recoding the data in order to establish three categories of strategy users, in an effort to more clearly determine how highly self-regulated learners vs. minimally selfregulated learners view learning, it was noted that highly self-regulated learners typically 
answered that they learn math "as well or better" than planned. Furthermore, a regression analysis (using Total Math SAT Scores) yields that Math SAT Scores are good predictors of the type of learner that the reflective writing journals reveals them to be. A regression analysis for each sub-section of the Total Math SAT score revealed that math computation and math application scores contributed highly to the significant results obtained by the Total score.

Lastly, an interview was conducted with each of the teachers that implemented the reflective writing journal component. The issues of how they planned for the journal writing and the actual uses were explored along with their reflections. These interviews highlighted some of the issues which emerged as a result of analyzing the student reflective writing journals. 


\section{CHAPTER V}

\section{SUMMARY, DISCUSSION AND CONCLUSIONS}

Teaching young children to self-regulate in order that they may to some extent control their learning can be a complicated task. Ideally, a fixed set of objectives could be taught to any student wishing to engage in the task of learning; unfortunately as is often the case in life, it is never quite that simple. Although past research has documented that teachers can teach skills for regulating learning (Bandura, 1986; Butler \& Winne, 1995; Winne, 1997a; Winne \& Hadwin, 1997b), there are issues as to when it is developmentally appropriate (Paris \& Newman, 1990) to begin engaging students in these types of activities.

Numerous studies were examined to establish the pertinence of self-regulation for the elementary school student and the feasibility of establishing a journal activity that could enhance (or possibly even teach) these skills: (Carr, 1996; Corno, 1987; Pintrich \& De Groot, 1990; Schunk, 1982; Schunk, 1990; Schunk, 1998; Sink, 1991; van Kraayenoord \& Paris, 1997; Zimmerman, Bandura \& Martinez-Pons, 1992; Zimmerman \& Martinez-Pons, 1986) The literature supported the use of journaling/graphing activities that encourage self-regulatory skills. Furthermore, past studies by Rendulic and Terrell (1997a, 1999) indicated the need to incorporate a component of the study that would support reflection of strategy use.

Prior studies have established that a number of categories of self-regulated learning strategies can be identified (Bandura, 1986; Schunk, 1984; Zimmerman, 1983). Building on past research, the current study focused on many of the self-regulated learning 
strategies identified in the literature because "results suggested that theoretical conceptions of students as initiators, planners, and observers of their own instructional experiences have empirical and practical merit" (Zimmerman \& Martinez-Pons, 1986). The present study also found that analyzing the use of self-regulated learning strategies was meaningful and of practical merit to those with an interest in education. For purposes of establishing an organized discussion, this section will begin with a summary of the study, followed by a discussion of the results obtained in relation to the research questions and subsidiary questions posed in Chapter I. Furthermore, the remainder of the chapter will focus on the limitations of the study and their implications and, last, recommendations for further research.

\section{Summary of the Study}

The major premise of this study was to ascertain whether or not a reflective writing journal implemented with a group of fourth grade students could significantly increase the use of self-regulatory strategies. Data for this study was collected across eighteen weeks (two semesters) of action research during which sixty-six students participating in the study were asked to utilize a reflective writing journal for the purpose of tracking their progress in mathematics. Past research established that the literature on self-regulated learning is well grounded within the framework of psychological literature attributed to motivation, metacognition, strategy use and learning. The reflective writing journal was created with five research questions to be addressed: the first question helped students establish how they felt they did with respect to the math grade they earned last week, a second question established the things that helped them to learn, the third question was 
aimed at establishing the things that did not help them to learn, a fourth created a plan for learning for the upcoming week, and the last question was aimed at encouraging the students to think of a repair strategy for learning math.

A convenience sample of fourth grade students at an elementary school in Broward County, FL were used for this research. The reflective writing journals were analyzed using many of the strategies established by the Self-Regulated Learning Interview Schedule (SRLIS) as a criteria. Furthermore, the researcher used qualitative analysis techniques in order to analyze the writings present in the journal and present an overview of the findings. The research questions were analyzed using descriptive statistics, frequency counts, cross-tabs and chi-square analyses.

Results based on student-use of the journals and teacher interviews indicated that the incorporation of a reflective writing journal into a mathematics curriculum does promote self-regulated learning strategy use to the extent in which the student is engaged in the journaling process. Those students who were identified as "highly" self-regulated learners on the basis of their strategy use, were shown to regularly claim that they learned math "as well" or "better" than they had planned. The reverse was found for students who were "minimally" self-regulated, in that they consistently felt that they "had not learned math as well as planned." This finding is consistent with the literature focused on academic achievement which asserts that students can serve as active managers of their own learning (Schunk, 1982; Zimmerman, 1989a). Self-regulation processes and perceptions of self-efficacy are assumed to be responsible for these outcomes. Furthermore, this study found that good self-regulators were able to recognize specific 
strategies that helped them do well and they consistently changed their strategies across time based on the planned learning objectives.

The effect of planned change and/or resistance to change was also addressed in this study from the perspective of the teacher. The follow-up teacher interviews revealed that the teachers were an important component of this study and that the role of the teacher has historically been something that researchers should always address. Obviously, these were teachers that were trained in the journaling process, and this component remains as a vital piece of interaction that can have lasting impacts on the results of any study. Ashton and Webb (1986) defined "teaching efficacy" as the teacher's judgment about the potential influence of teaching on a child's learning. Although this domain of research is not of primary interest to the current study, it nevertheless is something which should be discussed in that the role of the teacher is central to the findings reported.

Based on the journals and the interviews, this study finds that the systematic use of metacognitive, motivational and/or learning strategies can have a positive effect on student's responsiveness to their learning environment. Furthermore, it reflects that teaching students how to learn can be a vital part of the effectiveness of any curriculum. Reflective writing journals can provide just the impetus necessary for young students to begin thinking about what helps them engage in the learning process successfully at a new level of competence.

The remainder of this chapter presents the major findings for each of the research and subsidiary questions, as well as relevant discussions, conclusions and recommendations. 
- To what extent does a reflective writing journal promote or facilitate the use of SelfRegulated Learning strategies?

The answer to this question is not a simple statistical measure, but rather a complex integration of results that, when viewed in combination, serve as an explanation. First, we can turn to the journal page used by the students for guidance in search of the answer to this question (Appendix A). The way in which the journal page was constructed helps students to identify strategies that may/may not facilitate their learning. Questions number 2 and 5 on the journal writing page specifically address the research question in that they probe students to think about what strategies helped them to learn (question 2) and what repair strategy they believe they can or should employ to help them learn better (question 5). The nature of the journal writing assignment in and of itself helped promote the use of self-regulated learning strategies.

Second, in search of evidence to provide a response to this question, the researcher looked to the data collected from the student journals. The journals showed that students were capable of thinking about their math grades as they engaged in a weekly evaluation of their own progress by establishing if they learned math better than planned, as well as planned or not as well as planned. Furthermore, the nature of the journal asked them to establish what helped them learn math better. The answers to this question were all strategies for positively engaging in the learning process: "did math with my teacher", my mom helped me", "I looked at my math book", "used my flash cards", "practiced them and wrote them five times each", "completed and turned in my homework", etc. Conversely, 
the journal assignment was such that it also encouraged students to think of strategies that did not help them learn: "start to play during math homework", "watched tv", "played video games", "did not pay 'attion' (sic) to the teacher", etc. Most importantly, the last question of the journal assignment encouraged reflection, in that it asked for students to provide feedback for an extended period of time, that would in essence help students come up with repair strategies for future math encounters.

Third, the answers provided by the teachers to questions number 11 and 12 during the interviews addressed this particular research question. Question 11 of each interview asked the teacher to reflect upon the students in the class and to recall one who may have benefited from the reflective writing journal assignment. As expected, all three teachers were able to recall at least one student who appeared to have benefited. Mrs. Q was able to recall that she is still in contact with six or seven of the students and that they often write to her or speak with her, yet she was unable to be specific as to how the project affected one student. Mrs. $\mathrm{O}$ and Mrs. $\mathrm{M}$ were able to identify one student each, as the question had requested. One identified a male student and one identified a female student. What was interesting to note was the fact that each teacher chose a child that was struggling with the learning process. In other words, the question was open-ended in that it did not ask specifically for a child that was struggling and then improved, however both teachers did discuss a child that was in this predicament. This would serve to support the literature and findings provided by Zimmerman, Bandura and Martinez-Pons (1992, p.664) who state that "Experimental studies have shown that teaching low-achieving students to set proximal goals for themselves enhances their sense of cognitive efficacy, 
their academic achievement, and their intrinsic interest in the subject matter." These two teachers found this to be true, for when they were asked to recall one student who may have benefited, they immediately recalled the low-achieving student that was empowered by the process. Specifically, Mrs. O was able to pinpoint the fact that the student "was very receptive to the positive that he got each week and his grades definitely went up and he became more responsible for his own work in all subjects."

The analysis of question 12 of the interview instrument served to generalize the findings reported by each teacher for their class as a whole. Mrs. O and Mrs. Q (both had the journal/graphing component) each felt that their classroom of students did benefit from having participated in the reflective writing journal component. So, to what extent would they feel that this journal promoted the use of self-regulated learning strategies? It is unclear from Mrs. Q's answer because she answered only "yes" with no details. However, the exchange between the researcher and Mrs. O made clear the fact that the journaling experience certainly could focus students on their use of strategy if implemented correctly. The following exchange between the researcher and Mrs. O serves to validate the assertion that reflective writing journals do promote or facilitate the use of self-regulated learning strategies because the details provided by Mrs. $\mathrm{O}$ are certainly evidence of a successful learning experience:

L. DiBello That's a great thing to hear. For your class as a whole, do you believe that the reflective writing journal was or was not beneficial and can you elaborate a little? 
Teacher 1 Well, again, I think that it was very, very beneficial for students to do selftracking. To realize that they have control over the grade by studying and so they have to learn what studying means and, on the side we would have-to study means: you may have to write it three times each or say it three times each or ask someone to say it to you and you say it back to them-but that's what studying means. And that study shows up when you do your work and you take your test. So when they were writing in the journal they used some of those techniques and we had one that was teach your dog the multiplication tables and they would write that as a strategy.

L. DiBello Oh yes.

Teacher 1 Say read to my dog, or teach my dog the multiplication tables.

L. DiBello I was just about to tell you that analyzing your group in particular, the biggest strategy, the one that was used quite, quite often involved the family pet.

Teacher 1 Right.

L. DiBello And I thought it was fantastic because it isolated it completely from all the other journal groups that I've been analyzing but it showed directly that there was a link in this class where the class was connected by the teacher and it happened to be that strategy. It was great. I loved it. I always told my husband, "Look, another pet!"

Teacher 1 Well, you know and I say that, in all honesty because sometimes that's all they have to talk to and that's really sad. A really sad realization, but if mom and dad are busy or at work or helping with little brothers and sisters, the dog is very available, or the cat.

L. DiBello Well, and then they're also thinking about the fact that "I'm saying this aloud" so it would match with the read aloud strategy but it's really, they're thinking. They're thinking about it and saying it, and when you think about things and say things over and over, its going to stick.

Teacher 1 It also goes back to the cooperative learning. You remember $95 \%$ of what you teach someone else.

L. DiBello That's right.

Teacher 1 So they're pretending to teach the dog or the family pet. 
L. DiBello Right, that's true. I'm so glad you said that because it was on the tip of my tongue I wanted to tell you that the pets came up so often, it was so great.

Teacher 1 Well that came from me.

L. DiBello I know.

Teacher 1 That was one of my strategies. I still use it.

Clearly, this exchange between the researcher and Mrs. O supports the fact that reflective writing journals can facilitate the use of self-regulated learning strategies. However, the extent to which the journal promotes strategy use is contingent upon how much time and effort goes into it on behalf of the teacher and especially the students. To put this in context, recall that Mrs. M answered question 12 of the interview by stating that she didn't think "they truly got a sense of why they were doing it or what it was supposed to achieve" and that in the end she wished she could have "talked it more to the children." Both comments made by Mrs. M uphold the assertion that a journal can facilitate the use of strategies to the extent that they are supported by teachers, researchers and the learners themselves.

- Is the graphing assignment necessary to incorporate with the writing journal due to the developmental level of the students and the need for concrete reinforcement?

The answer to this research question lies in both the analysis of the writing journals and the teacher interviews. Given that both classes whose journals were analyzed received both the graphing component and the journal component, the teacher interviews will reveal the most with respect to determining the difference between the treatment groups. Furthermore, the teacher interviews were conducted with the teachers from all groups that 
participated with the writing journal in order to collect as much detail as possible regarding the differences which existed between the groups. Yet, the researcher would be overlooking some very important information if the journals themselves were not used in support of this question.

In analyzing this research question, the researcher first looked to the journal writing page for support. The first question which asks students "When I think about the grade I earned in math last week (check only one of the following):

-- I think I learned math better than I had planned

-- I think I learned math as well as I had planned

-- I did not learn math as well as I had planned speaks to this research question. An analysis of the journal pages submitted by the students shows that many of the students determined how well they had done in math the previous week based on the average obtained of their math grades. For example, a student wrote "no change, my line went up..." This student is indicating that he/she knows how well he/she did based on the score obtained which they recorded on their graph. The students in the journal only group did not average their math scores on a weekly basis and, as a result, they did not track the cumulative progress of their math scores. Therefore, no mention was ever made of a numerical score or average that may have improved on as a result of the application of a new learning strategy. This serves to support the notion that only those students in the graphing/journal groups could make this connection and that as a result of this more concrete exercise, the graphing component served to support the developmental need of the students in fourth grade to numerically 
track their progress. The research of Paris and Newman (1990) is upheld with these findings. Their research showed that preschool and elementary age children are typically more concerned with immediate feedback received from the teacher rather than how they themselves analyze and interpret their learning or achievement. Furthermore, the fact that their studies show an increase in self-reflection as students get older attests to the fact it was not inappropriate to believe that fourth graders could write and reflect upon their learning. It is not surprising that students often focused on the 'number' being affected because that was their concrete cue as to how they were doing.

The interviews conducted with the teachers shed much light on this research question and provided the concrete detail necessary to definitively frame an appropriate response to this question. The teacher that did not have both components (journal/graph) often alluded to the fact that her class was missing out on something. Mrs. M recalled

I don't think they had a true sense of the program because that's all they did was the journaling. I think that had they had the other component then there would have been more of a connection or more of a thing of how it all came together. Because they didn't quite get the connection between the...I don't think they truly got a sense of what they were doing it or what it was supposed to achieve.

Of course, the "journal only" teacher goes on to provide further evidence of a developmental nature when she asserts that the "success rate would be so much higher with middle school children."

This notion that older children would fare better with this type of study was also supported by the other teachers. Mrs. Q recalls that it was too time consuming for her group. The entire process was "very difficult for a lot of the students." She further notes that it was actually the graphing that caused her students a great deal of trouble, which in 
the end made the project more time consuming than perhaps she had originally intended.

Of course, she also noted the fact that this project took place in fourth grade which is the year for everything related to standardized testing in a Florida school! But, the most telling statement she made that stood in direct support of the need to support the developmental level of the students by providing both the graph and the journal came when she stated

I think I had it probably the best because we were doing both the journal and the graphing and then I heard... just the journals or just the graphing...I don't remember exactly what everybody was doing. It's just that I remember saying well maybe if we were doing the graphing or maybe if we were doing the journals... you know, so I think together it seemed to make a difference...

Mrs. O (journal and graph treatment), made it clear that the graph was a successful component of the project for her students. She discussed an important lesson her students learned as they tracked their grades each week.

Because a lot of students at that maturity age will receive one bad paper and they'd give up. They'd quit for whatever duration of time they feel was necessary for them to shut down and they realized that "just because I failed this test, if I average it in with the other ones, yes it does bring my average down, but next week if I study real hard then I can bring my average back up" and that was the power play that they had was in knowing that they had control of that little line that went up and down on the scale graph.

She made it quite clear that it worked to her advantage to have had both components of the study. Furthermore, she detailed the fact that she found the feedback that the students got from the graph to be very helpful to the students at her grade level. She even incorporated the concept in her new school with great success, focusing on the fact that the students required role models with these concepts. 
- Are Motivation scores, Metacognition scores, Standardized test scores (Total Math SAT's) predictive of what type of learner a student is: high self-regulated learning strategy user or low self-regulated learning strategy user?

In order to answer this research question, it required the researcher to obtain measures that were collected during the larger research study (Rendulic \& Terrell, 1999). It is important to note that an in-depth analysis of the obtained scores was available as a result of the larger study, however for purposes of the present study only the measures that are relevant with respect to answering this research question are addressed.

Given the results of the Rendulic and Terrell (1999) analyses, the researcher was aware of the possibility that perhaps a relationship existed between scores received on the math SAT or the metacognition instrument and the use of self-regulated learning strategies. With the literature establishing that self-regulators are more effective learners and a link exists with academic achievement (Butler \& Winne, 1995; Paris \& Newman, 1990; Zimmerman, 1989a; Zimmerman, Bandura \& Martinez-Pons, 1992) it seemed logical to hypothesize that perhaps these scores (math SAT, metacognitive and motivational) could possibly predict the type of learner each student was. To this end, the researcher originally intended to run a multiple regression analysis using the data collected for the larger study as the independent variables or predictor variables (Rendulic \& Terrell, 1999) and the "total strategy count" variable as the dependent variable. With the development of the SRLIS, the literature confirmed that highly self-regulated learners employed the use of more strategies (Zimmerman \& Martinez-Pons, 1986), so this justified the researcher's use of strategy counts as a measure of level of self-regulation. 
The preliminary analysis that is necessary to conduct before running a multiple regression for purposes of confirming or predicting helped the researcher determine that a multiple regression would not be the appropriate statistical technique to employ in the case of the present data. The preliminary analysis, as discussed in the Results section, revealed that there was no correlation between two of the three predictors and the dependent variable: the scores on the metacognitive instrument and the motivation instrument failed to independently yield a correlation with the dependent variable determined to establish the level of self-regulation (total strategies used). Although there was a significant correlation between the math SAT scores and the dependent variable and no evidence of mulitcollinearity, it was not appropriate to run a multiple regression analysis based on the requirements delineated by Stevens (1998). Therefore, the researcher yielded to the results of a simple regression analysis (Table 13) using the one predictor (Post-study math SAT Scores) that did meet the necessary pre-condition for further analysis. Interestingly enough, the simple regression did produce a significant finding which confirms the notion that achievement and self-regulation are related (Zimmerman, 1990). Perhaps further study as to a more appropriate instrument for measuring metacognition and motivation with young elementary school students is warranted in that the research could then progress to conducting a more in-depth analysis of predictors and their ability to estimate self-regulation.

- Based on Interviews with participating teachers: Are teachers who participated in the Sunshine FIU project more likely to employ learned strategies in the future? 
The literature supports the fact that teachers are a very important part of the learning process (Driscoll, 1994, p. 311). What goes on in classrooms around the world is dictated in part by the actions and beliefs of the teachers. As a result, this study chose to explore the component of teacher effect and efficacy through a particular lens which is focused on change. How likely were the teachers involved in the FIU research project to change their strategies and change their teaching methods in order to employ techniques supported by this study? How likely were the teachers to change their plans and methods of teaching to include a reflective writing journal component with their students or were they more likely to resist the change? More importantly, this question addresses the issue of how likely these teachers were to use the techniques they learned with future classes.

As stated in the question, the findings which support the answer to this research question are based directly on the interviews with the participating teachers. More specifically, the answers to questions 13,16 and 17 speak directly to this research question.

- Question 13--Have you found that having participated in the FIU project made a difference in your teaching methods? If yes, how so.

- Question 16--Have you considered incorporating a reflective writing journal into your curriculum?

- Question 17--Are there any aspects of the study that you have found yourself using since the study was completed? 
The answers provided by all three of the teachers in general reflect that all of them were effected in one way or another by the project. Of interest to the researcher was the level of interest expressed by the teachers and the opinions from each teacher as to how they were effected. All teachers do not participate with the same level of enthusiasm, and the researchers were aware of the level of commitment expressed by some. It is the purpose of this section of the analysis to use the responses provided by the teachers in order to paint a picture of how these teachers responded to the implementation of planned change of their programs.

In response to question 13, Mrs. O specifically addressed how she currently follows up every test with a scale on the board representing the distribution of scores attained. She discusses class standings with her students and then reminds students that "these are your numbers and where are you and where do you want to be, and what can you do if you want to be in the place that you're not?" She adds that she wants students "to be reflective of what's going on in the whole classroom because that's real life." The conversations with Mrs. O highlight the fact that she has changed her method of presenting test scores as a result of her participation in the project. Her answers to questions 16 and 17 further serve to support her overall commitment to the project. Mrs. O recalls that she has incorporated a self-tracking score sheet with her current class and that the class does keep a morning daily journal. Furthermore, she described in detail how she took a class of underachieving students and had them personally track their progress in order to motivate them to learn more and focus on the aspects of how to improve. The statements made by Mrs. O taken as a whole are reflective of the fact that she was 
extremely involved in the project and has changed as a result of having participated. This study supports the writings of Chin and Benne (1985) who suggest that you can appeal to people because you assume they are rational. In the case of this study, the lead researcher involved the teachers and helped them feel ownership of the project because he was aware of the fact that the success of the project depended highly on their support. Mrs. O corroborates this sentiment when she stated "we helped him design the surveys and the graph that he was going to use..." Chin and Benne (1985) would likely categorize Mrs. O as going beyond the level of "empirical-rational" and using strategies at the level where real change could take place: "normative re-educative" strategies, because of the fact that she is motivated by underlying beliefs and values and she worked collaboratively with the project.

Prior to having conducted the interviews there was a distinct feeling among the researchers that there was a difference in the way in which the teachers were implementing the project in their classrooms. The researchers arrived at that conclusion having participated in the journal writing sessions with the students, and after having analyzed some of the student journals to note the types of strategies the students were using and the detail in the plans. Yet, the interviews failed to significantly highlight some of the differences that the researchers were likely to assert. Nevertheless, an in depth look at some of the statements made by Mrs. M and Mrs. Q do point out a few of the distinctions that the researcher would like to make clear. The writings of Chin and Benne (1985) put this into perspective in that they discuss the three ways about which to implement change: empirical rational, normative re-educative and power coercive. We've established, based 
on the interview, that Mrs. O would likely fall into the normative re-educative category of strategy use because her answers indicate that she was truly involved in the project and she felt a sense of collaboration with the researchers beyond just the level of rational acceptance. It is also safe to acknowledge that the teachers were not employing "powercoercive" strategies in that they all acknowledged in the interviews that their participation was not mandatory but rather a voluntary project that they felt could benefit their students. So, the question now aims at establishing how Mrs. M and Mrs. Q would be categorized based on the Chin and Benne (1985) descriptions and, more importantly, how their answers during the interview support their further use of strategies learned based on having participated in the FIU study.

An in-depth look at the answers provided by Mrs. M show that she did continue to focus on having students set high goals. However, she stated that she does not have students write out their goals on a weekly basis as was presented in the study. Rather, she just states to the students "these need to be your goals and this is how you need to go about achieving them and then I'm constantly trying to get them to set goals." Therefore, in essence although she did recognize the importance of having students set goals she has not implemented any of the strategies or techniques she formally used from the study. Her answers to questions 16 and 17 also reflect this in that she claims not to have incorporated the use of a journal since the study and that she had forgotten about the techniques employed etc. The answers to these questions served to support the researchers notion that there was a difference between the teachers and their level of commitment to the study. The writings of Chin and Benne (1985) would likely categorize Mrs. M as 
employing strategies at the empirical-rational strategy level in that she agreed that their participation was voluntary and she alluded to the fact that the strategies being employed were important. Given the chance to participate in another study she states that she would because she believes it to be "beneficial".

The third teacher interviewed (Mrs. Q) was the second teacher from the combined treatment group. Similar to Mrs. M, we find that Mrs. Q asserts that having participated in the project helped her focus in on the importance of goal setting in the classroom. It helped her recognize the need to "be more specific". She further comments that she uses the goal setting component of the reflective writing journal to this day, and her students prepare a planner where they keep long-term and short-term goals. This coincides with Mrs. M's reflection that both teachers keyed in on the importance of this factor, yet neither one of them chose to continue a format that would help students write about learning strategy use. Ironically, when asked if there was any other aspect of the study that she found herself using since her participation in the project, she felt it was important to note that the graphing component she found to be too time consuming for her classroom. This happened to be the one factor that Mrs. M felt had prohibited her group from succeeding. She alluded twice in the interview to the fact that her group was missing a vital component and that this made things difficult for the students to understand. Yet, this missing piece was the same piece that Mrs. Q felt was difficult for the students to comprehend and that Mrs. O still successfully uses with low-achieving students. Using the criteria established by Benne and Chin (1985) the researcher is led to determine that both Mrs. Q and Mrs. M should be categorized as "empirical-rational" in their strategy use in 
that they both rationalize the need for participating in projects such as this one, yet they are still not convinced at a level where real change can take place.

The findings with respect to this research question are consistent with the findings from the literature. Gibson and Dembo (1985) found that teachers with high performance efficacy may believe that they are effective in their own classrooms but may not believe that working with other teachers in planning curriculum change will ultimately lead to any improvements. As a result, they have found that often there is resistance to participation in any change effort. The researcher found that all of the teachers participating in this project did have an interest in seeing the project work, yet they had issues as to how to implement the various components and, as a group, only one of the teachers has chosen to really continue the implementation of some of the pieces of the study. The interview did serve to remind Mrs. M of the goals of the project and follow-up conversations have found her implementing the reflective writing journal with her current group of sixth graders.

\section{Discussion of Findings Based on Subsidiary Questions}

- Do students who are identified as good self-regulators expect to do "as well or better" than they planned?

The analysis for this question required the researcher to establish first and foremost who the good self-regulators were and how many times throughout the study they answered the first question on the journal page by stating that they had "learned math better than they had planned" or "as well as they had planned." As the results represented in Table 17 portray, only six of the students in the good self-regulated learning group 
$(6 / 24$ or $25 \%)$ did not feel that they consistently learned math as well or better than they had planned at least half of the time. In other words, greater that $50 \%$ of the time at least three-quarters of the students in this group felt that they were learning math the way they had planned or better. This is significant in that it shows that good self regulators typically prepare themselves to learn the objectives they have planned and to also implement the strategies a good percentage of the time. It's important to note that good self-regulators also typically are quite perceptive and tend to be good monitors of their progress. This could mean that a good self-regulator expects more of him/herself and that he/she is likely to rate that they "did not do as well as planned" because they did not meet their own high criteria of $100 \%$ on the task. The literature put forth by Paris and Newman (1990) does support that fourth graders should be able to accurately reflect on the learning process and attempt to analyze and self-reflect as to why they did better or worse during specific academic challenges. Yet, Zimmerman (1990) makes clear that students who tend to be good self-regulators are high achievers that will create their own rewards and punishments to motivate their achievement. So, it can be likely that the percentages attained in this section of the analysis reflect the findings that the good self-regulators are high achievers that may also expect more from themselves during the learning process. Hence, not all good self-regulators expect to do as well or better than planned every week of the study. Yet, a higher percentage of the time they will be meeting their own expectations as a result of their desire to meet their objectives.

- Do students who are identified as good self-regulators recognize specific strategies that helped them do well? 
The answer to this subsidiary question lies in the reflective writing journals

prepared by the students. In order to conduct an appropriate analysis of the data for the purpose of answering the second, third, fourth and fifth subsidiary questions it is necessary to look directly at the reflective writing journals of the students. Each of the four questions focused on determining a pattern for the way in which good self-regulators employed learning strategies across time. Due to the fact, that there were twenty-four students identified as being good self-regulators the researcher randomly selected a few from this group to detail in order to support the position established by the data. The second subsidiary question asked the researcher to find data to support whether or not good self-regulators recognize specific strategies that helped them do well.

As mentioned previously, two-thirds of the good self-regulators were in Mrs. O's class. A random sample of the good self-regulators from her group revealed that although some of the answers were similar, the students typically wrote in their own words what strategies helped them to learn. Answers included:

"Did my math with my mom and she help me".

"I listen in class".

"I do all my homework and turn it in".

"I learned shapes and angles. I listened".

"Doing my best. Handing in my work".

Typically, a pattern existed in that a good majority of the students took the time to detail at least one thing that helped them. The pattern of responses was clearly different 
for those randomly sampled from Mrs. Q's class. Here the students answered typically in one or two word summaries about what helped them do well:

"Study more".

"Practice".

"Study".

"Ask for help".

"Pay itenshon"(sic).

Of major importance to note is the fact that although the classes typically answered differently, as a whole they were very different from the group identified as low selfregulators. As expected, the low group rarely identified what helped them learn and more often than not their journal pages reflected just plans for the upcoming week (as previously noted, this component of the journal was teacher guided and expected to yield high correlation rates within each class).

- For good self-regulators, do their strategies change across time with respect to why they did better?

The third subsidiary question had the researcher look at what types of strategies students claimed to have used across time, for a week in which they felt they did "better than planned". For this question, the researcher looked at a group of randomly selected students from each class. Then, the researcher looked at each week in which the student felt they had learned math "better" than they had planned in order to determine if the strategies that helped them learn were similar. Interestingly enough, the students from Mrs. O's class did not show a similar pattern across students and time. They tended to 
change their strategies across time, which of course was to be expected in that the literature supports the fact that good self-regulators are in touch with their learning objectives and the strategies that worked for them (Bandura, 1986; Butler \& Winne, 1995; Zimmerman, 1989a). However, the researcher expected to see the same outcome from the journals produced from the good self-regulators in Mrs. Q's class and this was not the case. The students did not typically change their strategies across time and they were regularly one-word responses. This could be a result of less time dedicated to the project in this class, wherein the students did not feel they had time to elaborate their positions in their journal. Or, this finding could be a result of a teacher effect in which students responded to modeling provided in their class setting. Regardless of the cause, the finding was certainly not supported in the literature.

- For different objectives do they recognize the need to use different strategies?

The literature maintains that good self-regulators note the need to employ different strategies in order to master different objectives. "Undoubtedly, all learners use regulatory processes to some degree, but self-regulated learners are distinguished by (a) their awareness of strategic relations between regulatory processes or responses and learning outcomes and (b) their use of these strategies to achieve their academic goals" (Zimmerman, 1990, p. 5). Therefore, we would expect the reflective writing journals to show how students adjust their choice of strategy (for the repair plan in question five of the journal) to connect with the intended objective. This would establish the relationship that the literature notes must exist (van Kraayenoord \& Paris, 1997). 
As expected there did appear to be a change in intended strategy use when there was a change in the plan for learning math. The researcher could see that the students in both Mrs. O's class and Mrs. Q's class wrote their math plans as a group and then brainstormed ideas for meeting these objectives. Every student did not always follow the plan, in fact some weeks students had different plans and different repair strategies cited. Of particular interest is the fact that many of the good self-regulators felt it was important to repeat repair strategies on a weekly basis. Often there would be the same things written for number five in the journal across all nine weeks of the semester and then students would use the last couple of lines to add what they had discussed in class as support. For example, a particular student in Mrs. O's class, that was identified as a good self-regulated learner, listed as her intended plan every week to "do homework, do classwork, listen and study". Without fail, these four things were consistently written as part of her plan, yet being the good self-regulator that she is, she often added a special strategy that related directly to the plan for the week. For instance, on the week in which the plan included "measurement" she added to the plan that she would work with a "ruler." This was a typical response for the high self-regulating students. They had their core set of strategies from which they would deviate in order to meet the needs of the new objective.

- For good self-regulators, when they recognize that they "did not do as well as planned", what did they pinpoint as reasons why?

As expected, good-self regulators did not often rate themselves as not doing as well as planned. This was an atypical response for this group of students in that their desire to always think about the appropriate strategies to use each week often kept them 
from having a week in which they did not do as well as planned. This is not to say that good self-regulators always did "as well or better" than planned. In fact, Table 12 reflects that such is not the case. However, more often than not if the good self-regulators did not answer that they had done "as well or better" than planned it was not because they "did not do as well as planned", but rather that they did not answer the question at all and therefore it could not be coded. Nevertheless, there were a handful of times in which this group of students did feel the need to answer that they had not done as well as planned. In these cases, the researcher noted that the students typically were able to identify many reasons which may have led them to this predicament. The reasons given were almost always a result of outside influences on the ability of the student to study or complete his/her work. For example, the following reasons were cited by good self-regulators as reasons why they did not do as well:

"Watched TV".

"Played with my dog".

"I went downtown". "Play".

"Did not bring home my math book".

The analysis of this question brought to light the fact that the students in Mrs. Q's class often wrote that "nothing" (or "none") prevented them from learning. It is unclear if this was a direct result of a class decision to speed up the journal writing process or if the students came to the decision on their own to consistently write the same answer on a weekly basis regardless of how they felt they had learned math for the week. One would 
expect that if the student answered that they "did not learn math as they had planned" that they could or would at least occasionally recall why this may be the case. Yet, the researcher can only speculate from the interview that had been conducted that the students in Mrs. Q's class were pressed for time and this was their way of meeting the time requirement and the obligation to write in the journal. The literature review on motivation serves as support of the findings for this question in that typically good self-regulators are intrinsically motivated and evaluate their own work without adult intervention (Pintrich \& DeGroot, 1990). However, even the best self-regulators must receive some type of motivation to respond in an appropriate manner and perhaps the reflective writing journal task did not often provide an appropriate amount of feedback in that the teachers did not read them. Furthermore, the journal writing continued over eighteen weeks and there was a marked decrease in strategy use and journal writing at the end of every semester. This probably reflects the fact that both the students and the teachers were losing interest in the study and they found it difficult to continuously participate at a high level of enthusiasm; or that the teachers and students were effected by outside pressures to perform well on standardized tests (accountability), so their priorities were elsewhere.

\section{Limitations of the Study}

Several limitations must be taken into consideration when examining the findings of this research study. The most important limitation is the ex post facto nature of this investigation. This lessened the degree of control in the study as the researcher was unable to manipulate the independent variable. Furthermore, although there was a natural comparison group (Mrs. M's) class that only received the journal component of the study, 
the data was unavailable to the researcher and therefore a comparison between the graphing/journal and journal only groups could not be made. The retrospective analysis did reveal many important aspects in relation to implementing a reflective writing journal with young elementary school students. However, the inability to compare treatment groups limited the types of analyses that could be conducted.

This study was also limited by the population that was investigated. The subjects selected were limited to students enrolled in fourth grade at one elementary school in Broward County. Furthermore, the teachers who participated (although they did so voluntarily) were limited to the teachers employed by the elementary school. Two of the three teachers involved in the journal component of the study did not return to this elementary school in the subsequent Fall semester and this made it quite difficult to follow-up with the teachers in order to conduct the interviews. The time lapse between the project participation and the follow-up interviews was certainly a factor that the researcher had to keep in mind when discussing the study and subsequently analyzing the data.

Conclusions and Implications

Based on the findings of this investigation, this researcher concluded that the implementation of a reflective writing journal appears to support the use of self-regulated learning strategies with elementary school students to the extent that the students are engaged in the journaling process. The use of the reflective writing journal afforded these students the opportunity to think about their progress in mathematics for two full semesters and to analyze their strategy-use for the purpose of isolating skills which led to 
their success or failure. In analyzing the data, the researcher came upon two distinct issues which are of consequence. First, and foremost is the issue of how well the reflective writing journal met the goal of increasing self-regulation in fourth grade students. But, also the findings with respect to teacher-regulation are worth noting; in that somewhere within the interaction of these findings (teacher and self-regulation), lies the merit of this study. Although it was not an intended area of research at the outset of this study, it is acknowledged that Teacher-Regulated Learning became an issue to address, along with the intended area of Self-Regulated Learning.

\section{Teacher-Regulated Learning}

Teachers routinely provide a great deal of assistance to young students. The concept of Teacher-Regulated Learning would focus on this aspect of teacher as guide or facilitator of the learning process. Ashton and Webb (1986) define "teaching efficacy" as the "expectation that teaching can influence student learning... despite external obstacles such as family background and student ability" (p. 6). The work of Bandura (1986) in which he presents his notion of "triadic reciprocality" speaks directly to this issue of teacher-regulated learning. He views human functioning as a series of reciprocal interactions between behavioral, environmental, and personal variables.

As students work on mathematical tasks (behavior) they mentally note their progress (personal variable), which conveys to them that they are capable of learning and raises their self-efficacy. An example of the influence of environment on behavior occurs when teachers introduce an unusual mathematical formula (environmental variable) and students direct their attention toward it (behavior). Behavior can also affect the environment. If students act bewildered by a teacher's explanation (behavior), the teacher may reteach the material (environmental variable). (Schunk, 1998, p. 139) 
For purposes of this study the triadic relationship could be established between the behavioral (math scores), the personal (student journals) and the environmental (the teachers). This accurately assesses the findings of the researcher, in that the separation of the three components is quite difficult to analyze, due to the fact that there is a very important relationship which exists.

The researcher found that the reflective writing journals were implemented in a variety of ways. Although the researchers were present on a weekly basis for the first semester of the study to ensure that the treatment groups were receiving the same instruction, level of enthusiasm, etc. It remained clear from analyses of the journals and teacher interviews that each classroom had its own way of implementing the study and delivering the components to the students. These findings are not surprising in that the literature supports the fact that motivation can be an important factor in school classrooms (Bandura, 1997; Schunk, 1990). The area of research in Social Learning Theory supports this as well (Bandura, 1986). Students are motivated by the teacher and surrounding peer group with which they work. Findings with respect to motivation and feedback imply that a researcher must always keep in mind teacher effect and create a study that controls for this factor, knowing fully that there is a point where the researcher can no longer control but rather must guide those involved in order to ensure their participation at a highly motivated level.

Interestingly enough, it was the teacher interview component of this study that shed an interesting light on the findings. Clearly, Mrs. O was highly engaged in the research project and her students reflected a higher rate of strategy use across the eighteen 
weeks. This implies that often a teacher can dictate the success/failure of a research project. Nevertheless, the interviews also revealed positive insights from the two other teachers that were engaged in the project. The teacher that received both treatments (Mrs. Q) still espouses the importance of having students prepare goals and objectives and the teacher that only received the journal treatment also claims that setting goals is a factor for her current middle school students. Probably the most important factor that came into play with the interviews was the fact that each of the three teachers seemed to express an interest in continuing the role of the journal with their current students. In fact, one of the teachers requested an old journal page in order to begin implementation with her middle school students as soon as possible. It seems, the follow-up aspect of the study has had an even greater effect in that all three of the teachers were engaged in a reflection about the study that has motivated them to search for new ways of improving their current teaching strategies. This finding implies that although research does not always end with the intended results, there are always factors that make the participation in a project worth the effort.

Self-Regulated Learning

The findings with respect to strategy use were supported by previous studies that showed students at this developmental level are capable of learning to self-regulate their skills (Paris \& Newman, 1990; van Kraayenoord \& Paris, 1997; Zimmerman, 1998). The nature of the journal supported the use of strategies on a weekly basis by the students and provided the classes with opportunities to engage in dialogue with respect to what helped them to learn. This metacognitive piece of the study was highly effective in that the 
researcher could conclude that for eighteen straight weeks these students were engaged in an activity that required them to think about their learning. The findings showed that although there was a drop off each semester in the level of strategies employed, there was still evidence that a significant amount of reflection was taking place in each of these classes.

Self-reflective practice allows learners to monitor, evaluate, and adjust their performances during learning. This study found that through the use of a journal, learners were capable of adjusting their strategies based on weekly assessments of their learning progress and therefore they were in control of determining what activities would best assist them in accomplishing their learning goals. Studies conducted by Schunk (1998) came to similar conclusions in that he states, "results suggest that modeled strategy instruction, learning goals, and opportunities for self-evaluation help to focus children's attention on the task and direct their self-regulation of problem-solving strategies" (p. $153)$.

A definite link can be made between the use of a reflective writing journal and the increase in self-regulatory skills with young children. This study highlights the fact that young students can recognize that strategies such as "completing homework" or "studying" can have a positive effect on their weekly mathematics scores. Conversely, the journal reveals that these students are also capable of recollecting certain things which may not have contributed to their learning, such as "playing too much" or "watching tv." Furthermore, these students were afforded the opportunity of expressing their weekly goals in mathematics, for which past research (Schunk, 1996b) has indicated very positive 
results. Goal orientations help students focus in on their intentions for learning, and they most definitely cue students as to the tasks which are important for learning. Lastly, the journal provided students with the opportunity to devise a repair strategy for continued improvement in the learning process. The analysis revealed that although most students viewed parental involvement as an important strategy for continued success in the learning process, they most definitely shifted the responsibility of learning onto themselves as the study continued and they were more likely to list the importance of completing homework and classwork or listening in class.

The use of this reflective writing journal provided a model for supporting selfregulation and feedback with young children. For students who were found to be "highly" self regulated, it was shown to support their use of strategies and afforded them just another way of attaining success within the school day. However, for students who initially struggled with the assignment, the reflective writing journal most definitely provided them a schema from which to begin to organize their thinking. Schunk (1998) found that external monitoring (teacher-regulated learning) requires teacher assistance, which limits the benefits of self-directed practice. However, teaching self-monitoring, as supported by the reflective writing journal, would have the opposite effect in that the students could work independently at achieving a positive outcome.

Self-monitoring also can help promote long-term maintenance of selfregulatory strategy use. Much strategy instruction research shows that students may learn and practice strategies that benefit their performance but may discontinue strategy use when no longer required. The may believe that the strategy is not useful in improving their performances. Students who continue to monitor and record their use of strategies should be less apt to discontinue their use. (Schunk, 1998, p. 153) 
Most definitely, the length for which this study was conducted (eighteen weeks) sustained the use of many positive strategy uses and allowed for students to almost habitually engage in the journaling process. As the journals and interviews showed, this ultimately had two effect--some students found that engaging in the process was no problem and they happily shared their thoughts and strategies. Whereas, others found that this was not a process that they enjoyed participating in and they ultimately began leaving journal entries blank or just repeatedly writing the same strategy for the sake of filling in the blanks. It is the researcher's contention that in this case the presence (enthusiasm) of the teacher made a great deal of difference, hence the prior discussion based on teacher efficacy and elements of change.

\section{Recommendations for Further Research}

Educators are currently in search of ways to enhance a learning environment so that it is supportive of learners that accept responsibility for their own learning. The reflective writing journal provides a probe and a model for young learners that are in need of guidance when it comes to self-regulating their learning. The findings from the study could give insight for further research in the following areas:

1. Further research should be conducted using the reflective writing journal without the graphing component. The interviews revealed that there was a sense of isolation for the teacher that received this treatment solely. This supports the need to conduct this research at two concurrent school sites (with the populations matched as closely as possible), with each school site receiving the same treatment (either journal only or journal with the graph). This would allow teachers to increase communication regarding the 
project, as opposed to creating an atmosphere in which teachers do not feel equal or a part of the same project.

2. A longitudinal study should be conducted which allows for the researcher to measure the effects of the reflective writing journal across time. The interviews with the teachers revealed that a great deal of information is retained by the participants across time and therefore this would allow researchers to trace effects on their school grades, etc. 3. As suggested by the teachers, this study should be replicated with older students to determine if many of the issues which emerged (graphing too difficult, too time consuming, etc.) are a direct result of the fourth graders' inability to developmentally handle such a complex task.

4. Further research is needed to establish if the use of the SRLIS is feasible with younger students. The current study only chose to use the established categories of strategy use to help prepare the data recording instrument for the researcher. Actual use of the SRLIS was not attempted, yet the literature establishes that the instrument is valid and reliable for older students.

5. Replication of this study is also recommended with a different student population. The current study attempted to implement the reflective writing journal in order to teach self-regulating skills to students who traditionally do not make use of their learning strategies. It would be relevant to the literature to establish if students from different socioeconomic backgrounds would have similar experiences. 
Ashton, P. T., \& Webb, R. B. (1986). Making a difference: Teachers' sense of efficacy and student achievement. New York: Longman.

Bandura, A. (1986). Social foundations of thought and action: A social cognitive theory. Englewood Cliffs, NJ: Prentice-Hall.

Bandura, A. (1997) . Self-efficacy: The exercise of control . New York, NY: W.H. Freeman \& Co.

Bartlett, F. C. (1932). Remembering: A study in experimental and social psychology. Cambridge, England: Cambridge University Press.

Bennis, W. G., Benne, K. D. \& Chin, R. (1985). The planning of change. New York: Holt, Rinehart, and Winston.

Berliner, D. C. \& Rosenshine, B. V. (Eds.). (1987). Talks to teachers. New York, NY: Random House, Inc.

Bliss, J., Monk, M. \& Ogborn, J. (1983). Qualitative data analysis for educational research: A guide to uses of systemic networks. London: Croom Helm.

Bredekamp, S. \& Copple, C. (1997). Developmentally appropriate practice in early childhood programs. Washington, DC: NAEYC.

Brophy, J. (1987) . On motivating students. In D. E. Berliner \& B. V. Rosenshine (Eds.), Talks to Teachers (pp. 201-288). New York, NY: Random House, Inc.

Broward County Public Schools (2000). About BCPS. http://www.browardschools.com/about/index.htm

Brown, A. L. (1982). Learning and development: The problem of compatibility, access, and induction. Human Development, 25, $89-115$.

Brown, A. (1987) . Metacognition, executive control, self-regulation, and other more mysterious mechanisms. In Weinert, F. E. \& Kluwe, R. H. (Eds.), Metacognition, motivation and understanding (pp. 65 - 116). Hillsdale, N.J.: Lawrence Erlbaum Associates, Inc.

Brown, A. L. \& Campione, J. C. (1981). Inducing flexible thinking: A problem of access. In M. Friedman, J. P. Das, \& N. O'Connor (Eds.), Intelligence and learning (pp. 515 - 530). New York: Plenum Press. 
Butler, D. L. , \& Winne, P. H. (1995) . Feedback and self-regulated learning: A theoretical synthesis. Review of Educational Research, 65(3), $245-281$.

Carver \& Scheier (1981). Attention and self-regulation: A control-theory approach to human behavior. New York: Springer-Verlag.

Carr, M. (1996). Teaching children to self-regulate: A resource for teachers (Instructional Resource No. 34). (ERIC Document Reproduction Service No. ED 400 517)

Chin, R. \& Benne, K. D. (1985). In Bennis, W. G., Benne, K. D. \& Chin, R. (Eds.), The planning of change (pp. 36 - 125). New York: Holt, Rinehart, and Winston.

Cole, P. (1994, February). A cognitive model of journal writing. A paper presented at the 16th Annual National Convention of the Association for Educational Communication and Technology sponsored by the Research and Theory Division in Nashville, TN.

Corno, L. (1987) . Teaching and self-regulated learning. In Berliner, D. \& Rosenshine, B. V. (Eds.), Talks to teachers (pp. 150 - 182). New York, NY: Random House, Inc.

Cremin, L. A. (1957). The republic and the school: Horace Mann on the education of free man. New York, NY: Teacher's College Press.

Cremin, L. A. (1959). Dewey on education: Selections. New York: Teacher's College Press.

Csikszentmihalyi, M. \& Csikszentmihalyi, I. S. (1988). Optimal experience: Psychological studies of flow in consciousness. Cambridge, NY: Cambridge University Press.

Derry, S. J., \& Murphy, D. A. (1986). Designing systems that train learning ability: From theory to practice. Review of Educational Research, 56, 1 - 39 .

Driscoll, M. P. (1994). Psychology of learning for instruction. Needham Heights, MA: Allyn \& Bacon.

Duell, O. K. (1986). Metacognitive skills. In G. D. Phye and T. Andre (Eds.), Cognitive classroom learning (pp. 62 - 97). Orlando: Academic Press.

Feather, N. T. (1966). Effects of prior success and failure on expectations of success and subsequent performance. Journal of Personality and Social Psychology, 3, 287 - 298 . 
Flavell, J. H., Friedrichs, A. G. \& Hoyt, J. D. (1970) . Developmental changes in memorization processes. Cognitive Psychology, 1, $324-340$.

Flavell, (1979). Metacognition and cognitive monitoring: A new area of psychological inquiry. American Psychologist, 34, 906 - 911.

Gagné, R. M., \& Driscoll, M. P. (1988). Essentials of learning for instruction ( $2^{\text {nd }}$ ed.). Englewood Cliffs, NJ: Prentice-Hall.

Garcia, T. \& Pintrich, P. R. (1994). Regulating motivation and cognition in the classroom: The role of self-schemas and self-regulatory strategies. In D. H. Schunk \& B. J. Zimmerman (Eds.), Self-regulation of learning and performance: Issues and educational applications (pp. 127 -253). Hillsdale, NJ: Erlbaum.

Gardner, H. (1978). Commentary on animal awareness papers. Behavioral and Brain Sciences, 4, 572 .

Ghatala, E. S., Levin, J. R., Pressley, M., \& Goodwin, D. (1986). A componential analysis of the effects derived and supplied strategy-utility information on children's strategy selections. Journal of Experimental Psychology, 41, 76 -92.

Gibson, S. \& Dembo, M. H. (1984). Teacher efficacy: A construct validation. Journal of Educational Psychology, 76(4), 569 - 582.

Gibson, S. \& Dembo, M. H. (1985). Teacher's sense of efficacy: An important factor in school. Elementary School Journal, 86(2), 173 - 184.

Gray, S. S. (1991). Ideas in practice: Metacognition and mathematical problem solving. Journal of Developmental Education, 14(3), 24 - 28.

Haladyna, T. , Haas, N. \& Allison, J. (1998). Continuing tensions in standardized testing. Childhood Education, 74(5), $262-273$.

Hofer, B. K, Yu, S. L., \& Pintrich, P. R. (1998). Teaching college students to be self-regulated learners. In D. H. Schunk \& B. J. Zimmerman (Eds.), Self-regulated learning: From teaching to self-reflective practice. (pp. $57-85$ ). New York, NY: The Guilford Press.

Kinnear, P. R. \& Gray, C. D. (1994). SPSS for windows made simple. East Sussex, UK: Psychology Press.

Klein, D. (1966). Community dynamics and mental health. New York: Wiley. 
Kluger, A. N. \& DeNisi, A. (1998). Feedback interventions: Toward the understanding of a double-edged sword. Current Directions in Psychological Science, 7(3), $67-72$.

Krueger, D. W. (1990). Success and success inhibition. In R. J. Sternberg \& J. Kolligian (Eds.), Competence considered (pp. 246 - 260). New Haven: Yale University Press.

Kurtz, B. E. \& Borkowski, J. G. (1984). Children's metacognition: Exploring relations among knowledge, process, and motivational variables. Journal of Experimental Child Psychology, 37(2), $335-354$.

Markus, H., Cross, S., \& Wurf, E. (1990). The role of the self-system in competence. In R. J. Sternberg \& J. Kolligian (Eds.), Competence considered (pp. 205 225). New Haven: Yale University Press.

McCombs, B. L. (1989). Self-regulated learning and academic achievement: A phenomenological view. In B. J. Zimmerman \& D. H. Schunk (Eds.), Self-regulated learning and academic achievement: Theory, research, and practice (pp. 27 - 50). New York: Springer-Verlag.

McLaughlin, M. W. \& Berman, P. (1977). The art of retooling educational staff development in a period of retrenchment. Santa Monica, CA: Rand Corporation.

Meyer, L. (1986). Strategies for correcting students' wrong responses. Elementary School Journal, 87, 227 - 241.

Mish, F. C. et al. (Eds.). (1985). Webster's ninth new collegiate dictionary. Springfield, MA: Merriam-Webster Inc.

National Commission on Excellence in Education. (NCEE). (1983). A nation at risk: The imperative for educational reform. Washington, DC: U. S. Government Printing Office.

Norem, J. K. \& Cantor, N. (1990). Cognitive strategies, coping, and perceptions of competence. In R. J. Sternberg \& J. Kolligian (Eds.), Competence considered (pp. 190 - 204). New Haven: Yale University Press.

Palincsar, A. S., \& Brown, A. L. (1984). Reciprocal teaching of comprehensionfostering and monitoring activities. Cognition and Instruction, 1, 117 - 175.

Paris, S. G., Cross, D. R., \& Lipson, M. Y. (1984) . Informed strategies for learning: A program to improve children's reading awareness and comprehension. Journal of Educational Psychology, 76, 1239 - 1252. 
Paris, S. G. \& Newman, R. S. (1990). Developmental aspects of self-regulated learning. Educational Psychologist, 25(1), 87 - 102.

Piaget, J. (1969). Science of education and the psychology of the child. New York: Viking Press.

Piaget, J. (1976). The grasp of consciousness: Action and concept in the young child. Cambridge, MA: Harvard University Press.

Pintrich, P. R., \& De Groot, E. V. (1990). Motivational and self-regulated learning components of classroom academic performance. Journal of Educational Psychology, 82, $33-40$.

Pintrich, P. R. (1991). A manual for the use of the motivated strategies for learning questionnaire (mslq) (Reprinted from the National Center for Research to Improve Postsecondary Teaching and Learning Project on Instructional Processes and Educational Outcomes). (ERIC Document Reproduction Service No. ED 338 122)

Pressley, M., Ross, K. A., Levin, J. R., \& Ghatala, E. S. (1984) . The role of strategy utility knowledge in children's strategy decision making. Journal of Experimental Child Psychology, 38, 491 - 504.

Pressley, M. \& McCormick, C. B. (1995) . Cognition, teaching, and assessment. New York, NY: HarperCollins College Publishers.

Pylyshyn, Z. (1978). Computational models and empirical constraints. The Behavioral and Brain Sciences, 1, 93 - 99.

Rendulic, P. A., \& Terrell, S. R. (1997a, April). A 5-Year Investigation of Alternative formats of Classroom Feedback: Toward a Conceptual Framework of Applied Motivational Theory. Paper presented at the Annual Meeting of the American Educational Research Association, Chicago, IL.

Rendulic, P. A., \& Terrell, S. R. (1997b). Linking classroom assessment in instruction and learning: The need for administrative support. FASCD Policy Review, $\underline{5}(2), 3-8$.

Rendulic, P. A. \& Terrell, S. R. (1999, April). The Effect of Self-Generated Feedback on Students' Learning. Paper presented at the Annual Conference of the American Educational Research Association, Montreal, Canada.

Rosenshine, B. V. (1987). Explicit teaching. In D. Berliner \& B. V. Rosenshine (Eds.), Talks to Teachers (pp. 51 - 86). New York: 
Rozin, P. (1976). The evolution of intelligence and access to the cognitive unconscious. Progression in Psychobiology and Physiological Psychology, 6, 245 - 280.

Schunk, D. H. (1982). Effects of effort attributional feedback on children's perceived self-efficacy and achievement. Journal of Educational Psychology, 74(4), 548 556.

Schunk, D. H. (1984). The self-efficacy perspective on achievement behavior. Educational Psychologist, 19, 199 - 218.

Schunk, D. H. (1990) . Goal setting and self-efficacy during self-regulated learning. Educational Psychologist, 25(1), 71 - 86.

Schunk, D. H. \& Zimmerman, B. J. (Eds.). (1994). Self-regulation of learning and performance: Issues and applications. Hillsdale, NJ: Erlbaum.

Schunk, D. H. (1996, October). Self-evaluation and self-regulated learning. Paper presented at the Graduate School and University Center, City University of New York, NY.

Schunk, D. H. (1996b). Goal and self-evaluative influences during children's cognitive skill learning. American Educational Research Journal, 33, 359 - 382.

Schunk, D. H. (1997, March). Self-monitoring as a motivator during instruction with elementary school students. Paper presented at the Annual Meeting of the American Educational Research Association, Chicago, IL.

Schunk, D. H. (1998) . Teaching elementary students to self-regulate practice of mathematical skills with modeling. In D. H. Schunk \& B. J. Zimmerman (Eds.), Selfregulated learning: From teaching to self-reflective practice. (pp. 137 -159). New York, NY: The Guilford Press.

Sink, C. A. (1991, April). Self-regulated learning and academic performance in middle school children. Paper presented at the Annual Meeting of the American Educational Research Association in Chicago, IL. (ERIC Document Reproduction Service ED 334 270)

Sternberg, R. J. \& Kolligian, J. (Eds.). (1990). Competence considered. New Haven: Yale University Press.

Stevens, J. (1990) . Intermediate statistics: A modern approach. Hillsdale, NJ: Lawrence Erlbaum Associates. 
Stevens, J. (1998). Applied multivariate statistics for the social sciences. (3rd ed.). Mahwah, NJ: Lawrence Ehrlbaum Associates.

Terrell, S. R., Greenberg, B., \& Rendulic, P. A. (1995). The Use of Technology to Increase Achievement in Elementary School Children. Proceedings of the 13th Annual Conference of the Society for Applied Learning and Technology, Kissimmee, FL.

Terrell, S. R. \& Rendulic, P. A. (1996). Using computer-managed instructional software to increase motivation and achievement in elementary school children. Journal of Research on Computing in Technology, 28(3), 403 - 414.

U. S. Department of Education. (USDE). (1991). America 2000: An education strategy. Washington, DC: U.S. Government Printing Office.

van Kraayenoord, C. E. \& Paris, S. G. (1997). Australian students' self-appraisal of their work samples and academic progress. The Elementary School Journal, 97(5), $523-537$.

Vygotsky, L. S. (1978). Mind in society: The development of higher psychological processes. Cambridge, MA: Harvard University Press.

Weiner, B. (1990) . History of motivational research in education. Journal of Educational Psychology, 82, 616 - 622.

Weinert, F. E. \& Kluwe, R. H. (1987). Metacognition, motivation and understanding. Hillsdale, N.J.: Lawrence Erlbaum Associates, Inc.

Winne, P. H. (1997a). Experimenting to bootstrap self-regulated learning. Journal of Educational Psychology, 89, 397 - 410.

Winne, P. H. \& Hadwin, A. F. (1997b). Studying as self-regulated learning. In D. J. Hacker, J. Dunlosky, \& A. C. Graesser (Eds.), Metacognition in educational theory and practice (pp. 279 - 306). Hillsdale, NJ: Erlbaum.

Zimmerman, B. J. (1989a). Models of self-regulated learning and academic achievement. In B. J. Zimmerman \& D. H. Schunk (Eds.). Self-regulated learning and academic achievement: Theory, research, and practice. (pp. 1 - 26). New York, NY: Springer-Verlag.

Zimmerman, B. J. (1989b ). A social cognitive view of self-regulated academic learning. Journal of Educational Psychology, 81(3), 329 - 339.

Zimmerman, B. J. (1990) . Self-regulated learning and academic achievement. Educational Psychologist, 25(1), 3 - 17. 
Zimmerman, B. J. (1998). Developing self-fulfilling cycles of academic regulation: An analysis of exemplary instructional models. In D. H. Schunk \& B. J. Zimmerman (Eds.). Self-regulated learning. (pp. 1 - 19). New York, NY: The Guilford Press.

Zimmerman, B. J. (2000, April). In search of academic self-regulation: A social cognitive journey. Paper presented at the Scribner Award Address at the meeting of the American Educational Research Association, New Orleans, LA.

Zimmerman, B. J., Bandura, A. \& Martinez-Pons, M. (1992). Self-motivation for academic attainment: The role of self-efficacy beliefs and personal goal setting. American Educational Research Journal, 29(3), 663 - 676.

Zimmerman, B. J. \& Martinez-Pons, M. (1986) . Development of a structured interview for assessing student use of self-regulated learning strategies. American Educational Research Journal, 23(4), 614 - 628.

Zimmerman, B. J. \& Martinez-Pons, M. (1988) . Construct validation of a strategy model of student self-regulated learning. Journal of Educational Psychology, $\underline{80}(3), 284-290$.

Zimmerman, B. J. \& Schunk, D. H. (1989c). Self-regulated learning and academic achievement: Theory, research, and practice. New York: Springer-Verlag. 
APPENDICES 
Appendix A -- Reflective Writing Journal Page 


\section{Sunshine Elementary School - FIU Research Project \\ Reflective Writing Journal \\ Weekly Entry - Week 1}

Look back at what you wrote last week about learning math. Think about what you actually did last week to help yourself learn math and think about how well you did in math. Do you think you did well or do you think you could have done better? Ask yourself each of the following questions and write out your answers in the space provided. Remember, there are no right or wrong answers.

1. When I think about the grade I earned in math last week (check only one of the following):

-- I I think I learned math better than I had planned

-- I Ihink I learned math as well as I had planned

-- I did not learn math as well as I had planned

2. When I think about how well I did in math last week, these are the things I did that helped me to learn:
A.
B.
C.
D.

3. When I think about how well I did in math last week, these are the things I did that did not help me to learn:
A.
B.
C.
D.

4. I plan to learn the following in math this week:

5. When thinking about how I learn best, I plan to do the following things this week when I am learning math.
A.
B.
C.
D.
E.
F. 
Appendix B -- Teacher Interview Questions 


\section{Teacher Interview Questions}

1. Tell us a little about yourself. Please state your name and give us some background on your teaching experience. How long have you been a teacher? What grade levels have you taught? What area do you hold your teaching certification in? etc...

2. What do you recall about having participated in the Sunshine Elementary School FIU Project?

3. Was your participation in the project/study mandatory or voluntary?

4. Can you tell us in your own words what you believe the study was about?

5. Do you recall how much time you would spend on average each week with the reflective writing journals?

6. How did you plan for the journal writing assignment? How did you actually use it?

7. How did the students use the journal? Did they make use of it at other times or only when required? 
8. On a scale of 1 to 5 (with 5 being very enthusiastic and 1 being not at all enthusiastic), How enthusiastic do you believe the students were about the reflective journal writing assignment? Can you give examples as to why you got this impression?

9. On a scale of 1 to 5 (with 5 being very enthusiastic and 1 being not at all enthusiastic), How enthusiastic do you believe the teachers were about the reflective journal writing assignment? Can you give examples as to why you got this impression?

10. Did you talk about this project amongst yourselves? (Share anecdotes, planning ideas, etc...?)

11. Reflecting back on your students, can you recall a particular child who may have benefited from the reflective journal writing assignment?

12. For your class as a whole, do you believe that the reflective writing journal was or was not beneficial? Please explain.

13. Have you found that having participated in the FIU project made a difference in your teaching methods? If yes, how so.

14. Take a look at one of the Reflective Writing Journal pages. Students typically had the opportunity to reflect every week on their plans and objectives for mathematics. Did you find it helpful having students reflect upon their goals for the week? 
15. How do you think that the other teachers who participated in the project benefited?

16. Have you considered incorporating a reflective writing journal into your curriculum?

17. Are there any aspects of the study that you have found yourself using since the study was completed?

18. What limitations did you note with the reflective journal writing assignment? What were the specific barriers to your implementing the journal?

19. We know that it's always difficult to add other things to the curriculum even when the benefits are obvious:

How difficult was it to include this in your teaching?

What would you have to do on a daily or weekly basis in order to make this project work?

20. Are there any comments or suggestions you would like to make for future projects? 
Appendix C -- Transcript of Teacher 1 Interview 
L. DiBello There we go, and hopefully this will all work out. I'm sure it will. Okay, for the first question I just wanted to ask you to tell us a little bit about yourself and give us your name and some background on your teaching experience and maybe how long you've been a teacher and the grade levels that you've taught or what kind of certifications that you have. I know that when you went from Florida to North Carolina you probably had to do some changes in your certifications so just tell us a little bit about yourself.

Teacher 1 Okay, my name is Mrs. O and I'm actually a second, this is my second career in teaching. I originally started as a secretary in my younger years and decided to go back to school when I had a son and I graduated from Florida International University in December of 1989 and began teaching at Sunshine Elementary in January of 1990. I started as a second grade teacher went to fourth grade and then I went to be a science teacher for the entire school K-5 which was great.

L. DiBello Wow

Teacher 1 And then I went to fifth grade and the following year I tried a pilot program that was totally inclusion. It was a fourth grade/fifth grade split with one-third of the children in a classroom as identified full-time learning disabled or emotionally handicapped and it was a wonderful pilot project that we did. We had two full-time teachers and an assistant in there at all times; although we had thirty children, we had ten that were identified fulltime. Then the year after that I went back to fourth grade and finished up at Sunshine Elementary with eight years there sitting at fourth grade. I moved to Service School Elementary and was hired as a fourth grade teacher and this is my third year at Service School Elementary in NC. My certification from Florida is K5 and it did not change. The only thing that North Carolina wanted me to do was take the Practice Test and I said "I don't think so, is there anything else I can do?" And they said well, work here for two years and if your principal says that you're a good teacher then you don't have to take it. So I said "that sound's great to me" and I got my official letter and my North Carolina certificate is on its way without having to do anything else. I'm currently working on a Master's degree in reading $\mathrm{K}-12$.

L. DiBello Do you recall having participated in Sunshine Elementary School's FIU project?

Teacher 1 Of course. 
L. DiBello And, do you remember if your participation in the project or the study was a mandatory thing or was it a voluntary project at your school?

Teacher 1 We met with Dr. R as a team, as a fourth grade team, and he explained to us what his purpose was and we helped him design the surveys and the graph that he was going to use, as far as using a bar graph or a line graph, and it was voluntary that fourth grade do this. We were not forced to do it. It was not a mandatory activity. We did it as a group.

L. DiBello And you decided though as a team?

Teacher 1 Yes, we decided it as a fourth grade team because he had to have-we had six fourth grades at the time. Of course he had to have a control where there were no materials being used

\section{DiBello Exactly}

Teacher 1 Then there was a group that just did journal writing, a group that just did graphing and a group that did both and then I believe, I believe there were, I'm not sure if there were two classes that just did journal writing or oneor two classes that didn't do anything-I believe one of the classes was a special ed class that didn't do anything.

L. DiBello Right, right. And then there were two groups that did both-that had the graphing with a journal.

Teacher 1 Okay, so that's it. There were two groups that did both.

L. DiBello Right. That's actually what my study is going to be detailing. The differences in those two groups. So that's been interesting to get the group that was only journals with the group that had both things. Can you tell us in your own words what you believed the study was about?

Teacher 1 Okay. I think that Dr. R was trying to find out if the students really felt like they were in control of their own grades at such a young level and that they shall learn to be self-tracking and self-responsible for the end result not just their grade or their test scores but that they were indeed responsible for the number at the top of their paper. That that was from their input and from their study skills and to help them realize if I do this, then this is the result. So they wrote down study skills in their journals and some of the things that they did, and that helped them be better learners and I think it really helped them become better learners to say "Well if I write my times tables three times each then when I take the test I can do better" 


\section{DiBello Right.}

Teacher 1 And I think that that was what the study was about, was to let students realize at a young age that they are indeed responsible for their own studies and the end result is success or not.

L. DiBello Do you recall how much time you'd spend on average each week with the reflective writing journals?

Teacher 1 We spent about a half an hour to an hour depending on the number of papers that they had to record - an average-and of course, it took them longer at first because it was totally foreign to them. It took them longer at first and they were not very calculator literate and we let them use their calculators to average their grades and of course those first few months were a lot longer, but after those first few months they became quite proficient at averaging their own grades and putting the information, their data, on the graph.

L. DiBello Great. How did you plan for the journal writing assignment? How did you actually use it in your class?

Teacher 1 Well, we printed it every Wednesday because that's when Dr. R came to the classroom to make observations about them and I felt that for him to become even more in tune to what was happening with his project that it was important for them to do it when he was there. So I knew that he always came on Wednesdays so we did it every Wednesday whether he was there or not and we did it as a weekly routine. This is what you're going to do, here are your grades, you record them, average them and then we're going to write in our writing journal. And of course, fourth grade has a writing test so we used that as a personal experience. A personal narrative for them to write their successes and not so successful things in math.

L. DiBello Oh. So you used the recording that they wrote in the journals for other things besides just the project.

Teacher 1 Right.

L. DiBello Okay. How, when you're thinking about the students, how did the students use the journal? Did they make use of it at other times or did you only bring it out when it was required to do the recording? 
Teacher 1 If we were using a health lesson to talk about positive self-statements, then we would refer to the math journal and say, "Well, what did you write in your math journal that was a positive self-statement?" And they may pull it out and look at it. Also, in math when the graphing unit came in to play I could say "like your math journal, which is a line graph and that we could transfer the information to a bar graph" so it was used sort of crosscurriculum and they did reflect back on their journals when they got their week's worth of papers they would reflect back-I would have them reflect back to the prior week, "well what did you write as a strategy? Did that strategy work or did it not work? Will you use it again this week or will you try something else?" And so it was used as a personal reflection.

L. DiBello So you did refer to it often during the classroom time but maybe their actual accessing the journal and writing on their own free time wasn't something that was typical.

Teacher 1 No it wasn't. It was used specifically for the research project.

L. DiBello Okay. Good. On a scale of $1-5$ with 5 being very enthusiastic and 1 being not at all enthusiastic, how enthusiastic do you believe the students were about the reflective journal writing assignment?

Teacher 1 I would have to say that it was a 5 after the first two months. It was a chore to begin with, as I said, because they were unfamiliar with the task.

L. DiBello Okay.

Teacher 1 But as they became familiar with the task and they realized that there was success through journal writing and graphing and tracking their own progress then when I would say "lets take out your math journal" they would go "YES." You know how they are "YES!" They would take out their math-they were excited about taking out their math journals and being able to reflect on their week's scores.

L. DiBello And maybe by then they would have already had enough data recorded that they could actually see how far they've come.

Teacher 1 Right.

L. DiBello Whereas in the beginning its just plotting these little points and then having to write about it and they weren't really seeing the full picture.

Teacher 1 Right. And the other thing that they realized was that you could make one bad grade and although it would bring your average down, it was not the end of the world. 
L. DiBello Right.

Teacher 1 Because a lot of students at that maturity age will receive one bad paper and they'd give up. They'd quit for whatever duration of time they feel was necessary for them to shut down and they realized that 'just because I failed this test, if I average it in with the other ones, yes it does bring my average down, but next week if I study real hard then I can bring my average back up' and that was the power play that they had was in knowing that they had control of that little line that went up and down on the scale graph.

L. DiBello On a scale of 1-5 now-not thinking about the students, but about the teachers that were involved-and 5 as being enthusiastic and 1 not at all enthusiastic, how enthusiastic do you believe the teachers were about this journal writing assignment.

Teacher 1 On an average I would say maybe a 4. I was very enthusiastic. I thought it was a wonderful project and something to do. The other teacher who had journal writing had expressed some concern about the length of time that the journal writing did take.

L. DiBello Right.

Teacher 1 And then some of the other teachers' comments were that they were wondering if our students were being so successful then were their students lacking in some area by not writing in the journal or not doing the graph. And not being able to understand that that's the way the experiment had to be. There had to be some doing nothing, some doing one, some doing the other, and some doing both.

L. DiBello Oh, so they wanted to have the benefit of both things.

Teacher 1 Right. Well they were a little concerned about that. Where they, you know, oh we're just graphing it, what's the point. Or, we're just writing in the journal, what's the point?

L. DiBello Right.

Teacher 1 Or, we're just writing in the journal, what's the point?

L. DiBello Right. Its true.

Teacher 1 Because they couldn't see the results. 
L. DiBello Its true. Did you talk about this project amongst yourselves as teachers? Did you share anecdotes or maybe some planning ideas of how you could implement it easier or maybe like in your case when you mentioned that it took so much time, how they could mix it in so that it took less time?

Teacher 1 Right. And like I said, we actually helped-we actually gave Dr. R some ideas of how to create the project itself. So we were actually among the initial-in on the initial planning of the project. All the fourth grade teachers were in on the kind of graph that we thought would be the most successful one.

L. DiBello Oh.

Teacher 1 How to set it up, and how to make the lines on their graph and how to make the lines on the averaging thing and he brought us a rough draft and then, of course, he put it through the computer.

L. DiBello I didn't know that part. I did know though, that between the first semester and the second semester that you changed the way the journal looked so that it would have the actual week listed on the top, which made it easier for you to keep track of what week you were on, and quite frankly in the analysis stage now, I know when it was the second semester and what week you were on because it's labeled and on the first semester its hard when a child's absent to keep up on which page they were supposed to be on.

Teacher 1 Right. And so that's, you know, he was very receptive to any suggestions that we had as far as the format of the experiment went and then we would comment amongst ourselves about whether we thought the students were benefiting or not and, of course on my side, I felt that it was a great benefit. Personalities do play some into it and if you are not a particularly flexible teacher that couldn't take that extra 15 minutes that they might be dragging or, you know, to realize that it was important information to do, then they were less receptive to it, but education is all flexibility, so we let them take as long as it takes sometimes in order to find success so that next time they won't take so long.

L. DiBello Right. And I'm pretty sure that they'll be seeing this in their lives again and they'll be able to say, "I did this when I was in fourth grade."

Teacher 1 Right 
L. DiBello When you reflect back on your students can you recall one or a few particular students or a child who might have benefited from the reflective journal writing assignment? It doesn't have to be a name.

Teacher 1 I started with a student, and he was classified as socially maladjusted. He was not a happy person or a nice student. He tripped people and he spit on their food and stuff like that. He was really not a very sociable character; but when he began to record his own grades and realized that he was in control and could do good things and see it, its more of almost instant gratification. Its Wednesday to Wednesday, whereas to get your report card you wait for nine weeks and you have no idea where you stand for that whole nine weeks until you get your report card and either you're in trouble or you're not.

L. DiBello Right.

Teacher 1 He was very receptive to the positive that he got each week and his grades definitely went up and he became more responsible for his own work in all subjects. As a matter of fact, after I moved up here he called me.

L. DiBello Oh that's wonderful. And you still keep in touch with him a little?

Teacher 1 I haven't heard from him lately. He called me one time and told me that he missed me and that was after he was already finished with fourth grade that year.

L. DiBello I don't think that had anything to do with the journal writing assignment. That's the teacher.

Teacher 1 Well, I think that that helped his self-esteem though, in that he felt better about himself.

L. DiBello That's a great thing to hear. For your class as a whole, do you believe that the reflective writing journal was or was not beneficial and can you elaborate a little? 
Teacher 1 Well, again, I think that it was very, very beneficial for students to do selftracking. To realize that they have control over the grade by studying and so they have to learn what studying means and, on the side we would have - to study means: you may have to write it three times each or say it three times each or ask someone to say it to you and you say it back to them-but that's what studying means. And that that study shows up when you do your work and you take your test. So when they were writing in the journal they used some of those techniques and we had one that was teach your dog the multiplication tables and they would write that as a strategy.

L. DiBello Oh yes.

Teacher 1 Say read to my dog, or teach my dog the multiplication tables.

L. DiBello I was just about to tell you that analyzing your group in particular, the biggest strategy, the one that was used quite, quite often involved the family pet.

Teacher 1 Right.

L. DiBello And I thought it was fantastic because it isolated it completely from all the other journal groups that I've been analyzing but it showed directly that there was a link in this class where the class was connected by the teacher and it happened to be that strategy. It was great. I loved it. I always told my husband, "Look, another pet!"

Teacher 1 Well, you know and I say that, in all honesty because sometimes that's all they have to talk to and that's really sad. A really sad realization, but if mom and dad are busy or at work or helping with little brothers and sisters, the dog is very available, or the cat.

L. DiBello Well, and then they're also thinking about the fact that "I'm saying this aloud" so it would match with the read aloud strategy but it's really, they're thinking. They're thinking about it and saying it, and when you think about things and say things over and over, its going to stick.

Teacher 1 It also goes back to the cooperative learning. You remember $95 \%$ of what you teach someone else.

L. DiBello That's right.

Teacher 1 So they're pretending to teach the dog or the family pet. 
L. DiBello Right, that's true. I'm so glad you said that because it was on the tip of my tongue I wanted to tell you that the pets came up so often, it was so great.

Teacher 1 Well that came from me.

L. DiBello I know.

Teacher 1 That was one of my strategies. I still use it.

L. DiBello Good. Have you found that having participated in the FIU project made a difference in the way you teach, your teaching methods or style, and if so, can you just explain a little.

Teacher 1 What it's done for me is that when I do a test, when I give my students a test, I will put a scale on the board and I will say one student made 100 or two students made 100, 3 made a 95 and so forth and so on, and then give them a scale on the board and then I will give them their tests back and explain to them that this is called your class standing. These are your numbers and where are you and where do you want to be, and what can you do if you want to be in the place that you're not?

L. DiBello Oh, that's a great extension.

Teacher 1 Get them to be reflective of what's going on in the whole class because that's real life. You don't get in college because you're a nice person. You're compared with all the other students who took the SATs on the same day you did.

L. DiBello That's right.

Teacher 1 And so, you're going to have to realize that sooner or later. That you're unfortunately at one point, and several points and times in your life you're a number, based on your performance and so I use that strategy. I have also-we do 'Success For All' Reading-which is John Hopkins reading. I don't know if you're familiar with it or not.

L. DiBello Yes. I know the Success For All Reading-and it is a little bit scripted. 
Teacher 1 Yes. No comment on that side. Anyway, they have a team score sheet for Success For All Reading and last year I had a group of fifth graders that were-there were 18 fifth graders that were all below grade level in reading. In North Carolina we have a test called the end of grade test and its rated on a 1-2-3 or 4 scale. If you are a 3 or 4 you are at grade level. I had all ones and twos in the fifth grade. And I volunteered for them. Anyway, what I did with the team score sheet, they continued to have the team score sheet, but I revised the team score sheet to just say score sheet and where it says story name I just put name which meant their name and they were responsible for tracking their own test scores in Success for All Reading. That means they have read aloud tests, they have story tests, they have reading comprehension tests, and they have meaningful sentence tests, every week that normally goes on the team score sheet. It was recorded on the team score sheet as well as the individual score sheet for these fifth graders.

L. DiBello And did they find that having responsibility for their own grade gave them a little more motivation since they weren't lagging with the team if the team was down?

Teacher 1 Right. And that was the whole thing. They've been in Success For All for three, four years, and by fifth grade they really don't care what the team is doing, only what's yours? They're pretty much, you know, I'm in it for myself kind of a deal and if they don't care, they don't care whether the team fails or not, and so they began recording their scores and of course, it took a while to use the calculator and average their scores and find out where they stood. The end result was that this group of fifth graders scored third highest in improvement points in the entire school on the Reading End of Grade Test.

L. DiBello That's fantastic.

Teacher 1 And I started with challenged students.

L. DiBello Yeah, ones.

Teacher 1 And they take, through the way that score was derived, was they took their end of grade from last year, the end of grade from this year and took the improvement points and for my class added them all up (for every class they added them up) they called them positive points or negative points ([sound of train in background] we live in front of the train tracks) they took the positive points and negative points and of all the whole school our class was third in positive points, over a hundred improvement points with those 18 children. 
L. DiBello That's fantastic. And do you think that they themselves attributed it to being able to track themselves?

Teacher 1 I think it had a lot to do with tracking themselves. It had a whole lot to do with tracking themselves.

L. DiBello Oh, that's great. I'm glad to hear that. I know you don't have one of the journal pages that the children wrote in front of you but, usually or typically the students had an opportunity every week to reflect on what the plans were going to be and the objectives were going to be and that's where the teacher came in. Where you let them plan for what they were going to learn for the following week.

Teacher 1 Right.

L. DiBello And did you think it was helpful for them to be able to reflect on their goals for the whole week?

Teacher 1 I think it was, because we all have strengths and weaknesses and if I said we are going to study division this week there was 'AWWWWWWWW'. And they wouldn't want to study division and I would talk about some of the strategies for learning division if you don't know your multiplication tables then you're not going to be as successful in division so one of the strategies that you can use for division is to learn your multiplication facts by heart and know them by heart and that's-I don't know if you found that as a strategy anywhere?

L. DiBello Yes.

Teacher 1 Ask for help from your parents or ask for tutoring after school or something or some other strategies so, for them to know ahead of time what their expectations were helped them decide on what some of their strategies were. 
L. DiBello And the reason I asked was because when you do the analysis of the journals, of course, its going to be very highly correlated across the particular classes what everybody wrote for that number which happened to be number 4 , you mostly saw the same thing written which is what we wanted to see, but then we were wondering "well, was that beneficial in any way to have them even write and record this" because as far as the analysis part was concerned, of course, we had very high correlation because everyone wrote more or less the same thing. We just wanted to know if it was worth taking that time or if maybe that's something that we could leave out because of the fact that it takes more time to write and we know that the biggest part about implementing this whole project is the time it takes out of the classroom day. So that's where that thinking came from.

Teacher 1 I think its important for them to know where they are headed because some of them know that they need to study more for that particular area and some of them might sit back and say "Phew, I already know that. My study strategies don't have to be as complicated as the person next to me because I already know how to divide or I already know how to multiply."

L. DiBello Yeah, in geometry. I loved-there was one group that had SAT prep for two weeks and I thought that one was funny because they had their regular goal and objective and then on the bottom there were little stars that said SAT prep and its true. That's the reality of the classroom.

Teacher 1 Right.

L. DiBello How do you think that the other teachers who participated in the project benefited? Did you--

Teacher 1 Well, because I don't know any of the results-I haven't seen any of the results even from their SAT test scores as compared to the other classes, I really can't give an honest answer to that question. How do you think that the other teachers who participated in the project benefited-I couldn't tell you.

L. DiBello Okay. Have you considered incorporating a reflective writing journal into your own curriculum, or obviously, you have.

Teacher 1 Right. Its not a writing journal-and I'm using the reading, self-tracking also this year. I have another challenging class this year. But they're not quite as in need as the other ones. They're fourth and fifth graders reading on a fourth grade level but some of them are still ones and twos. 
L. DiBello And mostly what you're using is the actual graph.

Teacher 1 And it isn't even a graph, really, its just a self tracking/--its a score sheetand they enter their scores all the way across, use a calculator to come up with an average so its a weekly average that they're tracking. We use a daily journal in our classroom anyway. A morning daily journal but its not really connected to reflective writing to a specific subject.

L. DiBello Right. And it doesn't have the same five questions involved. It just probably goes along with whatever it is you happen to be studying.

Teacher 1 Sometimes it does or its just a reflective journal like "today, if you could meet someone and talk to them today, who would it be? Who would you like to meet and talk to?" Just little things like that.

L. DiBello Get them to write.

Teacher 1 Right.

L. DiBello Are there any aspects of the study that you found yourself using since the study was completed?

Teacher 1 That one we've already answered.

L. DiBello What limitations did you note with the reflective writing journal assignment, and what were the specific barriers to implementing it?

Teacher 1 Some of the students in our class had very limited writing skills so if we have children who are severely learning disabled, especially if they are learning disabled in writing, had trouble putting down exactly what they wanted to put down in their journal so that was a barrier for them. Of course, that's always going to be in effect no matter what you do. Or the non-writers and non-readers are going to be a problem in your class at whatever grade level.

L. DiBello Yeah, that's true. We know that its always difficult to add things in the curriculum even though the benefits can be obvious. Was it difficult, or how difficult was it, to include this in your teaching and what would you have to do on a daily or weekly basis in order to make this project work?

Teacher 1 I didn't find it difficult because as soon as I found out that he was doing it I just incorporated it into my plans on Wednesday. And then what I had to do on a weekly basis was to set aside a half an hour for them to do that. And make sure that I graded all their papers on time. 
L. DiBello Yeah, so that was actually a benefit.

Teacher 1 It was a "I know I can't wait until next week to do these". I had to make sure that at least their math papers were graded on an efficient weekly basis so that they had those scores available for them. Which was not a bad thing really.

L. DiBello Yeah, I was going to say that was a big plus that you would never have thought of. Are there any comments or suggestions that you can give us for handling any kind of future project we might want to have?

Teacher 1 The only thing is that if there were published results of any kind as a result of your experiment with Sunshine Elementary's fourth grade class, I would like to know exactly what they were. I compared their SAT scores at the end of the year and had a lot of ups in math but I don't know what the comparison is for the other classes who did not write in their journal and keep their graph as well.

L. DiBello I know that nothing has been published yet on the results of the study but he has made a couple of presentations on the results and he's going to be contacting you as soon as I'm done with you and I'm done, so he'll be contacting you and letting you know all that kind of stuff and then as far as my part is concerned, my dissertation should be completed by December so we'll definitely get together and I'll pass along--

Teacher 1 Cross-curriculum. In other words, if you could track your grades for all subjects, which I know is a lot for elementary,--

L. DiBello That's true though, because then it would be something that you used automatically, it wouldn't be something that you stopped and said okay, its math time lets do this for the math component of the grade but maybe build it in.

Teacher 1 If there was an easy format for them to use at each subject of some kind, although its really a bad thing that we've become so test oriented because we spend less time on subjects that are not tested.

L. DiBello That's true. No social studies and science if you know that down the line they're not going to have to have a standardized assessment of it.

Teacher 1 Right. And they're not tested on those science and social studies areas and so we don't focus as much time on them, although they're more important than I think the tested areas a lot of times. But that would be nice to have something in a future project maybe to have tracking them on two subjects, two tested subjects. 
L. DiBello Yeah. That could be an easy one to do because your reading, language, arts and math are definitely tracked subjects.

\section{Teacher 1 Right.}

L. DiBello I will pass on all the suggestions to him. I wanted to just double-check your address because I wanted to send you a little follow-up.

Teacher 1 Okay. 
Appendix D -- Transcript of Teacher 2 Interview 
L. DiBello Can you tell us a little bit about yourself, giving us your name and some background on your teaching experience and how long you've been a teacher, maybe what grade levels you've taught or what areas you hold your certification.

Teacher 2 My name is Mrs. M. I've been teaching for 13 years. I started out teaching third grade, moved to fourth. I then accepted a position as an intermediate science specialist teaching at an elementary magnet school and from there I went to Sunshine where I started off teaching science and gifted and then the program changed and they did away with the science program and I went to teaching fourth graders and then I moved to middle school which is where I'm teaching now. I'm teaching sixth grade science at New River Middle.

L. DiBello Back to what you really like.

Teacher 2 Yes.

L. DiBello Do you recall having participated in the Sunshine Elementary School FIU Project?

Teacher 2 Yes I do.

L. DiBello And what do you recall about having participated in it?

Teacher 2 Well, I remember most Dr. R coming in and working with the kids and I also remember, with the program for my group, it did not show the improvement like the other teachers did. I think all I did in the program was; uh, they did, oh dear, there were like three variables I think and I only dealt with one.

L. DiBello Right. You were doing the journal component.

Teacher 2 Yes. And that was not as effective in and of itself, you know. Without the other components it didn't show the success.

L. DiBello Do you recall, was your participation in the project or the study mandatory or voluntary.

Teacher 2 It was voluntary. 
L. DiBello Can you tell us in your own words what you believe the whole study was about. If you had to think back upon it, what you thought it was trying to measure.

Teacher 2 Okay. It's been a while but if I can remember. What I kind of remember is they were looking at what variables, or what components create or cause the greatest increase in math, I think it was. Was it journaling-journaling and graphing and something else. I think there was a third.

L. DiBello The third one was the combined group. There was a group that received only the journal writing component, a group that only received graphing and then there were two classes that received both components.

Teacher 2 Okay. That's what it—all right, I didn't remember that.

L. DiBello Right. It's hard. Do you recall how much time you'd spend on average each week with their writing journals? Because I know you had only the writing journal.

Teacher 2 Right. Gosh. I do not remember that.

L. DiBello Did it take an entire school day or part of the day?

Teacher 2 Oh, no oh, no no no no. I know I taught math every day. I can't remember if we did the journaling every day or at the end of a lesson. I just don't remember exactly how I did the journaling. I just don't remember.

L. DiBello That's okay. How did you plan for using the journal writing assignment? Did you plan for using it maybe on a weekly basis or, I know you don't really recall having-

Teacher 2 I sure don't-I know that they did do the journaling at least once a week but I don't know if we did it after-at the beginning-I just truly-it's, it's

L. DiBello It's fuzzy

Teacher 2 It's very very fuzzy. I know the kids looked at-they wrote down how they thought they were going to do and what they were going to-oh this is really-set a goal-how they were going to reach that goal and then at the end they went back to see what the outcome was-you know, did they actually reach their goal and if not, something-

L. DiBello I can read you the questions if you would like. 


\section{Teacher 2 Please.}

L. DiBello The first one was-it said in the beginning of the reflective writing journal, it said: "Look back at what you wrote last week about learning math." And then he always wrote: "Think about what you actually did last week to help you learn math and think about how well you did in math. Do you think you did well or do you think you could have done better? Ask yourself each of the following questions and write out your answers in the space provided. Remember that there are no right or wrong answers." So the very first question he always asked was: "When I think about the grade I earned in math last week" and then he asked them to check one of the following: they either checked I I think I learned math better than I had planned, _ I think I learned math as well as I had planned, or _ I did not learn math as well as I had planned." So they had one of those three choices, and then from there, their second question asked them "When I think about how well I did in math last week these are the things I did that helped me to learn." And it gave them some lines to write what helped them. Then they wrote "When I think about how well I did in math these are the things that did not help me to learn." And that's when they were supposed to reflect on some of the things that probably prohibited them from doing what they were supposed to have done. And then the fourth thing they asked was "I plan to learn the following in math this week" and that's when you all gave your objectives and they were to write them. More or less consistently across the board. And then the last thing was "When thinking about how I learned best, I plan to do the following things when I am learning math" so that was like their correction plan for what they wanted to correct. Do you recall if you had them doing it as part of the regular school day or if its something that they could go to whenever they wanted, or-

Teacher 2 It was a part of the math--during the math block. That's when I would allow time for that-for the journaling. That I do remember. It wasn't something that was open at some point during the day. I usually would set aside a time. That I do remember doing.

L. DiBello Okay. On a scale of 1 to 5 with 5 being very enthusiastic and 1 being not at all enthusiastic, how enthusiastic do you believe the students were about using their reflective writing journal?

Teacher 2 Maybe a 4 but they didn't seem to mind doing it and because of what they thought or how they felt about Dr. R and him coming in-they liked him and so it was like they thought "I want to please him" that kind of a thing so it was not a negative for them. 
L. DiBello Okay. Even when he wasn't around?

Teacher 2 Exactly. But they knew he would be there.

L. DiBello Yeah, and he would get it.

Teacher 2 Exactly.

L. DiBello Okay. So on a scale of 1 to 5 , same thing, 5 being very enthusiastic and 1 being not at all enthusiastic, how do you believe the teachers who participated felt about the reflective writing journal assignment?

Teacher 2 Ah.

L. DiBello And you can be honest.

Teacher 2 No no no, um, that was a strange year. I did not, to be very frank, I did not really have a rapport, even though I-the connection. I didn't have the connection I guess with the other teachers so we didn't really talk about it. I didn't have lunch with them or anything.

L. DiBello Oh, that was my next question. Did you talk to the other teachers?

Teacher 2 No. It was just a personality thing I guess, and it just didn't work.

L. DiBello Had nothing to do with the teachers.

Teacher 2 We rarely discussed anything.

L. DiBello Okay.

Teacher 2 I was the outsider.

L. DiBello Oh. That's not a good thing. So I hope you're happier now.

Teacher 2 Oh, much. Thank God.

L. DiBello I can understand completely. So where would you put yourself though, on a 1 to 5 ? Just with the teachers and-

Teacher 2 I would put myself at a 4 because I wasn't-Oh yeah, you gotta do thisyeah, yeah-you know, but I did not-because they didn't mind, I didn't mind. It was something that kind of worked so I would put myself at a 4 with the kids. 
L. DiBello And I'm sure it didn't help that you had the totally different component that was isolated-just the journal.

Teacher 2 I was so sorry that we had not had more because those kids really needed the strength in math and my only concern-no, well, I'll let you finish and then I'll tell you my thoughts.

L. DiBello Okay. Let's see, number 11. Reflecting back on your students can you recall a particular child, and I know its been a while, but, who might have benefited from the reflective writing journal assignment.

Teacher 2 Uh-one. One child and she always struggled, but she really liked the program. She really liked having Dr. $\mathrm{R}$ come in and it was-she always tried a little harder. She wasn't always able to reach-you know, she'd set her goals I guess a little bit beyond where she was academically, I guess, but she always had such a positive feel and a positive sense of the program and you did see some growth for her but nothing like she would always set her goals for.

L. DiBello Right. So your class as a whole, thinking of all of them, do you believe that the reflective writing journal was or was not beneficial and can you just explain a little.

Teacher 2 I don't think they had a true sense of the program because that's all they did was the journaling. I think that had they had the other component then there would have been more of a connection or more of a thing of how it all came together. Because they didn't quite get the connection between the-I don't think they truly got a sense of why they were doing it or what it was supposed to achieve.

L. DiBello Okay. Have you found that having participated in the project made a difference for you and maybe in any of your teaching methods?

Teacher 2 I don't have kids write, but I always try to encourage them to set high goals. You know, you can do this and this is what you need to look at doing. I don't say, you know, this is what you need to write down as your goals for this lesson. But I just say these need to be your goals and this is how you need to go about achieving them and then I'm constantly trying to get them to set goals.

L. DiBello That's perfect because that was my next question. That particular aspect of the goal and setting their goals and having them reflect upon that. We were trying to get at if you found that part of it, that aspect of it was helpful for them. 
Teacher 2 Yes.

L. DiBello How did you think that the other teachers who participated in the project might have benefited since they had the other-

Teacher 2 I have no idea. Sorry. I had no connection with them at all.

L. DiBello Have you considered incorporating a reflective writing journal into your curriculum? I know you've changed grade levels but-

Teacher 2 I had not, but now that I think about it, its interesting. I have magnet kids-I have three blocks of children. 2 magnet groups and 1 group that they refer to as a regular science class. Really, its a bit of a developmental - because they may be reading at or-no, not even atthey're reading below grade level. For them something like that would be perfect. I had not even thought of it.

L. DiBello Well good. Because we were just trying to figure out if you found yourself using any aspects of this study since you might have completed it.

Teacher 2 You know I had totally forgot. But that would be perfect for them and it won't reach every child?

L. DiBello Never. No.

Teacher 2 But if I can get even a few of them to start goal-setting and looking at what they need to do to achieve goals-wow.

L. DiBello It could help.

Teacher 2 I like that.

L. DiBello I can fax these to you.

Teacher 2 I like that. I love it-please. Well, when you get finished I'm going to give you my husband's fax number.

L. DiBello I would be more than happy to share all that with you.

Teacher 2 Thank you - and we'll begin it for second semester and I'll actually look at-I can compare the first quarter with how they do at the end of the second quarter.

L. DiBello Right. To see if the journal might have made a difference for them.

Teacher 2 Absolutely. 
L. DiBello Dr. R would really love hearing about that. What limitations did you note with the reflective writing journal assignment. What were some specific barriers that might have stopped you from implementing the journal program-having done it before.

Teacher 2 What would stop me from doing it in the future?

L. DiBello No, like when you were actually using the journal-what barriers did you find that made it difficult to implement it?

Teacher 2 If anything, I may have made my plans-you know, this is the point where we're going to do this. Probably time.

L. DiBello Time. That's a good one.

Teacher 2 So I would have to put it another day in my plans because I didn't get to it the day before or the end of the week. You know, that kind of a thing. It's always a time element.

L. DiBello I have 2 more questions. One is, we know its difficult to add other things to the curriculum even when the benefits are sometimes obvious. How difficult was it to include it in your teaching and what do you think you would have to do on a daily or weekly basis if we were to redo this project in order to make it work. I mean, from a teacher's perspective if you were talking to a researcher, what would we have to change?

Teacher 2 I really don't think you would have to change anything. If I had an opportunity to be a part of a similar project I would. I think it would be beneficial-I would do it-you know what I would do differently-and that's maybe not even what you're looking for-

L. DiBello No, but I think that's what he wants to hear.

Teacher 2 What I would do differently-it's me personally-I would talk it more to the children. I think that was my shortcoming. I did not talk it enough to them. Having-

L. DiBello Modeling.

Teacher 2 And with older children too. I really-I think with the younger children I think its better to start this program early and then continue it. Because with fourth graders-its a new-I mean actually writing down-its goal setting. Elementary kids don't usually think about it in terms of that, but now, looking at middle school kids, I bet the success rate would be so much higher with middle school children. 
L. DiBello Oh yeah. One of the problems we had in implementing was we had them averaging their grades. Particularly the graphing group and we had to teach them how to average and that was a big barrier to start the project not even being able to have the basics down.

Teacher 2 Exactly. Middle school kids I'd bet you'd see a much higher success rate.

L. DiBello Right. Well good, I plan on sending this to you then.

Teacher 2 Thank you.

L. DiBello The last question. Are there any comments or suggestions that you'd like to make for any future projects?

Teacher 2 This probably wasn't what his goal was because his target group apparently was the elementary-I would rather like to have seen it with the middle school children. Especially sixth graders. Sixth graders are just so scattered. I mean some of them are just-the hormones and then the change from elementary to middle - that's when you need to get themthat's when they need to start really focusing and goal setting. I would rather see it with the sixth graders as opposed to fourth graders.

L. DiBello Great. Perfect. That's all I needed for my study part of it and I just wanted to thank you very very much for taking the time.

Teacher 2 I'm sorry for not getting back to you. I saw the email and it was like oh my God. I had 5 papers and 2 exams and its like it was just coming at me fast and furious and my home life is just chaotic so you know-

L. DiBello I know the feeling.

Teacher 2 Its too much. not in the way unfortunately.

L. DiBello Oh, no. I felt terrible nagging you. I kept thinking oh my God.

Teacher 2 Oh, no no no, I'm glad you did because I committed to talking to you and I just kind of fell apart-but let me give you my fax number. If you could fax that over to me please.

L. DiBello Sure.

Teacher 2 [Phone number given.] 
L. DiBello Okay. Perfect. I'll send that over to you and then as soon as I get anything on when we're done with all these models, I'm sure Dr. R would love to pass along the results of the study to you.

Teacher 2 Okay, I'd love to read it.

L. DiBello Okay. Thank you so much.

Teacher 2 Thank you so much for being patient and getting back to me and thanks for being persistent about it. And thanks again for the info you're going to fax. Have a good evening. 
Appendix E -- Transcript of Teacher 3 Interview 
L. DiBello If you could you tell us a little bit about yourself, please state your name and give us some background on your teaching experience, how long you've been a teacher, what grade levels you've taught and what area you hold your teaching certification in, what your teaching now, things like that.

Teacher 3 Okay. I have been teaching since 1989. I started out as a teacher's assistant while I was going to school and I worked as an interim teacher in third grade. I worked as an ESOL teacher in first, second, third and fifth grade and currently I am a fourth grade teacher at Sunshine Elementary. I am also the grade chair and this is my fifth year at that position. My certificate is in Elementary Ed, Bachelor's Degree and-a

L. DiBello I'll just ask you a quick question about fourth grade then. Since you're the head teacher or grade level chair, how many fourth grades are there now?

Teacher 3 There are seven of us.

L. DiBello And when the study took place, how many teachers were there? Did we use all of them or just a few?

Teacher 3 We used-I don't think we used all of them. I think we left one out and I believe there were six of us at that time.

L. DiBello Okay. Perfect. What do you recall about having participated in the Sunshine Elementary School FIU Project?

Teacher 3 Okay-I remember Dr. R very well-coming in and, you know, very enthusiastic. I remember he was excited about the project and he got everybody excited about it. I know its difficult when you have teachers - asking them to do one more thing and you usually have a negative response-no I shouldn't say that. There is sometimes a negative response, but with the way it was presented it was kind of exciting to be participating in this.

L. DiBello Great. Was your participation in the project or in the study a mandatory thing or was it voluntary for you? Or do you recall?

Teacher 3 I don't believe it was presented either way. We were just told we were going to participate in a project and we said okay. 
L. DiBello Perfect. Can you tell us in your own words what you think the study was about. Just a short recap of what you think we were trying to get at with the study.

Teacher 3 Okay. To the best of my recollection-I mean-I think-what I'm thinking, it was, in a nutshell, is making kids accountable for their own performance. To be able to monitor their progress and see what they need to do to possibly improve or, you know, what they can do to get a higher grade because they were constantly provided with that information and they were doing the actual progress and the graphing and all of that.

L. DiBello Right. Great. Do you recall how much time you'd spend on average each week with the reflective writing journals?

Teacher 3 We spent probably-I know when he came in we did talk about it probably 20 minutes and then we would probably-I would say at least 10 minutes every day - kind of review.

L. DiBello Great. How did you plan for the journal writing assignment? How did you actually use it. Did you plan for it in your lesson plans or-?

Teacher 3 Yeah. I went according to what I had planned for the week. You know, letting them know what was coming and then they would then set their goals or whatever they were doing according to whatever math lesson was coming.

L. DiBello Okay. How did the students use the journal? Do you recall if they made use of it at other times or only when you required them to pull out the journal.

Teacher 3 I believe it was only when required but the intent was to use it for everything. Not just to monitor your math progress but for any type of situation in school. That's what was encouraged but I'm not sure-I guess as they got more familiar with it the were more comfortable using it and I guess maybe some of them were using it for other things.

L. DiBello Right. On a scale of 1 to 5 with 5 being very enthusiastic and 1 being not at all enthusiastic, how enthusiastic do you believe the students were about the reflective writing journal assignment and can you give examples as why you might have gotten this impression? 
Teacher 3 Well. At first I would say not that enthusiastic because they weren't really clear until it was clarified that what was needed. They were setting very vague goals like I'm going to be a better student but they didn't specifically state what was going to make them a better student-come up with detailed information and then as they became more comfortable with it I don't-I mean I would say at first it was like take out your journals and it'd be UGHHHHH.

L. DiBello So that's 1 I guess.

Teacher 3 Yeah, at first. And then towards the end they just took it out so they readily accepted it.

L. DiBello But it was never very enthusiastic. So number wise you'd give it a 3 or 4 ?

Teacher 3 I would say towards the end probably a 4.

L. DiBello Okay. Same scale of 1 to 5 , with 5 being very enthusiastic and 1 being not at all, how enthusiastic do you believe the teachers were about the reflective journal writing assignment and can you give examples as why you got this impression?

Teacher 3 I'm speaking for myself that I really-I thought it was a great addition to the graphing because I-in fourth grade we do a lot of writing and it was just another way to put it into the curriculum and-you know, reflective writing is good for any type of practice in writing and I think probably I would say a 5 .

L. DiBello Okay. So you definitely thought it correlated with your curriculum then.

Teacher 3 Absolutely.

L. DiBello Okay good. Did you talk about the project amongst yourselves with the other teachers like sharing anecdotes or maybe planning ideas or was it each of the models implemented on its own and you didn't really share back and forth? 
Teacher 3 Honestly I don't really recall talking about it that much with Mrs. O or Mrs. M because we weren't really - their classrooms were so far away and we hardly ever met except for team meetings and things like that and I would imagine-I think that I had it probably the best because we were doing both the journal and the graphing and then I heard-just the journals or just the graphing-I don't remember exactly what everybody was doing. Its just that I remember saying well maybe if we were doing the graphing or maybe if we were doing the journals-you know, so I think together it seemed to make a difference because I thought it was great.

L. DiBello Good. When you reflect back on your students can you recall any particular child-not naming one-but just a child, that might have benefited from the reflective journal writing assignments? Someone that you might recall having used it.

Teacher 3 Yes, I do, and actually I'm probably still in contact with about 6 or 7 of them that write to me and we talk about different things but $I$ believe that it did benefit a majority of the class.

L. DiBello Great. For your class as a whole, do you believe it was beneficial? So that kind of answered it but-

Teacher 3 Yes.

L. DiBello Have you found that having participated in the FIU project made a difference in your teaching methods and if so, how did that happen?

Teacher 3 It kind of brought to mind some of the-you know, as far as setting goals, I mean I always have the children set goals but this brought it to light a little bit clearer. How to be more specific. You know, to get more when you're setting goals and things like that, not just I want to be a better student, but have specific reasons why or, you know, showing progress for what reason or how you're going to go about it.

L. DiBello Good. That's exactly what the next question is about. I didn't mean to cut you off but it asks that students typically don't really have the opportunity to reflect every week on their plans or the objectives and the fourth question specifically asks them to do that. Did you find that part helpful?

Teacher 3 Yes. Definitely.

L. DiBello How do you think that the other teachers who participated in the project benefited. 
Teacher 3 Was there anyone that participated the same way that had the journals and the graphing?

L. DiBello Yes. Mrs. O's class.

Teacher 3 Oh, okay. Yeah, I-um-and the question was how do I feel that everyone benefited?

L. DiBello Yes. Do you think that any of the other teachers-how do you think that any of the other teachers who participated benefited?

Teacher 3 Well, I would imagine any student who realizes that they have the opportunities to somehow make a difference or shed some light on how their grade is changing each week because they've done this or this, I mean I think that that's exactly what we want them to do. Become accountable for their own progress.

L. DiBello That goes well with Gore and Bush right now. Accountability.

Teacher 3 Oh, yeah.

L. DiBello Have you considered incorporating a reflective writing journal into your curriculum now?

Teacher 3 Actually, we have the school provide the student with a planner and at the bottom it has space and I have them set goals for the week. I have them set long term and short term goals. At the beginning of the year we do a long term goal and then we do short term goals and then we conference and we have the children set up different goals according to their needs.

L. DiBello Oh, so you've been using that part of it again.

Teacher 3 Yeah. I always use the goal setting.

L. DiBello Are there any other aspects of the study that you might have found yourself using since the study was completed?

Teacher 3 As far as the averaging the grades and the graphing? That was too time consuming in my opinion. It was very difficult for a lot of the students and he'll probably remember that too because we did spend a lot of time teaching them how to average and it just-I don't know-

L. DiBello We talked about the grade level being an issue, maybe. 
Teacher 3 Yes. Possibly. I don't know why it should be because we do do averaging in the fourth grade its just that the averaging with the graph and-I mean it was-maybe it was the particular group of students, I don't know.

L. DiBello That's true. What limitations did you note with using the journal part, not necessarily the graphing part but the journal writing where it asks the 5 questions, what limitations do you remember from that or any barriers that might have prevented you from implementing it.

Teacher 3 I don't really remember any limitations. I don't recall.

L. DiBello Okay. We know that its always difficult to add other things to the curriculum, even when the benefits are obvious. How difficult was' it to include this in your teaching? What would you have to do on a daily or weekly basis in order for us to make this project work?

Teacher 3 Boy, right now-ooh-that's a good question.

L. DiBello When you think back about it, what made it hard for you to implement as a-

Teacher 3 The hard part was actually preparing the students and getting them ready. I guess we had to teach them how to set the goals. We also had to review how to-you know-we hadn't gone to averaging yet so we had to teach them that. We also had to show them how to graph it with the line graph and that type of thing. It was kind of confusing for several weeks until they were used to it. I can remember some students never really getting it right, that had to be helped a lot.

L. DiBello Yeah that's true. This is the last question. Are there any comments or suggestions you'd like to make for any future projects?

Teacher 3 I think that it was a great idea. I loved the idea-you know, like I said, or you probably heard me say this a million times now on the tape, that I like that the children get to monitor their own progress. I think that's a wonderful part of this whole thing. It makes-I think that most children in my experience, I don't know, but most of the kids that I encounter on a daily basis want to be a better student and this is one way that they can do that, by setting goals, by keeping track of how they're doing and I constantly am giving them feedback. That type of thing is real important. 
L. DiBello Right. Well when you used the word accountability something clicked in my mind and I kept thinking you know, that's actually the perfect word because there's so much pressure with the accountability right now and I wonder how difficult, how even more difficult it would be now to implement something like this because it is time consuming and the focus in all schools really has changed to prepare for the test. Particularly fourth grade with Florida Writes.

Teacher 3 Yes. We don't even have Florida Writes now, its FCAT. Its the same type of format but they've changed it a little bit but its just called FCAT Writes. We also now have math which was not-we didn't have the math before, we were just tested on reading and writing. They've included math now and next year science. So it is a lot of pressure, it is a lot of time.

L. DiBello You know, the more I think about it the more I think fourth grade is just not really the grade level to be doing this with everything else that's going on.

Teacher 3 We have a teacher that's leaving and we cannot even find a replacement so that's-you know.

L. DiBello Everyone hear's fourth grade and they're like "no way."

Teacher 3 Yeah, its been easy to stay at that grade level, let me tell you.

L. DiBello Well, I appreciate your time so much and if you think of anything else you want to tell me you can email me because you have the address.

Teacher 3 Yes, I do, and I have your phone number.

L. DiBello Great. And I really appreciate you taking the time and tell your daughter good luck on her play.

Teacher 3 Thanks. I hope I don't sound like too much of a fool.

L. DiBello No, you don't. Absolutely not. And I'm going to pass on to all of you some of the results of everything together. That way you get an idea of what it was that took place and I know Dr. R's compiling all the other part. I know Mrs. O was very eager to find out what the results were as far as the standardized test and the grading correlation stuff and he's definitely willing to share with everybody-

Teacher 3 Oh, great. 
L. DiBello So I will be getting in contact with you very soon and hopefully I'll be done in a couple of weeks.

Teacher 3 Oh, I hope so. Good luck to you.

L. DiBello Thank you very much.

Teacher 3 And when you see him, Dr. R, tell him we all said hello.

L. DiBello I will, I'll see him this week.

Teacher 3 Thank you. 
March 3, 1967

1989

$1989-1992$

$1992-1993$

1995

$1996-2000$

2000 - present
Born, Miami, Florida

B.A., Psychology/Early Childhood

Tulane University

New Orleans, Louisiana

Early Childhood Teacher (PK-3)

Montgomery County Public Schools

Takoma Park, Maryland

Early Childhood Teacher (PK)

UM/Canterbury Preschool

Miami, Florida

M.S., Early Childhood Education

Florida International University

Miami, Florida

Graduate Assistant

Florida International University

Miami, Florida

Assistant Professor

Pre-K/Primary Graduate Program

Barry University

Miami Shores, Florida

\section{PUBLICATIONS AND PRESENTATIONS}

DiBello, L.C. (October, 2000). Beyond Inclusion: Issues and Policies Affecting Our Special Education Programs as We Adapt to Meet Curricular Requirements Posed for the Next Century. Paper presented at the meeting of the American Association for Teaching and Curriculum, Alexandria, Virginia.

Harlin, R.P. and DiBello, L.C. (November, 2000). Improving Beginning Teachers' Practices and Communication through Peer Coaching. Paper presented at the meeting of the National Association of Early Childhood Teacher Educators, Atlanta, Georgia. 
Harlin, R.P. and DiBello, L.C. (April, 2001). Improving Preservice Teacher Education through Peer Coaching: An Action Research Model. Paper presented at the meeting of the Association for childhood Education International, Toronto, Canada.

Harlin, R.P. and DiBello, L.C. (Spring, 2001). Improving Beginning Teachers' Practices and Communications through Peer Coaching. Journal of Early Childhood Teacher Education, 22(2001 in press, conference proceedings).

DiBello, L.C. (Winter, 2001). Mongolian Teens: Values, Customs and Practices. In J. Slater (Ed.). Teen Life Around the World. Greenwood Press. (Under contract). 